\title{
Post stroke Parkinsonism : a study on incidence and aspects of pathophysiology
}

Citation for published version (APA):

Korten, A. G. G. C. (2005). Post stroke Parkinsonism : a study on incidence and aspects of pathophysiology. [Doctoral Thesis, Maastricht University]. Maastricht University. https://doi.org/10.26481/dis.20051222agk

Document status and date:

Published: 01/01/2005

DOI:

10.26481/dis.20051222agk

Document Version:

Publisher's PDF, also known as Version of record

\section{Please check the document version of this publication:}

- A submitted manuscript is the version of the article upon submission and before peer-review. There can be important differences between the submitted version and the official published version of record.

People interested in the research are advised to contact the author for the final version of the publication, or visit the DOI to the publisher's website.

- The final author version and the galley proof are versions of the publication after peer review.

- The final published version features the final layout of the paper including the volume, issue and page numbers.

Link to publication

\footnotetext{
General rights rights.

- You may freely distribute the URL identifying the publication in the public portal. please follow below link for the End User Agreement:

www.umlib.nl/taverne-license

Take down policy

If you believe that this document breaches copyright please contact us at:

repository@maastrichtuniversity.nl

providing details and we will investigate your claim.
}

Copyright and moral rights for the publications made accessible in the public portal are retained by the authors and/or other copyright owners and it is a condition of accessing publications that users recognise and abide by the legal requirements associated with these

- Users may download and print one copy of any publication from the public portal for the purpose of private study or research.

- You may not further distribute the material or use it for any profit-making activity or commercial gain

If the publication is distributed under the terms of Article $25 \mathrm{fa}$ of the Dutch Copyright Act, indicated by the "Taverne" license above, 


\section{Post Stroke Parkinsonism}

A study on incidence and aspects of pathophysiology 
(C) Copyright A. Korten, Roemond 2005

ISBN $905278499 \times$

Omslagatbeelding Harry van de Boel, Hades, 2004.

Net zoals op deze afbeelding verhaalt dit manuscript van de

"...afdaling in de onderwereld en zoektochr naar de werking van de zwarte kernen..."

The study presented in this thesis was performed within the deparment of Neurology of the University Hospital Mastricht and the Institure Brain and Behaviour of the Maastricht University. Financial support for publication of this thesis was generously provided by GlaxoSmithKline, Ipsen, Janssen-Cilag, UCB Pharma, Boehringer Ingelheim, Mundipharma, Bristol-Myers Squibband Pfizer. 


\title{
Post Stroke Parkinsonism A study on incidence and aspects of pathophysiology
}

\author{
PROEFSCHRIFT
}

ter verkrijging van de graad van doctor aan de Universiteit Maastricht, op gezag van de Rector Magnificus, Prof.mr. G.P.M.F. Mols volgens het besluit van het College van Decanen, in het openbaar te verdedigen op donderdag

22 december 2005 om 12.00 uur

door

Arthur Gerard Godfried Catharina Korten geboren op 30 juni 1970 te Roermond

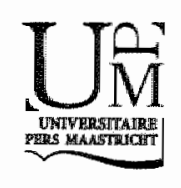




\section{Promotor}

Prof.dr. M. Limburg

Co-promotor

Dr. W.E.J. Weber

Beoordelingscommissie

Prof.dr. J. Th. Wilmink (voorzitter)

Dr. T. van Laar (Academisch Ziekenhuis Groningen)

Prof.dr. W.H. Mess

Prof.dr. G.J.J. Teule 
Voor mijn ouders: zij die aan het begin stonden van alles. 


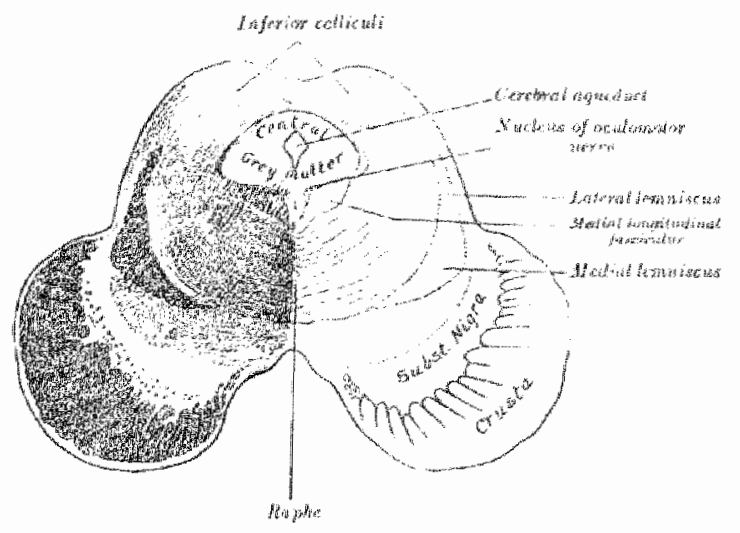

Read not to contradict and confuse, nor to believe and take for granted, nor to find talk and discourse, but to weigh and consider.

Sir Francis Bacon (1561-1626)

Figure taken from Grays Anatomy, 1918 


\section{Table of contents}

\section{General Introduction}

Parkinsonism as a result of cerebrovascular disease: a separate entity ? 9

\section{Chapter 1}

Extrapyramidal system dysfunction in 101 patients with acute first-ever stroke.

\section{Chapter 2}

Vascular parkinsonism: evolution of symptoms in a cohort of 101 first-ever stroke patients.

Chapter 3

Neuroradiologic correlates of parkinsonian signs in 83 first-ever stroke patients.

Chapter 4

Frontal lobe hyperperfusion in vascular parkinsonism patients.

\section{Chapter 5}

Dopamine availability in vascular parkinsonism and idiopathic Parkinson's disease: a comparison with [123I] FP-CIT and [ $\left.{ }^{123} \mathrm{I}\right]$ IBZM SPECT.

\section{Chapter 6}

Stroke and idiopathic Parkinson's disease: does a shortage of dopamine offer protection against stroke?

General Discussion

Samenvatting

Summary 
Dankwoord

Curriculum Vitae 


\title{
General introduction
}

\author{
Parkinsonism as a result of cerebrovascular \\ disease: a separate entity?
}

Adapted from:

Parkinsonisme ten gevolge van cerebrovasculaire aandoeningen: kan er gesproken worden van een aparte ziekte entiteit? Ned Tijdschr Neurol 2001; 3:186-191. 


\section{STROKE: GENERAL BACKGROUNDS}

Stroke is a clinical diagnosis made according to the following definition:

- A neurological deficit of sudden onset;

- with focal rather than global neurological dysfunction;

- with symptoms lasting longer than 24 hours or resulting in death before 24 hours;

- and in which, after adequate investigation, symptoms are presumed to be of a non-traumatic vascular origin [1].

Of all strokes about $15 \%$ is caused by cerebral haemorrhage and $85 \%$ by cerebral ischaemia [2]. In The Netherlands, every year 30.000 patients suffer from the consequences of a stroke. Forty percent of these patients die in the first 3 months after stroke. Half of the remaining 60 percent is more or less dependent from care by orhers [3].

\section{CEREBRAL ISCHAEMIA}

Ischaemic stroke develops in case of obstruction of cerebral blood flow and inadequate cerebral perfusion as a result of vessel wall changes in arteries or arterioles, cardiac embolism or a combination of both: emboli from atheromatous lesions more proximal in the arterial tree [4]. As a consequence of inadequate cerebral perfusion a central area of brain tissue is damaged irreversibly and results in cerebral infarction. Surrounding this area is the ischaemic penumbra, in which damage is reversible when circulation is restored in time.

\section{Subtypes of infarction}

Ischaemic infarcrion can be divided into bland infarction and haemorrhagic infarction. Bland infarction is the result of usually persisting occlusion caused by a thrombus. Haemorrhagic infarction is thought to be a 
result of reperfusion after embolic obstruction of a vessel with diapedesis of erythrocyts through their hypoxic walls [4].

Size and location of bland cerebral infarction differentiate lacunar brain infarcts from territorial brain infarcts. A Lacunar infant is diagnosed in case of an acute symptomatic stroke syndrome with a CT lesion compatible with occlusion of a single perforating artery, i.e., a small, subcortical, sharply marginated hypodense lesion with a diameter smaller than 15 $\mathrm{mm}$ (small deep infarct), or in case of a specific lacunar syndrome (unilateral motor and/or sensory symptoms and signs that completely involve at least 2 of 3 body parts (face, arm and leg) without disturbance of consciousness or language, visual field defecr or other signs of cortical dysfunction) when the CT scan shows no specific lesion. Disease of small penetrating arteries and arteriolae is the cause of lacunar infarcts [5]. A Territorial infarct is diagnosed in case of (1) an acute stroke syndrome with CT findings comparible with infarction involving the cortex, or (2) when no specific lesion is visible on $C T$, in case of a clinically identified cortical syndrome consisting of unilateral motor and/or sensory symptoms and signs in combination with signs of cortical dysfunction with or without visual field defect, of of incomplete involvement of two body parts, or of isolated monoparesis, or of isolated cortical dysfunction (usually dysphasia) $[1,2]$. Territorial infarction is caused by occlusion of large arteries at the skull base, mainly middle and anterior cerebral artery. This occlusion can be the result of spreading of a thrombus from an occluded more proximal artery or emboli from an atherosclerotic internal carotid artery [6-8]. Also cardiac emboli as a result of atrial fibrillation, valve disease or prosthesis can cause territorial brain infarcts $[6,7,9,10]$.

Apart from lacunar and territorial brain infarcts, CT scanning of patients with cerebrovascular disease, but also healthy controls, can show so called white matter lesions. White matter lesions or leukoaraiosis are defined as a CT finding consisting of focal or diffuse hypodensities in the periventricular or deep white matter, not involving the cortex, and with ill-defined margins to distinguish it from infarction $[11,12]$. The presence of white matrer lesions is clinicaly associated with dementia and cog- 
nitive disturbances [13-15], problems of gait and urinary incontinence [16]. However, they are also reported in healthy individuals [17-19].

\section{Clinical infarct syndromes}

Depending on presenting symptoms and signs, cerebral infarction can be divided into four subtypes with different narural history. Patients with a lacunar syndrome ( $L A C I)$ present with a pure motor stroke, pure sensory stroke, sensory-motor stroke or atactic hemiparesis / dysarthria-clumsy hand syndrome. A total anterior circulation infarct (TACI) syndrome is defined as the combination of higher cerebral dysfunction (e.g. dysphasia), homonymous visual field defect and ipsilateral motor and/or sensory deficit of at least two areas of the face, arm and leg. In case of a partial anterior circulation infarct (PACI) syndrome, patients present with only two of the three components of the TACI syndrome. A posterior circulation infarct (POCI) syndrome comprises of ipsilateral cranial nerve palsy with contralateral motor and/or sensory deficit, bilateral motor and/or sensory deficit, disorder of conjugate eye movement, cerebellar dysfunction withour ipsilateral long-tract deficit or isolated homonymous visual field defect [6].

\section{Vessel pathology}

Large vessel disease in which obstruction of the major arteries of the brain can occur, is the cause of territorial infarctions in the brain. Obstrucrion is caused by the development of an atherosclerotic plaque consisting of an intact endothelial lining overlaying a fibrous cap. The fibrous cap contains lipid laden macrophages (foam cells), transformed smooth muscle cells, lymphocytes, a connective tissue matrix and a central necrotic core. These plaques mainly occur at arterial branch points like the bifurcation of the common carotid artery. Disruption of the luminal surface of the plaque can propagate formation of thrombi causing obstruction either directly or as emboli [20]. 
Small vessel disease results in obstruction of small perforating arteries of the brain. This causes infarctions of smaller brain areas. Two types of small vessels can be discerned: the perforating arteries arising from the large arteries at the base of the brain (i.e. lenticulostriate arteries) and medullary arteries supplying deep cerebral white matter. Multiple sillent small deep brain infarcts are associated with arterioloscerosis (also called lipohyalinosis), whereas a single, mostly somewhat larger symptomatic infarce is associated with microatheromathosis [21-24].

\section{INTRACRANIAL HAEMORRHAGE}

Fifteen percent of strokes is caused by intracranial haemorrhage, making it the third most frequent cause of stroke after thrombotic and embolic stroke. Primary or hypertensive intracerebral haemorrhage, ruptured saccular aneurysm and vascular malformation and haemorrhage associated with bleeding disorders account for almost all of the haemorrhages that present as strokes.

Primary intracerebral haemorrhage occurs in the brain tissue itself and is strongly associated with hypertension. The most common sites for this type of haemorrhage are the putamen and adjacent internal capsule, various parts of the central white matter of temporal ${ }_{x}$ parietal or frontal lobes, thalamus, cerebellar hemisphere and pons [25]. It is usually caused by pathologic changes in a penetrating artery, mostly arteriolosclerosis (or lipohyalinosis) $[26,27]$. Thus, the underlying vascular pathology in this type of haemorrhage is closely related to that of ischaemic cerebral small vessel disease with multiple lesions.

Haemorrhage can also be the result from so-called amyloid angiopathy, in which amyloid deposits are found in intracerebral arteries which make the arterial wall prone to rupture and subsequent bleeding. This amyloidosis of cerebral vessels can occur familial, then referred to as cerebral amyloidosis - Dutch type, since the first report was from The Netherlands [28]. 
Signs and symptoms as a result of intracerebral haemorrhage vary. In case of massive bleeding, coma and death may occur within a few hours. Smaller haemorrhages present more like an ischaemic stroke: abrupt onset of for example paresis or sensory disturbance [25].

\section{PARKINSONISM: GENERAL BACKGROUNDS}

In 1817, James Parkinson (1755-1824) desribed six patients presenting with antecollis, tremor and problems of gait and speech [29]. In 1877,60 years later, Charcot added rigidity and akinesia to these symptoms and called the syndrome "Parkinson's disease" [30].

At present, the clinical diagnosis of a parkinsonian syndrome is made according to the "United Kingdom Parkinson"s Disease Society Brain Bank" (UKPDSBB) criteria. The UKPDSBB also formulates signs and symptoms which, in case of a parkinsonian syndrome, support the clinical diagnosis Idiopathic Parkinson's Disease (IPD) [31-33]. Table 1 summarizes criteria and signs and symptoms. Differentiating a parkinsonian syndrome as a result of IPD from parkinsonism due to other causes is important. In case of IPD, there is degeneration of dopamine producing cells in the substantia nigra with specific therapeutic consequences [34]. Apart from degeneration of dopamine producing cells in the substantia nigra, a parkinsonian syndrome can be caused by other neurodegenerative diseases, intoxications, trauma and infection (table 2).

Parkinsonism as a result of cerebrovascular disease was first described by Critchley [35]. Parkinsonism as a result of cerebral lesions in general was already known for a longer time [36]. Ever since first descriptions of parkinsonism and cerebrovascular disease, it is discussed wether it can be seen as a separate disease entity $[37,38]$. 
Table 1. UK Parkinson's Disease Society Brain Bank diagnostic criteria for parkinsonism and Parkinson's disease [31-33].

Step 1. Diagnosis of the parkinsonian syndrome

- Bradykinesia (slowness of initiation of voluntary movement with progressive reduction in speed and amplitude of repetitive actions)

- and at least one of the following:

- muscular rigidiry

- 4-6 Hz rest tremor

- postural instability not caused by primary visual, vestibular, cerebellar or proprioceptive dysfunction.

Step 2. Exclusion criteria for Parkinson's disease

- History of repeated strokes with stepwise progression of parkinsonian fearures

- History of repeated head injury

- History of definite encephalitis

- Oculogyric crises

- Neuroleptic treatment at onset of symptoms

- More than one affected relative

- Sustained remission

- Strictly unilateral features after 3 years

- supranuclear gaze palsy

- Cerebellar signs

- Early severe autonomic involvement

- Early severe dementia with disturbances of memory, language and praxis

- Babinski sign

- Presence of cerebral tumour or communicaring hydrocephalus on CT scan

- Negative respons to large doses of levodopa (if malabsorbrion excluded)

- MPTP exposure

Step 3. Supportive prospective positive criteria for Parkinson"s disease

(Three or more required for diagnosis of definite Parkinson's disease)

- Unilateral onser

- Rest tremor present

- Progressive disorder

- Persisting asymmerry affecting side of onset most

- Excellent response (70-100\%) to levodopa

- Severe levodopa induced chorea

- Levodopa response for 5 years or more

- Clinical course of 10 years or more

CT: compurer tomography. MPTP: 1-methyl-4-phenyl-1,2,3,6 tetrahydropyridine. 
Table 2. Differential diagnosis of the parkinsonian syndrome [93,94].

- Idiopathic Parkinson"s disease

- Other neurodegenerative diseases:

- Multiple system atrophy (Striatonigral degeneration / Shy-Dräger syndrome / Olivopontocerebellar atrophy)

- Progressive Supranuclear Palsy (Steele-Richardson-Olszewski)

- Corticobasal degeneration

- Diffuse Lewy Body disease

- Alzheimer's disease

- Huntington disease (Westphal variant)

- Infections:

- Encefalitis lethargica (Von Economo)

- Cerebrovascular disease

- Intoxications:

- MPTP

- CarbonMonoxide

- Manganese

- Medication:

- Neuroleptics

- Flunarizine / Cinnarizine

- Metoclopramide

- Reserpine

- Trauma:

- Dementia pugilistica

- Merabolic:

- Wilson's disease (hepatolenticular degeneration)

- Normal pressure hydrocephalus

- Brain tumour

- Other causes :

- Hallervorden-Spatz's disease

- Neuroacantocytosis

- Perinatal anoxia

MPTP : 1-methyl-4-phenyl-1,2,3,6 tetralhydropyridine. 


\section{PARKINSONISM AND CEREBROVASCULAR DISEASE}

In current literature, parkinsonism is mainly described in case of lacunar brain infarcts in the region of the basal ganglia or lesions of cerebral white matter (leukoaraiosis). Incidental case reports mention parkinsonism also as a result of cerebral vasculitis or other rare causes.

\section{Signs and symptoms}

Signs of parkinsonism caused by cerebrovascular disease are often localised in the lower extremities. Hence, the term "lower body parkinsonism" (LBP) was introduced by Thompson and Marsden [39-45]. Patients with LBP predominantly have problems of gait: short stepping ("marche à petit pas"), turning and starting problems and a slightly broad based gait. Thompson and Marsden describe 12 parients with frontal and parietal white matter lesions caused by Binswanger disease (subcortical arteriosclerotic encephalopathy). Apart from problems of gait and truncal ataxia these patients had, in contrast to patients with IPD, a straight posture. Also these patients had no propulsion or retropulsion. Falling with preserved rightning reflexes was often seen [39]. This gait disturbance is also indicated as "frontal gait" [46,47].

Apart from typical problems of gait, patients with LBP also have in contrast to IPD, a faster progression of symptoms, often high blood pressure and no positive reaccion on treatment with levodopa [42]. Some studies however describe patients with a parkinsonian syndrome, cerebrovascular disease and a normal substantia nigra on pathological examination, with a positive reaction on levodopa $[48,49,50]$. Possibly, this positive reaction on levodopa is a result of conversion of exogenous levodopa to dopamine in remaining striatal dopaminergic nerve terminals. In most cases, there is no tremor $[41,51]$. Olfactory function is not disturbed in patients with parkinsonism caused by cerebrovascular disease in contrast to findings in idiopathic Parkinson's disease [52]. 
When reported in literature, LBP is very often related to cerebrovascular disease. Most studies describe CT or MRI abnormalities [41,42,44, 5456]: lacunar infarcts in the basal ganglia or lesions of periventricular white matter often located mainly in the region of the frontal horns $[39,40,51]$. Other studies use other imaging modalities. Zijlmans et al. found with MR spectroscopy of patients with levodopa resistant LBP no metabolic evidence for ischaemia or neuronal damage [57].

Few studies report on PA findings in parients with LBP $[45,49]$. Yamanouchi and Nagara found in 24 patients with LBP, lesions of cerebrovascular origin in caudate nucleus, putamen, globus pallidus and thalamus. These lesions resembled those described in case of Binswanger's disease, but were mainly located in the region of the frontal horns [45]. Murrow et al. report multiple lacunar infarcts in the basal ganglia without degeneration of neurons in the substantia nigra in a patient with parkinsonism [49].

Of special interest is the study of Zijlmans et al. [53]. They describe PA characteristics of cerebrovascular abnormalities in 17 patients with a parkinsonian syndrome not attributable to IPD or any other known cause. Four of these patients presented with parkinsonism acute or delayed progressive after stroke and had mainly lacunar infarcts contralaterally in or near the external segment of the globus pallidus or ventrolateral nucleus of the thalamus. In the remaining 13 patients, parkinsonism had developed insidiously. Seven of these patients had lacunar infarcts or enlarged perivascular spaces in the putamen, caudate nucleus, internal capsule and internal segment of the globus pallidus. In the other 6 patients, parkinsonism was possibly caused by diffuse small vessel disease in the cerebral white matter.

\section{Parkinsonism and lacunar brain infarcts}

Several studies report on patients or patient series with parkinsonism and one or more lacunar infarcts in the basal ganglia region $[41,49,54,58$, $59,53,60]$. 
Reider-Groswasser et al, found parkinsonian signs in 26 of 45 patients with lacunar infarces of the basal ganglia [55]. Inzelberg et al. found on CT scan of the brain of 106 parkinsonian patients 20 with basal ganglia lacunar infarcts. Signs and symptoms of these patients closely resembled those of IPD with the exception of absence of tremor. All patients except one had a positive reaction on levodopa therapy [51]. Chang reports on three patients with parkinsonism as a result of lacunar infarct in the basal ganglia region, all with spontaneous recovery [41]. In a review of the literature concerning 240 patients with lesions in the basal ganglia and disorders of movement, 21 patients had a parkinsonian syndrome. These patients mainly had bilateral lesions in the lentiform nucleus [61]. In the previously mentioned study of Zijlmans et al., lacunar infarcts in patients with vascular parkinsonism were located in the external segment of the globus pallidus or ventrolateral nucleus of the thalamus [53].

Incidental case reports describe patients with IPD, improving as a result of a lacunar infarct. These lesions were located in subthalamic nucleus or crus posterior of the internal capsule $[62,63]$.

\section{Parkinsonism and white matter lesions}

White matter lesions are described in many ways: periventricular hyperintensities, leukoaraiosis and subcortical arteriolosclerotic encephalopathy of Binswanger. Gait disturbances resemble those in LBP. Also, urine incontinence, dementia and autonomic nervous system dysfunction can occur $[12,41,46,64-79]$.

Atchison et al. report on six patients with a "gait ignition failure". These patients have problems with starting to walk, but not with walking, once commenced. Five of these six patients had white matter lesions on MRI examination. The gait ignition failure is discerned from a frontal gait disorder as in LBP by the presence of a normal gait when walking, normal rightning reflexes and absence of retropulsion [46]. Elble et al. made a gait analysis of patients with parkinsonism and multiple deep infarcts and white matter lesions on CT or MRI examination of the brain. Gait stages 
were normal, but shift from one gait phase to another was disturbed $[40,80]$.

\section{Parkinsonism and non-ischaemic cerebrovascular disease}

A parkinsonian syndrome is also described in non-ischaemic cerebrovascular disease. Fénelon reported on parkinsonism in patients with dilatation of perivascular spaces in the basal ganglia ("état criblé") [80]. Parkinsonism is also described as a result of anoxic striatal lesions. Furthermore, subdural haemorrhage and haemorrhage in brain parenchyma can cause parkinsonism [59, 82-85]. Finally, parkinsonism is also reported as symptom of cerebrovascular disease related to periarteriitis nodosa, Fabry's disease and Sjögren's disease [86-88].

\section{Pathophysiology of parkinsonism in cerebrovascular disease}

The extrapyramidal system is comprised of several basal ganglia connected through various neuronal projections.

The principal striatal circuit starts in the caudate nucleus and putamen. Through white matter tracts in the corona radiata, these nuclei receive projections from ipsilateral neocortex and bilateral from premotor, motor and somatosensory cortex. Caudate nucleus and putamen project to the globus pallidus and from here through ansa lenticularis, fasciculus lenticularis and fasciculus thalamicus to the ventrolateral thalamic nucleus. From here, tracts proceed through the crus anterior of the internal capsule back to the cortex, mainly area 6 and the supplementary motor area (figure 1a). This circuit is the motor part of the extrapyramidal system, important for regulation of (automatic) movement.

Apart from the principal striatal circuit, there are four accessory circuits. Firstly, projections from the fasciculus thalamicus also reach centromedian and parafascicular nuclei of the thalamus proceeding to putamen, caudate nucleus and cortex. This circuit probably integrates sensory information in the extrapyramidal system (figure 1b). Secondly, 
Figure la - e. Circuits in the extrapyramidal system and their relation with surrounding structures.

1 Corona radiata. 2 Corpus nuclei caudati. 3 Putamen. 4 Fibrae strionigrales. 5 Capsula interna, crus posterius. 6 Nucleus rericularis thalami. 7 Nucleus centromedianus. 8 Fasciculus thalamicus. 9 Zona incerta. 10 Fasciculus lenticularis. 11 Nucleus subthalamicus. 12 Substantia nigra. 13 Nucleus parafascicularis. 14 Ansa lenticularis. 15 Nucleus ruber. 16 Tractus opticus. 17 Capsula interna, pars sublentiformis. 18 Cauda nuclei caudati. 19 Pedunculus cerebri. 20 Pons.

Reprinted with permission (Nieuwenhuys R et al. The human central nervous system. A synopsis and atlas. Copyright Springer-Verlag Berlin Heidelberg 1988).

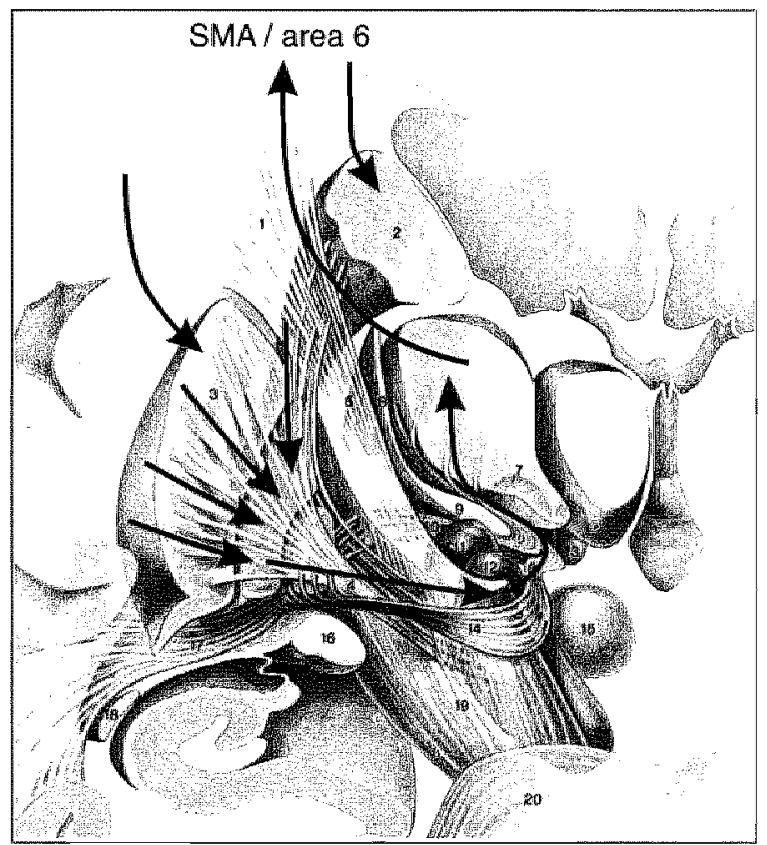

Figure 1a: Principal striatal motor circuit. 


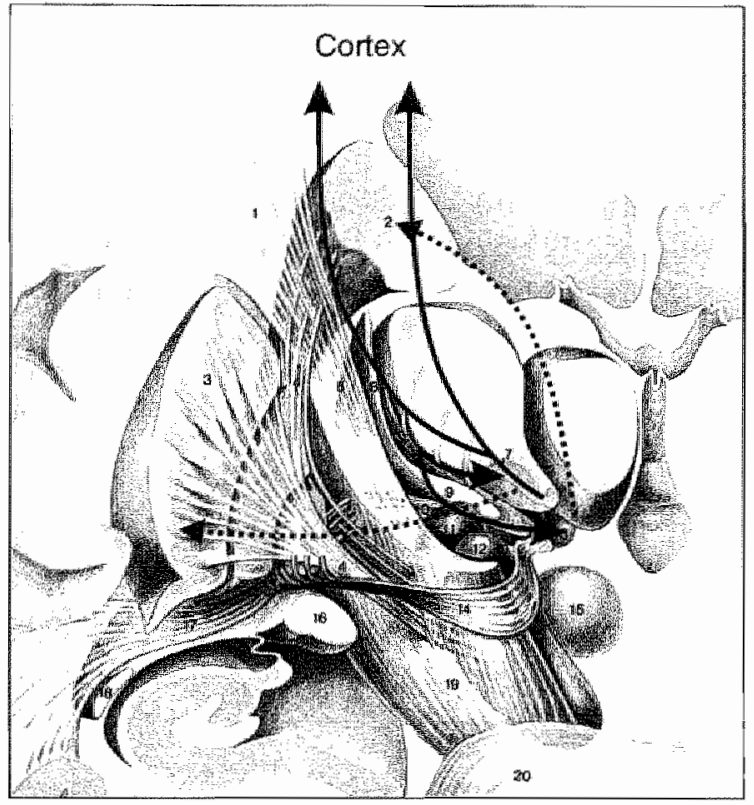

Figure 1 b: First accessory circuit.

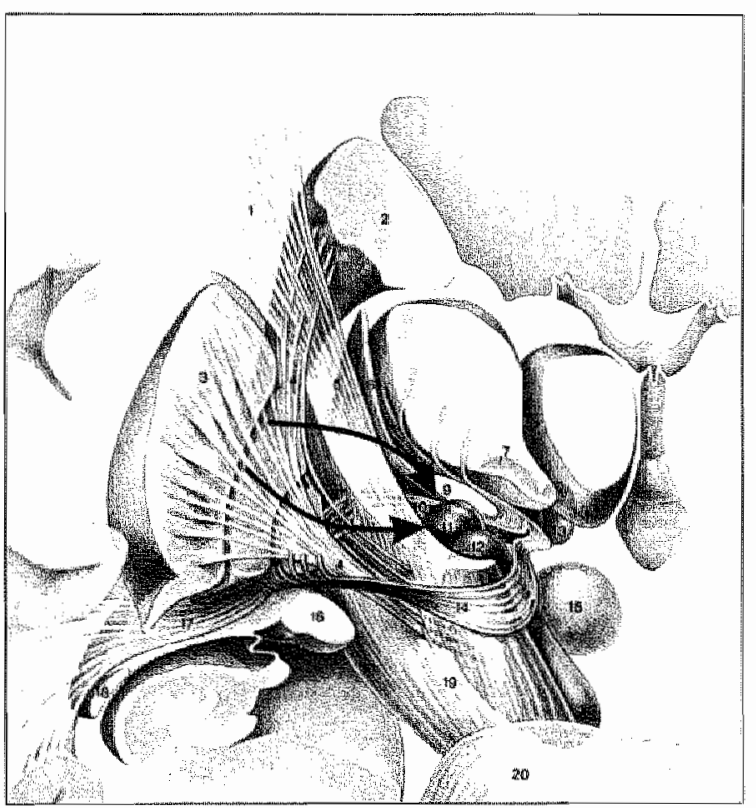

Figure 1a: Second accessory circuit. 


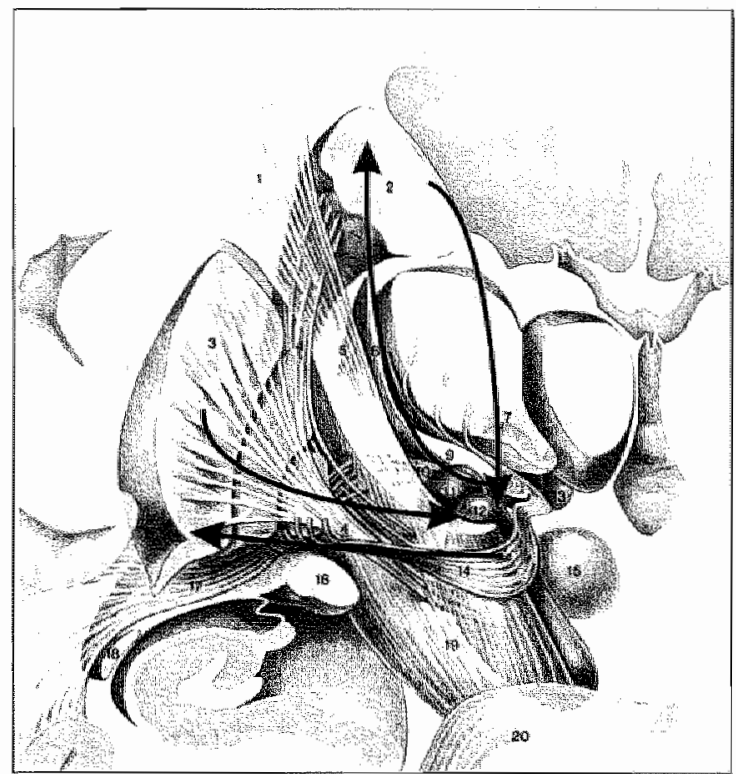

Figure 1d: Third accessory circuit.

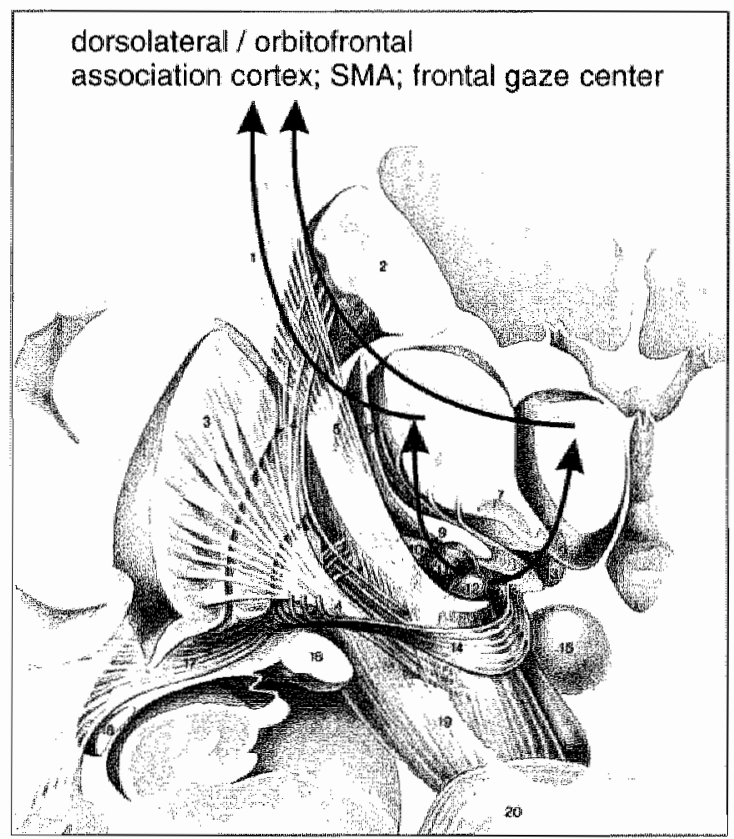

Figure 1e: Fourth accessory circuit. 
there are important connections between the external segment of the globus pallidus and subthalamic nucleus, inhibiting the extrapyramidall system (figure 1c). Thirdly, there are projections from the caudate nucleus and putamen to the pars reticulata of the substantia nigra and from the pars compacta back to the striatum. This last projection uses dopamine as neurotransmitter. In case of IPD, there is loss of the dopamine producing neurons in the pars compacta of the substantia nigra (figure 1d). And finally, there is a last projection proceding from the pars reticulata of the substantia nigra through the medial and ventro-anterior thalamic nuclei to the orbitofrontal cortex, frontal gaze center, supplementary motor area and the lateral prefrontal cortex. This projection is involved in emotions (orbitofrontal cortex), eye movement (frontal gaze center), memory, and evaluation of behaviour (lateral prefrontal cortex) (figure le) [89-90]. It is clear that a relatively small part of the brain contains the nuclei and their projections which are essential to normal functioning of the circuits described above. Furthermore, there are important efferent and afferent tracts of the extrapyramidal system in the corona radiata and crus anterior of the internal capsule. Nuclei and their projections can be damaged in case of cerebrovascular disease.

External segment of the globus pallidus and ventrolateral nucleus of the thalamus are essential for thalamocortical drive [92]. Thus, thalamocortical drive can be reduced by lacunar infarcts in these regions. Lacunar brain infarcts in other parts of the basal ganglia and internal capsule and WML may hamper cortical afferents to the extrapyramidal system or efferents to the cortex, especially the supplementary motor area $[39,42,71]$.

\section{CONCLUSIONS}

Parkinsonism is a well defined clinical syndrome with multiple causes. Parkinsonism in the context of IPD, caused by degeneration of dopamine producing neurons in the substantia nigra, is not a result of cere- 
brovascular disease. The cause of this neuronal degeneration is still subject of study.

There are several reports of parkinsonism as a result of one or more lacunar brain infarcts in the basal ganglia or their connecting white matter tracts. The parkinsonian syndrome resulting from these lacunar infarcts is often difficult to distinguish from IPD. Only in the minority of cases, this parkinsonism presents as lower body parkinsonism.

Parkinsonism in patients with white matter lesions often is LBP. LBP however, is also seen in patients with normal pressure hydrocephalus, multi-infarct dementia, and Binswanger's disease. Often it is difficult to establish if and to what extent, white matter lesions independently of other factors cause parkinsonism. Almost every study discussed here was retrospective and concerned cerebrovascular compromised patients presenting with parkinsonism. Parkinsonian symptoms in patients with a known cerebrovascular disease were never starting point of investigations. It is therefore unknown, how often parkinsonian signs and symptoms are part of stroke symptomatology and how they influence functional outcome. Related to this, stroke occurrence in patients with parkinsonism as a result of idiopathic Parkinson's disease also has to be studied. Furthermore, the pathophysiological mechanisms which cause parkinsonism in patients with cerebrovascular disease still have to be revealed. Finally, the value of ancillary examinations to differentiate parkinsonism caused by cerebrovascular disease from other causes of parkinsonism has to be established.

We started the present study with the following aims:

1. To study the frequency of parkinsonian signs in patients with acute stroke and six months thereafter as well as a possible relationship between the presence and progression of these signs and functional outcome (Chapters 1 and 2).

2. To study a possible relationship between a specific location of ischaemia and the presence of parkinsonian signs (Chapter 3). 
3. To investigate cerebral perfusion differences in patients with vascular parkinsonism and IPD to test the hypothesis that vascular parkinsonism is caused by ischaemic lesions in the frontal white matter (Chapter 4).

4. To investigate availability of dopamine and dopamine receptors in patients with vascular parkinsonism as compared to patients with idiopathic Parkinson's disease with Single Photon Emission Computed Tomography (SPECT) studies and to evaluate the possibility of distinghuishing IPD from vascular parkinsonism with these techniques (Chapter 5).

5. To investigate stroke occurrence in patients with parkinsonism as a result of idiopathic Parkinson"s disease and hypothesize regarding the role of the neurotransmitter dopamine in patients with stroke and idiopathic Parkinson's disease (Chapter 6).

\section{REFERENCES}

1. Bamford J. Clinical examination in diagnosis and subclassification of stroke. Lancer 1992; 339:400-402.

2. Warlow CP, Dennis MS, Van Gijn J. Hankey GJ, Sandercock PAG, Bamford JM, Wardlaw J. Sroke. A pracrical guide to managnent. Oxford: Blackwell Science; 1996.

3. Evers SMAA, Engel GL, Ament AJHA Cost of stroke in The Netherlands from a societal perspective. Stroke 1997; 28:1375-1381.

4. MohrJP, Sacco RL. Classificarion of ischemic strokes. In: Barnert HJM, Stein BM, Mohr JP. Yatsu FM, eds. Stroke. Pathophysiology, diagnosis, and managment, second ed. New York: Churchill Livingstone, 1992:29-48.

5. Fisher $\mathrm{CM}$. Lacunar strokes and infarcts: a review. Neurology 1982; $32.871-876$.

6. Bamford J, Sandercock P, Dennis M, Burn J, Warlow C. Classification and natural history of clinically identifable subtypes of cerebral infarction. Lancet 1991; 337:1521-1526.

7. Boiten J, Lodder J. Lacunar infarets. Pathogenesis and walidity of the dinical syndromes. Stroke $1991 ; 22: 1374-1378$.

8. Landi $G$. Cella $E$, Boccardi $E$, Musicco M. Lacunar versus non-lacunar infarcs: pathogenetic and prognostic differences. I Neurol Neurosurg Psychiatry 1992:55:441445. 
9. Lodder J, Bamford JM, Sandercock PA, Jones LN, Warlow CP. Are hypertension or cardiac embolism likely cause of lacunar infarction? Stroke 1990; 21:375-381.

10. Van Merwijk G, Lodder J, Bam ford J, Kester AD. How often is non-valvular atrial fibrillarion the cause of brain infarction? I Neurol 1990; 237:205-207.

11. Hachinski VC, Porter P, Merskey H. Leuko-araiosis. Arch Neurol 1987; 44:21-23.

12. Steingart A, Hachinski VC, Lau C, Fox AJ, Fox H, Lee D, Inzitari D, Merskey H. Cognirive and neurologic findings in demented patients with diffuse whice marter lucencies on computed tomographic scan (leuko-araiosis). Arch Neurol 1987; 44:36-39.

13. Longstreth WT, Manolio TA, Arrold A, Burke GL, Bryan N, Jungreis CA, Enrighr PL, O Leary D, Fried L. Clinical correlates of white matrer findings on cranial magnetic resonance imaging of 3301 elderly people. The cardiovascular Health Sudy. Stroke 1996; 27:1274-1282.

14. Breteler MM, Van Amerongen NM, Van Swieten JC, Claus JI, Grobbee DE, Van Gijn ], Hofman A, Van Harskamp F. Cognitive correlates of ventricular enlargement and cerebral whire matrer lesions on magnetic resonance imaging. The Rotterdam Study. Sroke $1994 ; 25: 1109-11115$.

15. De Groot IC, De Leeww FE, Breteler MMB. Cognitixe correlates of cerebral white matter changes. J Neural Transm Suppl 1998; 53:41-69.

1.6. Tarvonen Schroder S, Roytta M, Raiha I, Kurki T, Rajala T, Sourander L. Clinical features of leuko-araiosis. J Neurol Neurosurg Psychiatry 1996; 60:431-436.

17. Breteler MMB, van Swieten JC, Bots ML. Cerebral white matrer lesions, vascular risk. factors, and cognitive function in a population-based study: the Rotterdam Study. Neurology 1994; 44:1246-1252.

18. Fazekas F. Magnetic resonance signal abnormalities in asymptomatic individuals: their incidence and functional correlates. Eur Neurol 1989; 29:164-168.

19. Ylikoski a, Erkinjuntti T, Raininko R, Sarna $S_{x}$ Sulkava R, Tilvis R. White matter hyperintensities on MRI in the neurologically nondiseaesed elderly. Srroke 1995; 26:1171-1177.

20. DeGraba T), Fisher M, Yatsu FM. Atherogenesisand strokes. In: Barnet HIM, Stein BM, Moh.r JP, Yatsu FM, eds. Sirroke. Pathophysiology, diagnosis, and managment, second ed. New York: Churchill Livingstone, 1992:29-48.

21. Caplan LR. Intracranial branch atheromatous disease: a neglected understudied, and underused concept. Netrology 1989; 39:1246-1250.

22. Fisher CM. Lacunar infarcrs - a review. Cerebrovasc Dis 1991; 1:311-320.

23. Boiren J, Lodder J, Kessels F. Two clinically distinct lacunar infarctentiries? A hypothesis. Stroke 1993; 24:652-656.

24. Mast H, Thompson JL, Lee SH, Mohr JP, Sacco RL. Hypertension and diabetes mellitus as determinants of mulciple lacunar infarcts. Stroke 1995:26:30-33.

25. Adams RD, Victor M. Principles of neurology, $5^{\text {the }}$ edition. New York, McGraw-Hill, 1993.

26. Bogrousslavsky I, Castillo V. Kumral E, Henriques I, Melle GV. Stroke subtypes and hypertension. Primary hemorrhage vs infarction, large- vs small-artery disease. Arch Neurol 1996; 53:265-269. 
27. Offenbacher H, Fazekas F, Schmidr R, Koch M, Fazekas G, Kapeller P. MR of cerebral abnomalities concomitant with primary intracerebral hematomas. Am J Neuroradiol $1996: 17: 573-578$.

28. Haan J, Roos RAC, Algra PR, Lanser JB, Bots GT, Vegter-Van der Vis M. Hereditary cerebral haemorrhage with amyloidosis-Durch type. Magnetic resonance imaging findings in 7 cases. Brain 1.990; 113:1251-1267.

29. Parkinson J. An essay on the shaking palsy. London, Whitringham \& Rowland 1817.

30. Charcot JM. Lecrures on the diseases of the nervous system. London, The New Sydenham Sociery $187 \%$.

31. Hughes AJ "Daniel SE, Blankson S, Lees AJ. A clinicopathologic study of 100 cases of Parkinson's disease. Arch Neurol 1993; 50: 140-148.

32. Gibb WRG, Lees A. The relevance of the Lewy body to the pathogenesis of idiopathic Parkimson's disease. I Neurol Neurosurg Psychiary 1988; 51:745-752.

33. Gelb DJ, Otiver E, Gliman S. Diagnostic criteria for Parkinson disease. Arch Neurol $1999 ; 56: 33-39$.

34. Wolters ECh, Oertel WH. Special therapeutic problems of Parkinson's disease. In: Wolkers ECh ed. Parkinson's disease: sympromatic vs. preventive therapy. Current issues in neurodegenerative diseases, Dordrech, ICG 1994; 3:79-93.

35. Critchley M. Arteriosclerotic parkinsonism. Brain 1929; 52:23-83.

36. Brissand E. Leçons sur les maladies nerveuses. Paris, Masson $1895,486-501$.

37. Eadie MJ. Sutherland JM. Arteriosclerosis in parkinsonism. J Neurol Neurosurg Psychiatry 1964; 27:237-240.

38. Jankovic J. Parkinsonism-plus syndromes. Mov Disord 1989;4. Suppl.1:95-119.

39. Thompson PD, Marsden CD. Gait disorder of subcortical arterioscleroric encephaloparhy: Binswanger's disease. Mov Disord 1987; 2:1-8.

40. Elble RJ, Cousins R, Leffler K, Hughes L. Gait initiation by patients with lower-half parkinsonism. Brain 1996;119:1705-1716.

41. Charg CM, Yu YL, Leung SY, Fong KY. Vascular pseudoparkinsonism. Acra Neurol Scand 1992:86:588-592.

42. FirzGerald PM, Jankovic J. Lower body parkinsonusm: evidence for vascular eriology. Mov Disord 1989; $4: 249-260$.

43. Fénelon G, Houéto JL. Les syndromes parkinsoniens vasculaires: un concept controversé. Rev Neurol (Paris) 1998; 154:291-302.

44. Winikates J, Jankowic I. Clinical correlates of vascular parkinsonism. Arch Neurol 1999; $56: 98-102$.

45. Yamanouchi $H$, Nagura $H$. Neurological signs and frontal white matrer lesions in vascular parkinsonism. A clinicopathologic study. Stroke 1997; 28:965-969.

46. Atchison $\mathbb{P R}$.Thompson $\mathrm{PD}$, Frackowiak RSJ, Marsden CD. The syndrome of gat ignition failure: a report of six cases. Mov Disord 1993; 8:285-292.

47. Nutr JG, Marsden CD, Thompson PD. Human walking and higher-level gair disorders, particularly in the elderly. Views and reviews. Neurology 1993; $43: 268-279$.

48. Mark MH, Sage JI, Walcers AS, Duvoisin RC, Miller DC. Binswanger's disease presenring as levodopa-responsive parkinsonism: clinicoparhologic study of three cases. Mov Disord 1995; 10:450-454. 
49. Murrow RW, Schweiger GD, Kepes J], Koller WC. Parkinsonism due to a basal ganglia lacunar state: clinicoparhologic correlation. Neurology 1990; 40:897-900.

50. Zijlmans JC, Katzenschlager $\mathbb{R}$, Daniel SE, Lees AJ. The L-dopa response in vascular parkinsonism. J Neurol Neurosurg Psychiatry 2004; 75:545-547.

51. Inzelberg R, Bornstein NM, Reider I, Korczyn AD. Basal ganglia lacunes and parkinsonism. Neuroepidemiology 1994; 13:108-112.

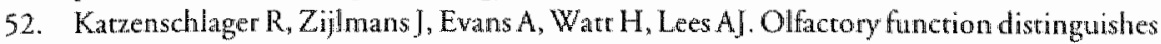
wascular parkinsonism from Parkinson's disease. I Neurol Neurosurg P'sychiatry 2004; $75: 1749-1752$.

53. Zijlmans JC, Daniel SE, Fughes AJ, Révész T, Lees AJ. Clinicopathological investigation of wascular parkinsonism, including criteria for diagnosis. Mov Disord 2004; 19:630-640.

54. Tolosa ES, Santamaria 『. Parkinsonism and basal ganglia infarcts. Neurology 1984 ; $34: 1516-1518$.

55. Reider-Groswasser I, Bornstein NM, Korczyn AD. Parkinsonism in patients with lacunar infarcts of the basal ganglia. Eur Neurol 1995; 35:46-49.

56. Trenkwalder C, Schwarz J, Gebhard J, Ruland D, Trenkwalder P, Hense HW at al. Stamberg triat on epidemiology of parkinsonism and hypertension in the elderly. Arch Neurol 1995; 52:1017-1022.

57. Zijlmans JCM, de Koster A, van 't Hof MA, Thijssen HOM, Horstink MWIM, Heerschap A. Proton magnetic resonance spectroscopy in suspecred vascular ischemic parkinsonism. Acral Neurol Scand 1994; 90:405-411.

58. Costa B, Zanette G, Bertolasi L, Fiaschi A. Hemiparkinsonism-hemiatrophy syndrome: neuroradiological and neurophysiological findings. Eur Neurol 1994; 34:107-109.

59. Ikeda K, Kotabe T, Kanbashi S, Kinoshita M. Parkinsonism in lacunar infarcts of the basal ganglia. Eur Neurol 1996; 36:248-249.

60. Peralta C, Werner P, Holl B, Kiechl S, Willeit J, Seppi K, Wenning G, Poewe W. Parkinsonism following striatal infarcts: incidence in a prospective stroke unit cohort. J Neural Transm 2004; 11 1: 1473-1483.

61. Bhatia KB, Marden CD. The behavioural and motor consequences of focal lesions of the basal ganglia in man. Brain 1994; 117:859-876.

62. Krauss JK, Grossman RG, Jankovic J. Improvement of parkinsonian signs after vascular lesions of the basal ganglia circuitry. Mow Disord 1997:12:124-125.

63. Yamada A, Takenchi $\mathrm{H}$, Miki H. Unilateral abolition of parkinsonian rigidiry after subthalanic nucleus hemorrhage. Rinshi-Shinkeigaku 1992; 32:887-9.

64. Baloh RW, YueQ, Socotch TM, Jacobson KM. White matrer lesions and disequilibrtum in older people. I. Case-control comparison. Arch Neurol 1995; 52:970-974.

65. Baloh RW" Vinters HV. White matter lesions and disequilibrium in older people. II. Clinicopathologic correlation. Arch Neurol 1995; 52:975-981.

66. Benner DA, Gilley DW, Wilson BS, Huckman MS, Fox JH. Clinical correlates of high signal lesions on magneric resonance imaging in Alzheimer's disease. I Neurol 1992 ; 239:186-190.

67. Briley DP, Wasay M, Sergent S, Thomas S. Cerebral white matter changes (leukoaraiosis), stroke and gait disturbance. J Am Geriatr Sac 1997; 45:1434-1438. 
68. Cummings JL. Vascular subcorrical dementias: elinical aspects. Dementia 1994; 5:177180.

69. Decarli C, Murphy DGM, Tranh M, Grady CL, Haxby JV, Gillette A er al. The effect of white matrer hyperintensity volume on brain structure, cognirive performance, and cerebral metabolism of glucose in 51 healthy adults. Neurology 1995; 45:2077-2084.

70. Inagaki $T$, Ishino $H$, Senoh $H$, Yamamori $C$, lijima $M$, Ideshita $H$ et al. A case of Binswanger disease with numerous diffuse plaques in the neocortex. No To Shinkei 1990 ; $42: 291-296$.

71. Hennerici MG, Oster M, Cohen $\$$, Schwartz A. Motsch $\mathbb{L}_{2}$. Daffertshofer M. Are gait disturbances and white-matter degenerarion early indicators of vascular dementia? Dementia 1994; 5:197-202.

72. Jellinger KA. Parkinsonism due to Binswanger's subcortical arreriosclerotic encefalopathy (letter). Mov Disord 1996; 11:461-462.

73. Korsiris $\mathrm{H}$, Barclay LL, Kheyfers $S$, Huljalkar A, Dougherty J. Urinary and gair disturbances as markers for early multi-infarct dementia. Srroke 1987:18:138-141.

74. Masdeu JC, Wolfson L, Lantos G, Tobin JN, Grober Ex Whipple R et al. Brain whitematter changes in the elderly prone to falling. Arch Neurol 1989; 46:1292-1296.

75. Murata $Y$, Harada $T$ Ishizaki F, Izumi Y, Nakamura S. Autonomic dysfuncrion in Parkinson's disease and vascular parkinsonism. Acra Neurol Scand 1997; 96:359-365.

76. Sacquegna T", Gutcmann S, Giuliani S, Agari R, Daidone R, Morreale Aetal. Binswanger's disease: a review of the literarure and a personal contriburion. Eur Neurol 1989;29)(suppl 2) $: 20-22$

77. Sakakibara $R$, Takamichi $H$, Uchiyama T, Yamanishi $T$. Urinary function in elderly people with and withour leukoaraiosis: relation to cognitive and gait function. J Neurol Neurosurg Psychiatry 1999; 67:658-660.

78. Miller Fisher C. Binswanger's encefalopathy: a review. J Neurol 1989; 236:65-79.

79. Zagten van M, Lodder J, Kessels F. Gair disorder and parkinsonian signs in parients with stroke relate to small deep infarcts and white matterlesions. Mov Disord 1998; 13:89-95.

80. Zijlmatns JCM, Poels PJE, Duysens J, van der Straaten J, Thien Th, van 't Hof MA er al. Quantitative gait analysis in patients with vascular parkinsonism. Mow Disord 1996; $11: 501-508$.

81. Fenclon G, Gray F, Wallays C, Poirier J, Guillard A. Parkinsonism and dilaration of the perivascular spaces (état crible) of the striarum: a dinical, magneric resonance imaging. and parholgical study. Mov Disord 1995; 10:754-760.

82. Hageman ATM, Horstink MWIM. Parkinsonism due to a subdural hematoma. Mov Disord 1994; 9:107-108.

83. Miyagi K, Imaizumi T, Nagura H, Yamanonchi H. A case of transienx parkinsonism due to mesencephalic hemorrhage. Rinsho-Shinkeigaku 1992; 32:743-746.

84. Ohnishi J, Yokoyama K. A case of vascular parkinsonism with unsuspected multiple cerebral hemorrhage. No To Shinkei $1996 ; 48: 181$.

85. Turjanski $N_{n}$ Pentland B, Lees AJ, Brooks DJ. Parkinsonism associated with acute intracranial hematomas: an ["HDDopa Positron Emission Tomography study. Mov Disord 1997; 12:1035-1038. 
86. Mayo J, Arias M, Leno C. Vascular parkinsonism and periarerisis nodosa. Nextrobogy $1986 ; 36: 874$

87. Orimo $S_{w}$ I wasaki T, Yoshmo H. Arai M, Hiyamuta E. An antopsied case of Fabry"s disease presenting with pakinsonism and cardiomegaly as a cardisal clinical mandestation. Rinsho Shinkeigaku 1994; 34: 1003-1007.

88. Mochizuki H, Okano M, Masaki T, Magara N, Kanakuna K. Acase of Sjögren's syndrome with a high titer of anticardiolipin antibody that developed as parkinsonisn. RinshoShinkeigaku 1997; 37:57-59.

89. Nienwenhuys R, Voogd J, van Huijzen Ch. The human central nerwous system. A symopsis and arlas. Berlin, Springer Vertag 1988.

90. Marrin JH. The basal Gangha. In: Martin JH. Neqroanatomy. Text andatlas. New York, Elsevier $1989,267-289$.

91. Alexander GE, Crutcher MD. Functional architecture of basal ganglia cictuits neural substrates of parallel processing. Trends Neurosci 1990; 13:266-271.

92. Wichmann T, Delong M. Funcrional and pathophysiological models of the basat ganglia. Curr Opin Neurobiol 1996; 6:751-758.

93. Manfredi M. Stocchi F, Vacca L. Differential diagnosis of parkinsonism. I Neural Transm $1995 ; 45: 1-9$.

94. Kishore A, Cane DB. Approach to the patient with a movement disorder and overwiew of movement disorders. In: Watts, RL, Kollew WC, eds. Movement disorders. Netrological Principles and Pracrice, New-York, McGaw-Hill 1997, 3-14, 

CHAPTER 1

Extrapyramidal system

dysfunction in 101 patients with

acute first-ever stroke

Arthur G.G.C. Korten MD; Jan Lodder MD, PhD; Fred W. Vreeling MD, PhD; Anita M.H.P. Boreas MD, PhD; Alfonso H.F. Kessels MD, MSc; Wim E.J. Weber MD, PhD.

BioMed Central Neurology, submitted. 
ABSTRACT

Background. Although the diagnosis of vascular parkinsonism, resulting from multiple strokes, is well established, the precise relation between the vascular lesions and the ensuing parkinsonism remains unclear. In particular, the prevalence of extrapyramidal tract dysfunction in acute, first ever stroke patients, is unknown.

Methods. We prospectively investigated the presence of symptoms of extrapyramidal dysfuncrion, judged clinically according to UKPDSBB criteria in 101 consecutive patients with acure stroke.

Results. Of 101 patients, 31 had rigidity, 3 patients resting tremor, 8 bradykinesia and 4 postural instability. A parkinsonian syndrome was present in 4 patients. Presence of rigidity was related to white matter lesions on CT or MRI and not to a deep lesion. Conclusions. Our results indicate that signs of parkinsonism and even complete parkinsonian syndromes are frequently present in acute first-ever stroke patients. These symptoms are related to white matter lesions resulcing in damage to "extrapyramidal" connecring white matter tracts. 


\section{INTRODUCTION}

Since Critchley's first description [1] of vascular parkinsonism (VP), this dinical concept has gained widespread acceptance. Most authors now agree on VP as a parkinsonian syndrome dominated by postural instability with shuffling gait and absence of tremor [2-11], occurring in 3-5\% of parients with parkinsonism [12,13]. Affected patients have vascular risk factors, often hypertension, and/or suffered one or more strokes, usually of the lacunar type $[2,5-10,12-15]$. The association of lacunar infarctions, as a result from small vessel disease, with VP is well established, both by imaging $[4,8,9,15,16]$ and histopathological studies $[14,17]$.

However, the precise relation between the vascular lesions and the ensuing parkinsonism remains unclear. Patients with VP from a single stroke in a specific cerebral location are a great minority and are most often published as case reports: locations include mesencephalon [18], substantia nigra [19], the striatum [20], basal ganglia [21], the anterior cerebral artery [22], cerebral peduncle [6,23], anterior choroidal artery [24,25]. The great majority of patients with VP suffers an insidious onset, where the relation of timing, location, and size of the infarct with the clinical syndrome is poorly understood [7, 13-15, 26$]$.

In particular, little is known about the prevalence of extrapyramidal tract dysfunction in acute, first-ever stroke patients. Parkinsonian symproms have traditionally received little attention in the acute phase of stroke, and, in contrast to disturbances of muscle power and sensory modalities, are often not included in stroke syndrome diagnosis or stroke scales $[2,27]$. We hypothesized that, in acute stroke, signs and symptoms of parkinsonism are present and are related to leukoaraiosis, asymptomatic lacunar brain infarcts or deep location of the symptomatic lesion. To study this, we assessed extrapyramidal tract dysfunction in a consecutive series of 101 parients with an acute, first-ever stroke. 


\section{METHODS}

Patients with acute stroke with symptoms lasting longer than 24 hours were examined in the second week after stroke for the presence of cardinal signs of parkinsonism: bradykinesia, rigidity, tremor and postural instability. Patients with a known history of idiopathic Parkinson's disease or other neurodegenerative disorder with parkinsonism, repeated head injury, exposure to 1-methyl-4-phenyl-1,2,5,6-tetrahydropyridine (MPTP) [28], definite encephalitis, a cerebral tumour or a hyd rocephalus on CT scan, or those using neuroleptic medication were excluded. The presence of bradykinesia was judged clinically. Grading was done according to the Unified Parkinson's Disease Rating Scale (UPDRS), item 31 [29]. Rigidity, tremor and postural stability were -if possible- also scored on both sides of the body according to the UPDRS, items 22, 20 and 30. Used UPDRS items and their scoring are shown in table 1 . Rigidity was judged by passively moving elbow, wrist and knee joints searching for the presence of a lead-pipe phenomenon [30]. Presence of tremor was inspected in rest and action. Postural stability was examined by scoring the standing patients reaction to a sudden, strong posterior displacement produced by a pull on the shoulders. Data on signs, symptoms, previous history and results of ancillary examinations were registered prospectively in the Maastricht Stroke Registry (MSR) [26]. Statistical analysis (univariate and multivariate regression analysis) was performed with the "Software Package for the Social Sciences" (SPSS) version 8.0, SPSS inc. 1997.

\section{Definitions}

Bradykinesta is defined as a slowness of initiation of voluntary movements with progressive reduction in the speed and amplitude of repetitive actions [31]. Patients are considered bradykinetic when UPDRS score on item 31 is 1 or more [29]. 
Table 1. UPDRS scoring of key symproms of parkinsonism [3].

Body bradykinesia and hypokinesia (II, 31.)

$0=$ none.

$1=$ minimal slowness, giving movement a deliberate character; could be normal for some persons. Possibly reduced amplirude.

$2=$ Mild degree of slowness and poverty of movement which is definitely abnormal.

Alternatively, some reduced aplitude.

$3=$ Moderate slowness, poverty or small amplitude of movement.

$4=$ Marked slowness, povercy or small amplitude of movement.

Rigidity (III, 22.)

$0=$ absent.

$1=$ slight or detectable only when activated by mirror or other movements.

2 = mild to moderate.

$3=$ mild, but full range of motion easily achicved.

$4=$ severe, range of morion achieved with difficulty.

Tremor at rest (III, 20.)

$0=$ absent.

$\mathbb{1}=$ slight and infrequently present.

$2=$ mild in amplitude and persistent. Or moderate in amplitude, but only intermitcently present.

$3=$ moderate in amplitude and present most of the time.

4 = marked in amplitude and present most of the time.

Postural Stability (III, 30)

$0=$ normal.

$1=$ retropulsion, but recovers unaided.

2 = absence of postural response; would fall if not caught by examiner.

$3=$ very unstable, tends to lose balance spontaneously.

$4=$ unable to stand without assistance. 
Rigidity is an increase in muscle tone during passive movement. Patients are considered rigid when UPDRS score on item 22 is 1 or more.

Tremor comprises involuntary oscillations of a body part produced by alternating or synchronous contractions of reciprocally innervated muscles. According to the UPDRS, tremor at rest is present when the score on item 20 is 1 or more.

Loss of postural reflexes presents with impaired righting reflexes and problems of maintaining balance (UPDRS $\geq 1$ ).

A parkinsoniansyndrome is the presence of bradykinesia and at least one of the following: rigidity, $4-6 \mathrm{~Hz}$ resting tremor or postural instability $[29,31$.$] .$

Lacunar stroke and territorial siroke definitions were used as described elsewhere $[10,27]$. Leukoaraiosis is defined as a CT finding consisting of focal or diffuse hypodensities in the periventricular or deep white matter, not involving the cortex, and with ill-defined margins to distinguish it from infarction. [32]. A "deep lesion" on CT or MRI was defined as a lacunar or striatocapsular infarct, or supratentorial deep haemorrhage. A "deep lesion stroke" was defined on the basis of clinical and CT or MRI findings as lacunar, striatocapsular or haemorrhagic stroke.

\section{RESULTS}

58 Males and 43 females were included in the study. Mean age was 75 years (SD 11.4; range 28 to 99 years). Information on comorbidity is listed in table 2. On CT or MRI 27 parients had a lacunar infarct, 30 a territorial infarct and five a striatocapsular infarct. Leukoaraiosis was present in 33 patients. Asympromatic lacunar brain infarcts were seen in 38 patients. Seventeen patients had an intracranial haemorrhage ( $\mathrm{CH}$ ), two of which were cerebellar. In 21 patients CT or MRI showed no symptomatic ischaemic lesions or haemorrhage. Eight of these patients however, had leukoaraiosis and 10 one or more asymptomaric lacunar brain infarcts. One patient had no CT or MRI on admission or during hospital 
Table 2. Comorbidity of 101 patients.

\begin{tabular}{lc}
\hline Diabetes mellitus & 23 \\
Hypertension & 45 \\
Coronary artery surgery & 10 \\
Mitral valve insufficiency & 17 \\
Angina pectoris & 21 \\
Peripheral arterial disease & 11 \\
Atrial fibrillation & 23 \\
Hypercholesterolaemia & 9 \\
Prior Transient Ischaemic Attack & 19 \\
Prior stroke & 23 \\
Chronic obstructive pulmonary disease & 18 \\
Smoking & 35 \\
\hline
\end{tabular}

stay. Combining clinical and radiology findings, final stroke type was classified in all 101 patients: 33 had a lacunar stroke, 51 a territorial ischaemic stroke (including 5 patients with a striatocapsular infarct) and 17 had intracerebral haemorrhage. Table 3 shows the frequency of parkinsonian symptoms related to final stroke type. Rigidity and resting tremor could be scored in all patients. Because of concomitant paresis, postural stability, the presence of a parkinsonian syndrome and bradykinesia could only be evaluated in 45 patients.

In univariate logistic regression analysis, bradykinesia, resting tremor, postural instability or parkinsonian syndrome were not related to leukoaraiosis, asymptomatic lacunar brain infarcts, deep lesion location on CT or MRI or a deep lesion stroke type (all $p$ values $>0.10$ ).

Fifteen of 33 patients with leukoaraiosis had rigidity. Univariate analysis showed leukoaraiosis on CT to be related to rigidity (odds ratio (OR) $2.71,95 \%$ Confidence Interval (CI) $1.12-6.56, \mathrm{p}=0.03$ ). Rigidity was not related to a deep lesion on CT or MRI (OR 0.76,95\% CI 0.33-1.80, $\mathrm{p}=0.54$ ), asymptomatic lacunar brain infarcts (OR $1.60,95 \% \mathrm{CI} 0.63$ $4.08, \mathrm{p}=0.32$ ) or a deep lesion stoke type (OR $0.95,95 \% \mathrm{Cl} 0.40-2.22$, $\mathrm{p}=0.91)$. 
Table 3. Parkinsonian signs in 101 stroke patients related to final stroke type.

\begin{tabular}{|c|c|c|c|c|}
\hline & $\begin{array}{l}\text { Territorial } \\
\text { infarct }\end{array}$ & Lacunar infarct & Hacmorrhage & TOTAL \\
\hline Age & $\begin{array}{l}\text { Mean } 76 \\
\text { SD } 10.4 \\
\text { range } 47.99\end{array}$ & $\begin{array}{l}\text { Mean } 73 \\
\text { SD 13.5, } \\
\text { Range 28-86 }\end{array}$ & $\begin{array}{l}\text { Mean } 78, \\
\operatorname{SD} 8.1 \\
\text { range } 69-95\end{array}$ & $\begin{array}{l}\text { Mean } 75, \\
\mathrm{SD} 11.4, \\
\text { range } 28-99\end{array}$ \\
\hline $\operatorname{Sex} M$ & 31 & 19 & 8 & 58 \\
\hline $\mathbb{F}$ & 20 & 14 & 9 & 43 \\
\hline Leukoaraiosis & $15(29.4 \%)$ & $12(36.4 \%)$ & $6(35.3 \%)$ & $33(32.7 \%)$ \\
\hline Bradykinesia & $2($ of 18$)$ & $4($ of 21$)$ & 2 (of 6$)$ & $8($ of 45$)$ \\
\hline Tremor at rest & $2($ of 51$)$ & $1($ of 33$)$ & $0($ of 17$)$ & $3($ of 101$)$ \\
\hline Postural instability & 2 of 18$)$ & $2($ of 21$)$ & 0 (of 6$)$ & $4($ of 45$)$ \\
\hline Rigidity & $16($ of 51$)$ & $10($ of 33$)$ & $5($ of 17$)$ & 31 (of 101$)$ \\
\hline \multicolumn{5}{|l|}{$\begin{array}{l}\text { At least one of four } \\
\text { parkinsonian }\end{array}$} \\
\hline symptoms & 20 (of 51) & 13 (of 33) & 7 (of 17$)$ & $40($ of 101$)$ \\
\hline $\begin{array}{l}\text { Parkinsonian } \\
\text { syndrome }\end{array}$ & $2($ of 18$)$ & $2($ of 21$)$ & $0($ of 6$)$ & $4($ of 45$)$ \\
\hline
\end{tabular}

(of $n$ ): number of patients that could be examined on this symptom.

Forty patients in total $(40 \%)$, and $17(52 \%)$ of the 33 with leukoaraiosis had at least one of four cardinal parkinsonian symptoms (bradykinesia, tremor at rest, rigidity and postural instability). In univariate analysis, the presence of one of four parkinsonian symptoms was related to leukoaraiosis (OR 3.84, 95\% CI 1.22-12.07, $\mathrm{p}=0.02$ ), but not to deep lesion location on CT or MRI (OR 0.90, 95\% CI 0.35-2.31, $\mathrm{p}=0.82$ ), asymptomatic lacunar brain infarcts (OR $1.40,95 \% \mathrm{CI} 0.50-3.93$, $\mathrm{p}=0.52$ ) or a deep lesion stroke(OR 0.70,95\% CI 0.27-1.81, $\mathrm{p}=0.46$ ). Results of multivariate analysis with final infarct types (lacunar and territorial) and deep lesion location or stroke type as covariates are shown in table 4 . 
Table 4 . Results of multivariate analysis.

\begin{tabular}{|c|c|c|}
\hline & Rigidity & $\begin{array}{l}1 \text { of } 4 \text { parkinsonian } \\
\text { symptoms }\end{array}$ \\
\hline Leukoaraiosis & $2.87(1.16-7.06)^{*}$ & $4.07(1.27-13.04)^{*}$ \\
\hline Deep lesion on CT & $0.67(0.27-1.62)$ & $0.73(0.27-2.00)$ \\
\hline Leukoaraiosis & $2.74(1.13-6.66)^{*}$ & $4.14(1.29-13.27)^{*}$ \\
\hline Deep lesion stroke type & $0.88(0.37-2.11)$ & $0.59(0.22-1.62)$ \\
\hline Leukoaraiosis & $2.74(1.13-6.67)^{*}$ & $4.18(1.28-13.62)^{*}$ \\
\hline Lacunar infarct subtype & $1.03(0.28-3.85)$ & $0.56(0.12-2.54)$ \\
\hline Terricorial infarct subtype & $1.18(0.34-4.04)$ & $1.26(0.28-5.70)$ \\
\hline Leukoaraiosis & $2.72(1.20-6.58)^{*}$ & $3.78(1.20-11.97)^{*}$ \\
\hline Haemorrhage & $0.89(0.28-2.89)$ & $1.18(0.29-4.77)$ \\
\hline
\end{tabular}

Odds Ratios. In brackets: $95 \%$ confidential interval. Lacunar infarct subtype includes striatocapsular infarct. ${ }^{*} \mathrm{p}<0.03$

\section{DISCUSSION}

We assessed, to our knowledge for the first time, the presence of parkinsonian signs in a consecutive series of patients with acute, first-ever stroke, in the second week after the onset of stroke. We found parkinsonian signs in 46 of 101 patients and a parkinsonian syndrome in 4 of 45 patients. Because of concomitant paresis we were not able to assess all parkinsonian signs in all parients, so this number is probably an underestimate. Alarcon and coworkers [33] found a lower prevalence $3.9 \%$ of patients, who within one year after an acute stroke, developed involuntary abnormal movements, probably because some patients have recovered within that year.

We found a relationship between the presence of leukoaraiosis and rigidity as well as the presence of one of four parkinsonian symptoms. This relationship remained when correcting for final stroke subtype and deep lesion location as covariate. As leukoaraiosis is often bilateral and located around the frontal horns, it is conceivable that projections from frontal 
cortex (for example supplementary motor area) to the basal ganglia and vice versa are damaged, resulting in parkinsonian motor symptoms [21]. However, leukoaraiosis did not stand out as an independent predictor of rigidity or presence of one of four parkinsonian symptoms on multivariate testing when using age and sex as covariate. Rigidity was not related to deep lesion location or asymptomatic lacunar brain infarcts, nor was any of the other parkinsonian signs. These findings suggest that damage to the deep nuclei by stroke is neither unique nor conditional for the occurrence of parkinsonian symptoms in acute stroke. Damage anywhere along the circuitry involved in the regulation of motor control may cause such symptoms. Lesion site rather than size may be of relevance in this respect, as one third of lacunar stroke patients had at least one symptom.

Most studies on VP focused on the identification of cerebrovascular lesions in patients presenting with parkinsonian signs or a parkinsonian syndrome $[2-7,10,13,15,17]$. Most prominent symptom in these studies is a parkinsonian gait, explaining the use of the term "lower body parkinsonism" $[4,5,8]$. We found a parkinsonian syndrome in almost ten percent of our patients who could be examined on all symptoms. In a general population of 55 years and older this prevalence was almost two percent [34].

Our study has some limitations. Firstly, patient numbers are relatively small and some parkinsonian symptoms could not be investigated in all patients because of concomitant paresis. Secondly, spasticity is another important motor sign resulting from stroke, the presence of which may have interfered with diagnosis of rigidity. However, spasticity is a velocity dependent phenomenon, discerning it from rigidity, which is not velocity dependent. Thirdly, although our study aimed to be prospective and consecutive, including measurement of the eventual development of vascular parkinsonism over time, relarively more patients with a lesser degree of neurological deficit agreed to participate, which resulted in a slight overrepresentation of younger patients, and those with a lacunar stroke. 'This may have biased towards underdetection of parkinsonian symptoms [3]. 
Our study shows that acute stroke lesions in basal ganglia or connecting white matter tracts can result in signs of parkinsonism or a parkinsonian syndrome. Further study is needed to clarify wether the incidence of these symptoms increases over time and whether early parkinsonian signs independently predict eventual vascular parkinsonism, and stroke prognosis in general.

\section{REFERENCES}

1. Critchley M. Arreriosclerotic parkinsonism. Brain 1929;52:23-83.

2. Chang CM, Yu YL, Ng HK, Leung SY, Fong KY. Vascular pseudoparkinsonisma. Acta Neurol Scand 1992; 86(6):588-592.

3. Demirkiran M, Bozdemir H, Sarica Y. Vascular parkinsonism: a distinct, heterogeneous clinical entity. Acta Neurol Scand 2001; 104(2):63-67.

4. FirzGerald PM, Jankovic J. Lower body parkinsonism: cvidence for vascullar etiology. Mov Disord 1989; 4(3):249-260.

5. Jankovic J. Lower body (vascular) parkinsonism. Arch Neurol 1990; 47(7):728.

6. Peters 5 , Eising EG, Przuncek $\mathrm{H}_{*}$ Muller T. Vascular Parkinsonism: a case report and review of the literature. J Clin Neurosci 2001; 8(3):268-271.

7. Sibon 1, Fenelon G, Quinn NP, Tison F. Vascular parkinsonism. I Neurol 2004; 251.(5):513-524.

8. Thompson PD, Marsden CD. Gait disorder of subcortical arteriosclerotic encephaloparhy: Binswanger's disease. Mov Disord 1987; 2(1):1-8.

9. Tolosa ES, Santamaria J. Parkinsonism and basal ganglia infarcts. Neurology 1984 ; $34: 1516-1518$.

10. van Zagten $M$, Lodder ]. Kessels F. Gait disorder and parkinsonian signs in paticnts with stroke rellated to small deep infarcs and white matter lesions. Mov Disord 1998; $13(1): 89$. 95.

11. Zijlmans JC, Poels PJ, Duysens J, van der Straaten I, Thien T, van't Hol MA, et al. Quancitative gait analysis in patients with vascular parkinsonism. Mov Disord 1996; 11(5):501508.

12. Foltynie $T$, Barker $R$, Brayne $C$. Vascular parkinsonism: a review of the precision and frequency of the diagnosis. Neuroepidemiology 2002; 21 (1):1-7.

13. Sibon I, Tison F. Vascular parkinsonism. Curr Opin Neurol $2004 ; 17(1): 49-54$.

14. Zijlmans IC, Daniel SE, Hughes AJ, Revesz T, Lees AJ. Clinicopathological investigation of vascular parkinsonism, including clinical criteria for diagnosis. Mov Disond 2004; $19(6): 630-640$. 
15. Zijlmans JC, Thijsen HO, Vogels OJ, Kremer HP, Poels PJ, Schoonderwaldt HC, et al. MRI in parients with suspected vascular parkinsonism. Neurology 1995; 45(12):21832188.

16. De Reuck I, Siau B, Decoo D, Santens P, Crevits L, Strijckmans K, et al. Parkinsonism in parients with vascular dementia: clinical, computed-and positron emission-tomographic findings. Cerebrowasc Dis 2001; 1 $1(1): 51-58$.

17. Yamanouchi $H$, Nagura $H$. Neurological signs and frontal white matter lesions in vascular parkinsonism. A clinicopathologic study. Stroke 1997; 28(5):965-969.

18. De la Fuente Fernandez R, Lopez JM, Rey del Corral P, De la Iglesia Martinez F. Peduncular hallucinosis and right hemiparkinsonism caused by left mesencephalic infarction. J Neurol Neurosurg Psychiatry 1994; 57:870.

19. Hunter R, Smith I, "Thomson T, Dayan AD. Hemiparkinsonism with infarction of the ipsilateral substantia nigra. Appl Neurobiol 1978; 4:297-301.

20. Nakane M, Teraoka A, Asato R, Tamura A. Degeneration of the ipsilateral substantia nigra following cerebral infarcrion in the striatum. Stroke $1991 ; 23: 328-332$.

21. Bhatia KP, Marsden CD. The behavioural and motor consequences of focal lesions of the basal ganglia in man. Brain 1994; 117:859-876.

22. Kim JS. Involuntary movements after anterior cerebral artery territory infarction. Stroke 2001; 32(1):258-261.

23. Sibon I, Rajabally $\mathrm{Y}$. Tison F. Parkinsonism as a result of a giant aneurysm. Mov Disord 1999; 14(1):159-161.

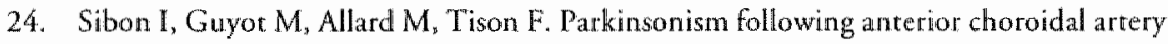
stroke. Eur \Neurol 2004; 11 (4):283-284.

25. Tuzun E. Anterior choroidlal artery territory infarction: a case report and review. Arch Med Res 1998; 29:83-87.

26. Boon A, Lodder J, Heuts-van Raak L, Kessels I. Silent brain infarcts in 755 consecurive patients with a first-ever supratentorial ischemic stroke. Relationship with index-stroke

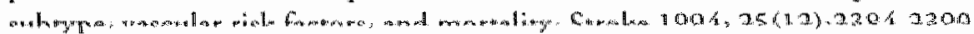

27. Bamford J, Sandercock P, Dennis M, Burn J, Warlow C. Classification and natural history of dinically idencifiable subtypes of cerebral infarction. Lancet 1991;337(8756):1521. 1526.

28. Langston JW. Ballard P, "Tetrud JW, Irwin I. Chronic Parkinsonism in humans due to a product of meperidine-antlog synthesis. Science 1983; 219(4587):979-980.

29. Fahn $S$, Elton R, comitree MorUd. Unified Parkinson's disease raring scale. In: Fahn $S$, Marsden CD, Calne DB. Goldstein M, editors. Recent development in Parkinson"s disease. Florham Park: McMillan Health Care Information; 1987. p. 153-163.

30. Geminiani $G$, Cesana BM, Tamma F, Contri P, Pacchetri C, Carella F, er all Interobserver reliability between neurologists in training of Parkinson"s disease rating scales. A multicenter study. Mov Disord 1991; 6(4):330-335.

31. Gibb WR, Lees AJ. The relevance of the Lewy body to the parhogenesis of idioparhic Parkinson's disease. ] Neurol Neurosurg Psychiatry 1988; 51 (6):745-752.

32. Hachinski VC, Porter P, Merskey H. Leuko-araiosis. Arch Neurol 1987; 44:21-23.

33. Alarcon F, Zijlmans JC, Duenas $G$, Cevallos $N$. Post-stroke movement disorders: report of 56 parients. J Neurol Neurosurg Psychiatry 2004: 75(11):1568-1574. 
Extrapyramidal dysfunction in early stroke

34. de Rijk MC, Breteler MM, Graveland GA, Ott A, Grobbee DE, van der Meche FG, et al. Prevalence of Parkinson's disease in the elderly: the Rotrerdam Study. Neurology 1995 ; $45(12): 2143-2146$. 


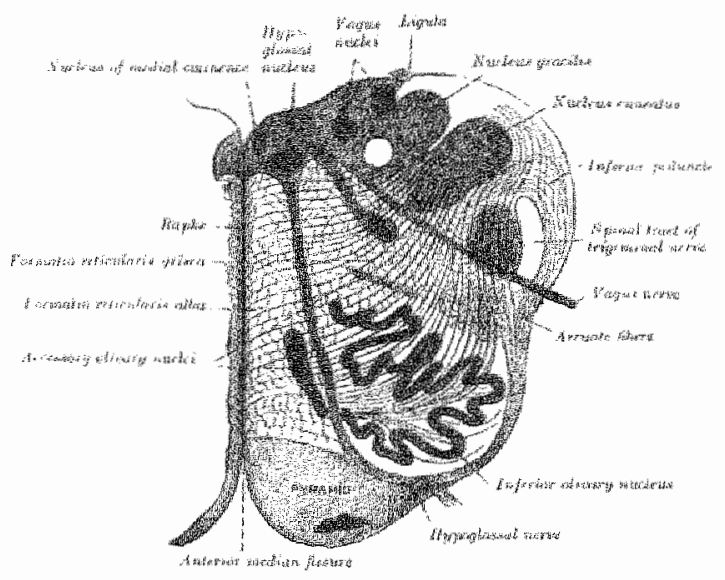

Und also sprach der Greis zur Zarathustra: "Nicht fremd ist mir dieser Wandrer: vor manchem Jahre ging er hier vorbei. Zarathustra hieß er; aber er hat sich verwandelt. Damalst trugst du deine Asche zu Berge: willst du heute dein Feuer in die Taler tragen? Fürchtest du nicht des Branditifters Strafen?"

Friedrich Nietzsche, Also sprach Zarathustra Figure taken from Gray's Anatomy, 1918 
CHAPTER 2

\section{Vascular parkinsonism: evolution of symptoms in a cohort of 101 first-ever stroke patients}

Arthur G.G.C. Korten MD; Wim E.J. Weber MD, PhD; Alfonso H.F. Kessels MD, MSc; Anita M.H.P. Boreas MD, PhD; Fred W. Vreeling $\mathrm{MD}, \mathrm{PhD}$; Jan Lodder MD, PhD.

BioMed Central Neurology, submitted. 
ABSTRACT

Background. Parkinsonian signs can develop as a result of cerebrovascular disease. The prevalence and evolution of these signs after first-ever stroke, and their impact on functional outcome is unknown. In an earlier study we found a high prevalence of parkinsonian signs in first-ever stroke patients. We here present the 6-month follow-up of these parients, correlaring the presence of parkinsonian signs with functional outcome and subtype of cerebral small vessel disease.

Methods. One-hundred-and-one consecurive patients admitted in our hospital with a first-ever stroke were clinically examined for the presence of cardinal parkinsonian signs (bradykinesia, rigidity, resting tremor and postural instability) as well as parkinsonian gait and funcrional status 2 weeks and 6 months after stroke.

Results. In total 101 parients were included. Two weeks after stroke, 40 patients had at least one of the four cardinal parkinsonian signs. After 6 months, 44 patients were examined of which 12 had at least 1 parkinsonian sign. The presence of at least one of four cardinal parkinsonian signs shortly after stroke predicted functional dependence or death at 6 months, independently of stroke type, but not age. White matter lesions were related to the presence of rigidity and a parkinsonian syndrome at 6 months as well as an independent predictor of progression of at least one of four parkinsonian signs.

Conclusions. Parkinsonian symptoms frequently develop after stroke and these, together with age, negatively impact functional outcome. Leukoaraiosis or white matrer lesions independently predict the presence and progression of parkinsonian symproms. This observation is in support of the view that parkinsonian features in stroke patients are specially related to cerebral arteriolosclerosis. 


\section{INTRODUCTION}

Vascular parkinsonism (VP) is a parkinsonian syndrome with predominantly symptoms of the lower body half: postural instability and shuffling gait. Tremor is markedly absent, in contrast to idiopathic Parkinson's disease [1-13]. Like patients with stroke in general, VP patients have vascular risk factors such as hypertension and previous stroke [2, 5-10, 12-15]. The exact mechanism by which cerebral lesions as a result of vascular disease can cause parkinsonism is not yet known. The great majority of patients with VP suffers an insidious onset, where the relation of timing, location, and size of the infarct with the clinical syndrome is poorly understood [7, 13-16]. A major reason for this is the fact that parkinsonian symptoms receive little attention in stroke patients: parkinsonian symptoms are not acknowledged in stroke syndrome diagnoses [17], thus obscuring prevalence and evolution of these symptoms. We recently found, in a consecutive series of 101 first-ever stroke patients, that 31 had rigidity, 3 patients resting tremor, 8 bradykinesia, 4 postural instability, and a parkinsonian syndrome was present in 4 patients $[18,19]$. In this study we found that these signs were related to lesions in the white matter or leukoaraiosis [20-23].

To our knowledge this was the first prevalence study of parkinsonian symptoms in a consecutive, unselected series of patients with a first-ever stroke. We now report on the evolution of these symptoms over six months in this patient cohort. This is important for two reasons. We found that the presence of parkinsonian symptoms is correlated with the functional status of the patients, so from a prognostic perspective one would want to know whether these symptoms worsen or dissolve over time. Secondly, follow-up would shed light on the validity of the hypothesis that there are two subtypes of lacunar infarcts: microatheromatosis and lipohyalinosis, the first associated with the presence of single, larger symptomatic lacunar infarcts, and the latter with hypertension, the presence of silent lacunar infarcts and white matter lesions, prognosis being more favorable in the first group [24-27]. If this hypothesis is correct, 
progression of parkinsonian signs would occur preferably in the patients with microatheromatosis-associated lacunar infarcts.

\section{METHODS}

Patients admitted to our hospital under the diagnosis of acute stroke with symptoms and signs lasting longer then 24 hours were examined for the presence of cardinal signs of parkinsonism: bradykinesia, rigidity, tremor and postural instability [19]. Also, in patients able to walk, gait was evaluated and scored as parkinsonian or not. Routine stroke investigations included standard blood tests, electrocardiogram, chest X-ray, CT scan of the brain, and ultra-sound carotid studies. Echocardiography, 24-hour ECG monitoring, MRI and cerebral angiography were done in selected cases $[10,16]$. Patients with a previous history of idiopathic Parkinson's disease or other neurodegenerative disorder with parkinsonism, repeated head injury, exposure to 1-methyl-4-phenyl-1,2,5,6-tetrahydropyridine (MPTP) [28], those with definite encephalitis or a cerebral tumour or hydrocephalus on CT scan, and patients taking neuroleptic medication were excluded.

As we found evaluation of gait of importance in as many patients as possible, but still aimed to study parkinsonian signs in the early stroke phase, first examination took place in the second week after stroke. Six months later, patients were re-examined. Again, presence of parkinsonian signs was examined and their severity graded.

The presence of bradykinesia was judged clinically. Grading was done according to the Unified Parkinson's Disease Rating Scale (UPDRS), item 31 [29]. Special attention was paid to bradykinesia in gait. Stride length and tempi in turning were measured in patients able to walk. Rigidity, tremor and postural stability were, if possible, scored according to the UPDRS [30]. Rigidity was judged by passively moving elbow, wrist and knee joints searching for the presence of a lead-pipe phenomenon. Presence of tremor was inspected in rest and action. Postural stabil- 
ity was examined by scoring the standing patients reaction to a sudden, strong posterior displacement produced by a pull on the shoulders. Progression of a parkinsonian sign was present when UPDRS scoring of one of these signs at six months was higher than scoring in the acute stroke phase. Table 1 in chapter 1 provides information on UPDRS scoring. Functional state was scored on admission, discharge from hospital and at six months using the modified Rankin scale [31]. Data on signs, symptoms, previous history and results on ancillary examinations of all patients were registered prospectively in the Maastricht Stroke Registry (MSR) [16]. Statistical analysis was performed with the Software Package for the Social Sciences version 8.0, SPSS inc. 1997, calculating odds ratio (OR) and $95 \%$ confidence interval (CI) using logistic regression analysis.

\section{Definitions}

Bradykinesia is defined as a slowness of initiation of voluntary movements with progressive reduction in the speed and amplitude of repetitive actions [32]. Patients were considered bradykinetic when UPDRS score on item 31 is 1 or more.

Rigidity is an increase in muscle tone during passive movement. Patients were considered rigid when UPDRS score on item 22 is 1 or more.

Tremor comprises involuntary oscillations of a body part produced by alternating or synchronous contractions of reciprocally innervated muscles [33]. According to the UPDRS, tremor at rest is present when the score on item 20 is 1 or more.

Loss of postural reflexes present with impaired righting reflexes and problems of maintaining balance (UPDRS item $30 \geq 1$ ).

A parkinsonian gait is defined as bradykinesia in walking with shuffling or short stepping and turning in three or more tempi. Freezing during walking is also considered as a possible part of parkinsonian gait.

A parkinsonian syndrome is the presence of bradykinesia and at least one of the following: rigidity, $4-6 \mathrm{~Hz}$ resting tremor or postural instability $[29,32]$. 
Lacunar stroke is defined as an acute symptomatic stroke syndrome with a CT' lesion compatible with occlusion of a single perforating artery, i.e., a small, subcortical, sharply marginated hypodense lesion with a diameter smaller than $15 \mathrm{~mm}$ (small deep infarct), or in case of a specific lacunar syndrome (unilateral motor and/or sensory symptoms and signs that completely involve at least 2 of 3 body parts (face, arm and leg) without disturbance of consciousness or language, visual field defect or other signs of cortical dysfunction) when the CT scan showed no specific lesion. Territorial stroke is defined (1) as an acute stroke syndrome with CT findings compatible with infarction involving the cortex, or (2) when no specific lesion was visible on CT, as a clinically identified cortical syndrome consisting of unilateral motor and/or sensory symptoms and signs in combination with signs of cortical dysfunction with or without visual field defect, or as incomplete involvement of two body parts, or as isolated monoparesis, or as isolated cortical dysfunction (usually dysphasia).

Leukoaraiosis is defined as a CT finding consisting of focal or diffuse hypodensities in the periventricular or deep white matter, not involving the cortex, and with ill-defined margins to distinguish it from infarction [21].

Patients with a lacunar syndrome (LACI) present with a pure motor stroke, pure sensory stroke, sensory-motor stroke or atactic hemiparesis / dysarthria-clumsy hand syndrome.

A total anterior circulation infarct (TACI) syndrome was defined as the combination of higher cerebral dysfunction (e.g. dysphasia), homonymous visual field defect and ipsilateral motor and/or sensory deficit of at least two areas of the face, arm and leg.

In case of a partial anterior circulation infarct (PACI) syndrome, patients present with only two of the three components of the TACI syndrome.

A posterior circulation infarct (POCI) syndrome comprises of ipsilateral cranial nerve palsy with contralateral motor and/or sensory deficit, bilateral motor and/or sensory deficit, disorder of conjugate eye movement, cerebellar dysfunction without ipsilateral long-tract deficit or isolated homonymous visual field defect [17]. 
A "deep lesion" on CT was defined as a lacunar or striatocapsular infarct, or supratentorial deep haemorrhage.

A "deep lesion stroke" was defined on the basis of clinical and CT findings as lacunar, striatocapsular or haemorrhagic stroke.

\section{RESULTS}

There were 101 patients, 58 males and 43 females. Mean age was 75 years (SD 11.4; range 28 to 99 years). Twenty-three patients had a modified Rankin score on admission of 3 or less, 78 patients had a score of 4 or 5 . Comorbidity is listed in table 2.

Symproms and signs on admission were compatible with a TACl syndrome in 14 patients, a POCI syndrome in 13 patients and a PACI syndrome in 37 patients [17]. Thirty-four patients had a LACI syndrome. Stroke syndrome was not classified in 3 patients.

On CT or MRI 27 patients had a lacunar infarct, 30 a territorial infarct, and 5 a striatocapsular infarct. Leukoaraiosis was present in 33 patients. Asymptomatic lacunar infarcts were seen in 38 patients (38\%). Seventeen patients had an intracranial haemorrhage (ICH), 2 of which were cerebellar. CT or MRI showed no symptomatic lesion in 21 parients. Eight of these patients however, had leukoaraiosis and 10 had one or more asymptomatic lacunar infarcts. One patient had no CT or MRI. Combining clinical and CT or MRI findings, final stroke type was classified in all 101 patients: 33 had a lacunar stroke, 51 a territorial ischemic stroke and 17 had ICH. As only 44 patients of 101 were available for follow-up at six months (see under), table 3 shows the frequency of symptoms in the acute phase in these 44 patients. Rigidity and resting tremor could be examined in all 101 patients. Due to concomitant severe paresis of left or right leg, postural stability, the presence of a parkinsonian syndrome and bradykinesia could only be evaluated in 45 patients and the presence of a parkinsonian gait in 53 . 
Table 2. Comorbidiry of 101 parients.

\begin{tabular}{lc}
\hline Diabetes mellitus & 23 \\
Hypertension & 45 \\
Coronary artery surgery & 10 \\
Mitral valve insufficiency & 17 \\
Angina pectoris & 21 \\
Peripheral arterial disease & 11 \\
Atrial fibrillation & 23 \\
Hypercholesterolaemia & 9 \\
Prior Transient Ischaemic Attack & 19 \\
Prior stroke & 23 \\
Chronic obstructive pulmonary disease & 18 \\
Smoking & 35 \\
\hline
\end{tabular}

Table 3. Parkinsonian signs in 44 stroke patients related to final stroke type, acute stroke phase.

\begin{tabular}{|c|c|c|c|c|}
\hline & \multirow{2}{*}{$\begin{array}{l}\text { Territorial } \\
\text { infarct } \\
\text { Mean } 73 \\
\text { SD } 11.4 \\
\text { range } 47-90\end{array}$} & \multicolumn{2}{|c|}{ Lacunar infarct Haemorrhage } & \multirow{2}{*}{$\begin{array}{l}\text { TOTAL } \\
\text { Mean } 70, \\
\text { SD } 12.6, \\
\text { range } 28-90\end{array}$} \\
\hline & & $\begin{array}{l}\text { Mean } 65, \\
\text { SD } 15.4 \\
\text { Range } 28-84\end{array}$ & $\begin{array}{l}\text { Mean } 73 \\
\text { SD } 2.7 \\
\text { range } 69-77\end{array}$ & \\
\hline Sex M & 13 & 10 & 4 & 27 \\
\hline $\mathrm{F}$ & 8 & 6 & 3 & 17 \\
\hline Leukoaraiosis & $2(9.5 \%)$ & $4(25 \%)$ & $1(14.3 \%)$ & $7(16.3 \%)$ \\
\hline Bradykinesuat & $1($ of 9$)$ & $3($ of 12$)$ & $2($ of 6$)$ & $6($ of 27$)$ \\
\hline Tremor at rest & $0($ of 21$)$ & $0($ of 16$)$ & $0($ of 7$)$ & $0($ of 44$)$ \\
\hline Postural instability & $1($ of 9$)$ & $0($ of 12$)$ & $0($ of 6$)$ & $1(0 f 27)$ \\
\hline Rigidity & $5($ of 21$)$ & $3($ of 16$)$ & $0($ of 7$)$ & $8(\operatorname{lof} 44)$ \\
\hline Parkinsonian gait & $2(069)$ & $2($ of 12$)$ & 3 of 6$)$ & $7($ of 27$)$ \\
\hline $\begin{array}{l}\text { Ac least one of four } \\
\text { parkinsonian } \\
\text { symproms }\end{array}$ & $6(0021)$ & $5($ of 16$)$ & $2($ of 7$)$ & 13 of 44$)$ \\
\hline $\begin{array}{c}\text { Parkinsonian } \\
\text { syndrome }\end{array}$ & $1(\operatorname{of} 9)$ & $1($ of 12$)$ & $0($ of 6$)$ & $2($ of 27$)$ \\
\hline
\end{tabular}

(of $n$ ): number of patients that could be examined on this symptom. 
Table 4. Parkinsonian signs in 44 stroke patients related to final stroke type, 6 months after stroke.

\begin{tabular}{|c|c|c|c|c|}
\hline & $\begin{array}{l}\text { Territorial } \\
\text { infarce. }\end{array}$ & Lacunar infarct & Haemorrhage & TOTAL \\
\hline Agge & $\begin{array}{l}\text { Mean } 73, \\
\text { SD 11.4, } \\
\text { range 47-90 }\end{array}$ & $\begin{array}{l}\text { Mean 65, } \\
\text { SD 15.4, } \\
\text { Range 28-84 }\end{array}$ & $\begin{array}{l}\text { Mean } 73 \\
\text { SD } 2.7 \\
\text { range } 69-77\end{array}$ & $\begin{array}{l}\text { Mean } 70 \\
\text { SD } 12.6 \\
\text { range } 28-90\end{array}$ \\
\hline Sex M & 13 & 10 & 4 & 27 \\
\hline $\mathbb{F}$ & 8 & 6 & 3 & 17 \\
\hline Leukoaraiosis & $2(9.5 \%)$ & $4(25 \%)$ & $1(14.3 \%)$ & $7(16.3 \%)$ \\
\hline Bradykinesia & 3 (of 15) & 2 (of 13) & $1($ of 6$)$ & $6($ of 35$)$ \\
\hline Tremor at rest & $1($ of 21$)$ & $1($ of 16$)$ & 1. $($ of 7$)$ & $3($ of 44$)$ \\
\hline Postural instability & 0 (of 13) & 0 (of 13) & $0($ of 6$)$ & 0 (of 33$)$ \\
\hline Rigidity & $4($ of 21$)$ & $3($ of 16$)$ & $1($ of 7$)$ & $8($ of 44$)$ \\
\hline Parkinsonian gait & $4($ of 14$)$ & $0($ of 14) & $2($ of 7$)$ & $6($ of 35$)$ \\
\hline $\begin{array}{l}\text { Ac least one of four } \\
\text { parkinsonian } \\
\text { symptoms }\end{array}$ & $7($ of 21$)$ & $4($ of 16$)$ & $1($ of 7$)$ & $12($ of 44$)$ \\
\hline $\begin{array}{c}\text { Parkinsonian } \\
\text { syndrome }\end{array}$ & 1 (of 13) & 1 (of 13) & $1($ of 6$)$ & $3($ of 33$)$ \\
\hline
\end{tabular}

(of $n$ ): number of patients examined on this symptom; 46 patients deceased; 11 lost from follow-up.

Six months after stroke 46 of the initial 101 patients had died $(46 \%)$ and 11. $(11 \%)$ refused further follow-up. So, 44 patients, 27 male and 17 female could be re-examined. Of these 44 patients, 16 initially had a lacunar and 21 a territorial infarct, and 7 an $1 \mathrm{CH}$. Asymptomatic lacunar infacts were present in 16 patients. 24 of 44 patients had a modified Rankin score of 4 or 5 six months after stroke, 14 a modified Rankin score of 3 or less. Eight patients had rigidity, three a parkinsonian syndrome and 12 at least one of four parkinsonian symptoms. Table 4 shows the frequency of other parkinsonian symptoms in the examined patients. Rigidity and resting tremor could be scored in all 44 patients. Postural stability and the presence of a parkinsonian syndrome could be examined in 33 , 
Table 5. Crude Odds Ratios.

\begin{tabular}{|c|c|c|c|}
\hline & leukoaraiosis & $\begin{array}{l}\text { deep lesion location } \\
\text { on CT }\end{array}$ & $\begin{array}{l}\text { deep lestion stroke } \\
\text { type }\end{array}$ \\
\hline Rigidiry & $\mathbb{1 1 . 0 ( 1 . 8 - 6 8 . 0 ) \dagger}$ & $0.4(0.07 \overline{-2} .1)$ & $0.9(0.2-4.1)$ \\
\hline Tremor at rest & $2.9(0.2-37.4)$ & $0.6(0.05-7.6)$ & $1.9(0.2-22.7)$ \\
\hline Bradykinesia & $4.3(0.5-34.5)$ & $1.1(0.2-6.2)$ & $0.6(0.1-3.6)$ \\
\hline Postural instability & no patients & no patients & no patients \\
\hline Gait disturbance & $4.3(0.5-34.5)$ & $0.5(0.07-3.0)$ & $0.3(0.04-1.7)$ \\
\hline $\begin{array}{c}\text { Parkinsonian } \\
\text { syndrome }\end{array}$ & $2.9(1.4-4.6)^{*}$ & $2.1(0.2-26.0)$ & $1.3(0.1-15.5)$ \\
\hline $\begin{array}{l}\text { At least one of four } \\
\text { parkinsonian } \\
\text { symptoms }\end{array}$ & $6.0(0.9-39.2)$ & $0.3(0.07-1.5)$ & $0.4(0.1-1.8)$ \\
\hline
\end{tabular}

in brackets: $95 \%$ Confidence Interval. * : $P<0.03$. $\neq: p<0.01$.

bradykinesia in 35 patients. Gait was evaluated in 35 patients. Again, due to walking difficulty as a result of paresis, it was not possible to examine all patients on these signs.

In univariate analysis, the presence of rigidity, OR $5.2(95 \%$ CI 1.8 15.5), $\mathrm{p}=0.0029$, at least one of four parkinsonian symptoms, OR $6.6(95$ $\%$ CI 2.2-19.6), $\mathrm{p}=0.0007$, and gait disturbance (OR 3.6 (95\% CI 1.0$12.8), p=0.05)$ in the acute stroke phase were related to a functional dependence or death at six months (Rankin score 5 or 6 ). When corrected for final stroke type, this relationship persisted. When corrected for age and sex however, it was no longer present.

Seven of the patients examined at six months had leukoaraiosis on CT or MRI. Four of these patients had rigidity and two a parkinsonian syndrome. In univariate logistic regression analysis rigidity and a parkinsonian syndrome 6 months after stroke were related to leukoaraiosis. When corrected for age, sex and stroke subtype in multivariate logistic regression analysis, this relationship persisted: OR $10.6(95 \%$ CI 1.4-80.2), $\mathrm{p}=0.02$ and OR $46(95 \%$ CI 2-1047), $\mathrm{p}=0.02$ respectively. The presence of parkinsonian symptoms at six months after stroke was not related to deep lesion location on CT or a deep lesion stroke type (table 5). 
Six of 44 patients at six months had progression of at least one of these symproms. Three of these patients had leukoaraiosis. In multivariate analysis leukoaraiosis corrected for age, sex and stroke type predicted progression of at least one of four parkinsonian symptoms, OR $11.0(95 \%$ CI 1.2-99.0), $\mathrm{p}=0.03$.

\section{DISCUSSION}

We recently found, in a consecutive series of 101 first-ever stroke patients, that 31 had rigidity, 3 patients resting tremor, 8 bradykinesia, 4 postural instability, and a parkinsonian syndrome was present in 4 patients $[18,19]$. In this study we found that these signs were related to lesions in the white matter or leukoaraiosis [20-23].

Our present, follow-up study on this patient cohort shows that 6 months after stroke a substantial part of stroke survivors still has parkinsonian signs: almost one third of the surviving 44 patients who could be tested on the presence of the four cardinal parkinsonian signs, had at least one such symptom. Independent of stroke type, rigidity or the presence of at least one of four parkinsonian signs in the acute stroke phase were related to worse functional outcome at six months. Resul ts of multivariate analysis, however, showed that this relation can be explained partly by older age in the group of patients with parkinsonian signs. We found that the presence of these signs as well as their progression are independently related to the presence of white matter lesions, but not to deep lesion location or presence of asymptomatic lacunar brain infarcts. White matter lesions result from arteriolosclerosis of the medullary small vessels, with apart from age, hypertension as important risk factor [24]. Our observation suggests that stroke patients with white matter lesions may have a higher risk not only for developing cognitive decline but also parkinsonian features. Some patients may develop both, which, ultimately, may finalise into the so-called Binswanger's disease with dementia, gait and balance disorders, pseudobulbar state or incontinence [15, 34-40]. 
As to the hypothesis of two distinct lacunar cerebral infact types [24-27], our results show no association between the microatheromatic type of cerebral small vessel disease and presence or progression of parkinsonian symptoms. This may be due to the relatively large number of patients who died within the six months follow-up. Most of these patients had larger infarctions, which may have led to bias towards underestimation of the relation between leukoaraiosis and parkinsonian symptoms, since 9 of these patients had concomitant leukoaraiosis. Eleven patients refused follow-up examination. Five of these had leukoaraiosis. If parkinsonian symptoms had also been present in these patients, this would again have led to underestimation of the relation between leukoaraiosis and parkinsonian symptoms.

Our study shows that parkinsonian symptoms frequently develop after stroke and that they, together with age, influence functional outcome. Leukoaraiosis or white matter lesions independently predict the presence and progression of parkinsonian symptoms. This observation is in support of the view that parkinsonian features in stroke patients are specially related to cerebral arteriolosclerosis.

\section{REFERENCES}

1. Critchley M. Arterioscleroric parkinsonism. Brain 1929;52:23-83.

2. Clrang CM, Yu YL, Ng HK, Leung SY, Fong KY. Vascular pseudoparkinsonism. Acta Neurol Scand 1992; 86(6):588-592.

3. Demirkiran M, Bozdemir H, Sarica Y. Vascular parkinsonism: a distinct, heterogeneous climicall entity. Acta Neurol Sand 2001; 104(2):63-67.

4. FirzGerald PM. Jankovic J. Lower body parkinsonism: evidence for vascular etiology. Mow Disord 1989; 4(3):249-260.

5. Jankovic J. Lower body (wascular) parkinsonism. Arch Neurol 1990; 47(7):728.

6. Peters $S$, Eising EG, Przuntek $H$, Muller $T$. Vascular Parkinsonism: a case report and review of the literature. J Clin Neurosci $2001 ; 8(3): 268-271$.

7. Sibon I, Fenelon G, Quinn NP, Tison F. Vascular parkinsonism. J Neurol 2004; $251(5): 513-524$. 
8. Thompson PD, Marsden CD. Gait disorder of subcortical arteriosclerotic encephalopathy: Binswanger's disease. Mov Disord 1987; 2(1):1-8.

9. Tolosa ES, Santamaria J. Parkinsonism and basal ganglia unfarcts. Neurology 1984; 34:1516-1518.

10. wan Zagten M. Lodder J, Kessels F. Gair disorder and parkinsonian signs in patients with stroke related to small deep infarctsand white matter lesions. Mov Disord 1998: 13(1):89. 95.

11. Zijlmans]C, Poels [P], Duysens J, van derStraten J, Thien T, van' Hof MA, et al. Quantitariwe gait analysis in patients with vascular parkinsonism. Mov Disord 1996; 11 (5):501508.

12. Folrynie $T$, Barker R, Brayne C. Vascular parkinsontsm: a review of the precision and frequency of the diagnosis. Neuroepidemiology $2002 ; 21(1): 1-7$.

13. Sibon I, Tison $\mathbb{F}$. Vascular parkinsonisn. Curr Opin Neurol 2004; 17(1):49-54.

14. Zijlmans $\int \mathrm{C}$, Daniel SE, Hughes AJ, Revesz T, Lees AJ. Clinicopathological investigation of wascular parkinsonism, including clinical criteria for diagnosis. Mov Disord 2004; $19(6): 630-640$.

15. Zijlmans JC, Thijsen $\mathrm{HO}$, Vogels OJ, Kremer HP, Poels PJ, Schoonderwaldt HC, er al. MRI in patients with suspected vascular parkinsonism. Neurology 1995; 45(12):21832188.

16. Boon A, Lodder J, Heuts-van Raak L, Kessels F. Silent brain infarcts in 755 consecutive parients with a first-ever supratentorial ischemic stroke. Rellationship with index-stroke subtype, vascular risk factors, and mortality. Stroke 1994; 25(12):2384-2390.

17. Bamford I, Sandercock P, Dennis M, Bun J, Warlow C. Classification and narural history of clinically identifiable subrypes of cerebral infarcrion. Lancet 1991;337(8756):1521-6.

18. Korten A, Lodder J, Vreeling F, Boreas A, wan Raak L, Kessels F. Stroke and idiopathic Parkinson's disease: does a shortage of dopamine offer protecrion against stroke? Mov Disord 2001; 16(1):119-23.

19. Korten AGGC, Lodder I, Vreeling FW, Boreas AMHP, Kessels AF, Weber WE]. Extrapyramidal system dysfuncrion in 101 parients with acure first-ever stroke. Submitted 2005.

20. Dozono K, Ishii N, Nishihara Y. Horie A. An autopsy study of the incidence of lacunes in relation to age, hypertension, and atteriosclerosis. Stroke 1991; 22:993-996.

21. Hachinski VC, Potter P, Merskey H. Leuko-araiosis. Arch Neurol 1987; 44:21-23.

22. Leys D, Engiund E, Del Ser T, Inzirar D, Fazekas F, Bornstein $\mathrm{N}$. White matter changes in stroke parients. Relatiosh ip with stroke subtype and outcome. Eur Neurol 1999; 42:67. 75.

23. Liao D, Cooper L, Cai ]. Toole J, Bryan N. Hutchinson R. Presence and sewerity of cerebral whire matter lesions and hypertension, irs treatment, and its control. The ARIC Sudy. Arherosclerosis Risk in Communicies Study. Srroke 1996, 27:2262-2270.

24. Boiten J, Lodder J, Kesse $\$ \mathrm{~s} F$. Two clinically distinct lacunar infarctentites? A bypothesis. Siroke 1993; 24(5):652-656.

25. de Jong $G$, Kessels $F$, Lodder J. Two types of lacunar infarcts: further arguments from a study on prognosis. Stroke 2002; 33(8)/2072-2076.

26. Fisher C. Capswlar infarcts: the underlying vascularlesions. Arch Neurol 1979; 36:65-73. 
27. Fusher C. Lacunar infracts: a review. Cerebrovasc Dis 1991; 1:311-320.

28. Langston JW, Ballard P. Tetrud JW, Irwin I. Chronic Parkinsonism in humans due to a product of meperidine analog syrthesis. Science 1983;219(4587):979-980.

29. Fahn S, Elton R, comitce MotUd. Unified Parkinson's disease racing scale. In: Fahn $S$, Marsden CD, Calne DB, Goldstein M, cdirors. Recent development in Parkinson's disease. Florham Park: McMillan Health Care Information; 1987. p. 153-163.

30. Geminiani $G$, Cesana BM, Tamma F, Contri P, Pacchett C, Carella F, eral. Interobserver reliability between neurologists in training of Parkinson's disease rating scales. A multicenter study. Mov Disord 1.991; 6(4):330-335.

31. Rankin J. Cerebrowascular accidents in patients over the age of 60 : 11. prognosis. Scott Med J 1957: 2:200-215.

32. Gibb WR, Lees AJ. The relevance of the Lewy body to the pathogenesis of idioparhic Parkinson's disease. J Neurol Neurosurg Psychiatry 1988; 51(6):745-752.

33. Jankovic J. Parkinson-plus syndromes. Mov Disord 1989; 4S:95-119.

34. Baloh RW, Vunters HV. White matrer lesions and disequilibrium in older people. II, Clinicoparhologic correlation. Arch Neurol 1995; 52(10):975-981.

35. Baloh RW, Yue Q, Socotch TM, Jacobson KM. White matter lesions and disequilibrium in older people. 1. Case-control comparison. Arch Neurol 1995; 52(10):970-974.

36. Benner D, Gilley D, Wilson B, Huckman M, Fox J. Clinical correlates of high signal lesions on magneric resonance imaging in Alzheimer's disease. J Neurol 1992; 239:186190.

37. Masdeu J, Wolfson L, Lantos G, Grober E, Whipple R, Brain white matter changes in the elderly prone to falling. Arch Neurol 1989; 46:1292-1296.

38. Piccini P, Pavese N, Canapicchi R, Paoli C, Dotto Pd, Puglioli M. White marter hyperintensities in Parkinson's disease. Clinical correlarions. Arch Neurol 1995; 52:191194.

39. Steingart A, Hachinski VC, Lau C, Fox AJ, Diaz F, Cape R, et al Cognitive and neurologic findings in subjects with diffuse white matter lucencies on computed tomographic scan (leuko-araiosis). Arch Neurol 1987:44(1):32-35.

40. Thajeb P. Gait disorders of multi-infarce dementia. CT and clinical correlation. Acta Neurol Scand 1993; 97:239-242. 
CHAPTER 3

\section{Neuroradiologic correlates of parkinsonian signs in 83 first-ever stroke patients}

Arthur G.G.C. Korten MD; Wim E.J. Weber MD, PhD; Fred W. Vreeling MD, PhD; Anita M.H.P. Boreas MD, PhD; Alfons H.F. Kessels MD, MSc; Jan Lodder MD, PhD.

BioMed Central Neurology, submitted. 


\section{ABSTRACT}

Background. In vascular parkinsonism, the exact spatial and temporal relation between the ischaenic lesion and the ensuing parkinsonism remains unclear. We recently found a high frequency of parkinsonian signs in a consecutive series of patients with a first-ever stroke. In this study we examine a possible relation between location of cerebral ischaemia and parkinsonian signs.

Methods. In a prospective series of 83 patients with ischaemic stroke, presence of the four cardinal parkinsonian signs (bradykinesia, rigidity, tremor at rest and postural instability) and location of ischaemia on CT or MRI was examined in a standardized fashion.

Rewhlts. A symptomatic lacumar infarct was presenc 26 patients, 36 had a territorial infarct and 37 one or more asymptomatic lacunar brain infarcts. 21 . Patients had no symptomatic infarction on CT or MRI. Eleven patients had at least one of four cardinal parkinsonian signs.

We found no relation between involvement of specific cortical gyri in territorial infarcts and parkinsonian signs. There was no relation berween location of the sympcomatic lacunar infarcts and parkinsonian signs. However, one or more asymptomatic lacunar infarcts in the supply area of the anterior choroid artery related to the presence of rigidity.

Conclusion. Asymptomaric lacunar infarcts in the supply area of the anterior choroidal artery are relared to the presence of parkinsonian signs. We hyporhesize that this lesion interferes with inpur from motor cortices ro basal ganglia through tracts in the posterior part of the internal capsule. 


\section{INTRODUCTION}

Symptoms and signs resulting from stroke are numerous and various. Although it is well known that stroke can cause parkinsonian symptoms, this so called vascular parkinsonism (VP) receives relatively little attention as part of stroke sympromatology [1-13]. Reports in literature mention association of VP with hypertension and lacunar brain infarction $[2,4,5-10,12-17]$. The precise relation between the vascular lesions and the ensuing parkinsonism remains unclear. Case reports link the acute occurrence of VP to a single stroke located in mesencephalon [18], substantia nigra [19], the striatum [20], basal ganglia [21], the anterior cerebral artery territory [22], cerebral peduncle [6,23] and anterior choroidal artery territory $[24,25]$. In patients with an insidious onset of VP, the relation with type, location and size of ischaemic lesion is poorly understood $[7,13-15,26]$. Scanning patients with parkinsonism, several authors found an anatomical relation with ischaemic lesions in the basal ganglia $[2,21,27]$, as did Reider-Groswasser when examining a series of patients selected for basal ganglia lesions on CT [28].

In an earlier study we found that in a consecutive series of acute first-ever stroke patients, signs of parkinsonism are frequent and related to white matter lesions $[29,30]$. In the present study on 83 first-ever stroke patients, we explored a possible relationship between ischaemiclesion site and the presence of parkinsonian signs: cortical versus deep lesions, as well as involvement of different cortical gyri in relation to parkinsonian signs.

\section{METHODS}

Patients admitted with acute stroke and symptoms lasting longer than 24 hours were examined on the presence of cardinal signs of parkinsonism: bradykinesia, rigidity, tremor at rest and postural instability. Routine stroke investigations included standard blood tests, electrocardiogram, 
chest X-ray, CT scan of the brain, and ultra-sound carotid studies $[10,26]$. Echocardiography, 24-hour ECG monitoring, MRI and cerebral angiography were done in selected cases. Patients with a previous history of idiopathic Parkinson's disease or any other neurodegenerative disorder with parkinsonism, repeated head injury, exposure to 1-methyl-4phenyl-1,2,5,6-tetrahydropyridine (MPTP) [31], those with definite encephalitis, and patients using neuroleptic medication or a cerebral tumour or hydrocephalus on CT scan were excluded. Patients with an intracranial haemorrhage, no abnormalities on CT or MRI during admission or those who did not have CT or MRI were also excluded. The presence of bradykinesia was judged clinically. Grading was done according to the Unified Parkinson's Disease Rating Scale (UPDRS), item 31 [32]. Rigidity, tremor and postural stability were, if possible, scored on both body sides also according to the UPDRS [33]. Rigidity was judged by passively moving elbow, wrist and knee joints searching for the presence of a lead-pipe phenomenon. Is was distinguished from spasticity as only the latter is a velocity dependent sign. Presence of tremor was inspected in rest and action. Postural stability was examined by scoring the standing patients reaction to a sudden, strong posterior displacement produced by a pull on the shoulders [32].

Lesion site on CT or MRI was determined unaware of the presence of parkinsonian signs. In symptomatic territorial infarcts we listed the involvement of different gyri according to Bories method [34]. Symptomatic lacunar infarcts were localised according to the involved nuclei or white matter tracts (i.e. caudate nucleus or anterior part of the internal capsule). Asymptomatic lacunar infarcts were scored according to different penetrating arteries supply area, using Damasio's templates [35], except for the supply area of the anterior choroidal artery, where we used the data by Hupperts and Lodder [36]. In patients who had both CT and MRI, ischaemia location was determined on MRI scan. Data on signs, symptoms, previous history and results on ancillary examinations of all patients had been registered prospectively in the Maastricht Stroke Registry (MSR) $[10,26]$. 


\section{Definitions}

Bradykinesia is defined as a slowness of initiation of voluntary movements with progressive reduction in the speed and amplitude of repetitive actions [37]. Patients were considered bradykinetic when UPDRS score on item 31 is 1 or more.

Rigidity is an increase in muscle tone during passive movement. Patients were considered rigid when UPDRS score on item 22 is 1 or more.

Tremor comprises involuntary oscillations of a body part produced by alternating or synchronous contractions of reciprocally innervated muscles[38]. According to the UPDRS, tremor at rest is present when the score on item 20 is 1 or more.

Loss of postural reflexes presents with impaired righting reflexes and problems of maintaining balance (UPDRS $\geq 1$ ).

A parkinsonian syndrome is the presence of bradykinesia and at least one of the following: rigidity, $4-6 \mathrm{~Hz}$ resting tremor or postural instability $[32,37]$.

Lacunar stroke is defined as an acute symptomatic stroke syndrome with a CT lesion compatible with occlusion of a single perforating artery, i.e., a small, subcortical, sharply marginated hypodense lesion with a diameter smaller than $15 \mathrm{~mm}$ (small deep infarct), or in case of a specific lacunar syndrome (unilateral motor and/or sensory symptoms and signs that completely involve at least 2 of 3 body parts (face, arm and leg) without disturbance of consciousness or language, visual field defect or other signs of cortical dysfunction) when the CT scan showed no specific lesion. Territorialstroke is defined (1) as an acute stroke syndrome with CT findings compatible with infarction involving the cortex, or (2) when no specific lesion was visible on CT, as a clinically identified cortical syndrome consisting of unilateral motor and/or sensory symptoms and signs in combination with signs of cortical dysfunction with or without visual field defect, or as incomplete involvement of two body parts, or as isolated monoparesis, or as isolated cortical dysfunction (usually dysphasia). 
Asymptomatic (silent) brain infarct is defined as a low density area on CT or hyperintensity area on MRI compatible with infarction, but withour a history of stroke, as taken from the patient's history, from family, or any other accessible information. Also, the stroke symptoms at study entry had to be anatomically incompatible with this infarct.

Leukoaraiosis is defined as a CT finding consisting of focal or diffuse hypodensities in the periventricular or deep white matter, not involving the cortex, and with ill-defined margins to distinguish it from infarction [38].

Statistical analysis was performed with the Software Package for the Social Sciences version 8.0, SPSS inc. 1997, calculating odds ratio (OR) and $95 \%$ confidence interval $(\mathrm{CI})$ using logistic regression analysis. Rigidity and the presence of at least one of four parkinsonian symproms were separately tested as dependent variables. Independent variables were: involved cortical gyri, asymptomaticlacunar infarcts in three different vascular supply areas and different locations of symptomatic lacunar infarcts. Analysis was performed univariate to calculate crude odds ratios, and multivariate with age, sex, and leukoaraiosis as covariates to calculate adjusted odds ratios.

\section{RESULTS}

We examined 101 consecutive patients admitted to our hospital with an acute first-ever stroke on the presence of parkinsonian signs [29,30]. Seventeen patients with intracranial haemorrhage on acute CT examination and one patient who did not have CT or MRI were excluded from further analysis. Of the remaining 83 patients, 50 were male and 33 female. Mean age was 75 years (SD 11.9; range 28 to 99 years). Twenty-six patients had a symptomatic lacunar and 36 a territorial infarct. Twentyone patients had no abnormalities on CT or MRI. Forty-six patients had at least one asymptomatic brain infarct. Thirty-seven of these patients had one or more asymptomatic lacunar infarct. In 37 patients there was at 
least one asymptomatic lacunar infarct in the supply area of the lenticulostriate arteries, in 5 patients in the supply area of the thalamostriate arteries and in 7 patients in the supply area of the choroid anterior artery.

Rigidity and resting tremor could be scored in all 83 patients. Due ro concomitant paresis, it was not possible to examine the other parkinsonian signs in all patients. Postural stability, the presence of a parkinsonian syndrome and bradykinesia alone could be evaluated in 38 patients. All four key parkinsonian symptoms could be examined in 37 of 83 patients. Bradykinesia was present in 6 patients, postural instability in 4 and rigidiry in 26. Only 3 patients had a tremor at rest. Eleven patients had at least one of the four key parkinsonian symptoms.

Of 36 patients with a territorial infarct, thirteen had rigidity. Table 1 summarizes the involvement of different cortical gyri in these patients. Only two of 36 pacients with a territorial infarct had a tremor at rest. In these two patients, the post-central and middle temporal gyrus were involved. Bradykinesia could be examined in 13 of 36 patients. Only one patient had a bradykinesia with involvement of post-central and precentral gyrus and cuneus. Postural stability was evaluated in 12 of 36 patients. Instability was present in only one patient with a cerebellar infarct. Examination of all four key symptoms of parkinson ism was possible in 12 of 36 patients with a territorial infarct. Three parients had at least one of these four symptoms. Table 2 summarizes the involvement of different corrical gyri in these patients. Univariate logistic regression analysis did not show that the involvement of any gyrus was related to rigidity or the presence of at least one of four parkinsonian symptoms. In multivariate analysis with age, sex and leukoaraiosis as covariates, there was also no correlation between involvement of a specific gyrus and rigidity or the presence of at least one of four parkinsonian symptoms.

Symptomatic lacunar infarcts were located in caudate nucleus, medial and posterior parts of the posterior leg of the internal capsule, genu of the internal capsule, thalamus and posterior part of the corona radiata. None of these locations was related to rigidity or the presence of at least one of 
Table 1. Affected cortical gyri in 36 patients with a cortical infarct; distinction berween 3 parients with rigidiry and 23 without. Number of parients with particular gyrus damaged.

Involved gyri Parients with rigidity Patients without rigidity $(n=13)$ $(n=23)$

Anterior cerebral artery territory

cingulate gyrus

superior frontal gyrus

1

0

1

Middle cerebral artery territory

$\begin{array}{lrr}\text { post-cenual gyrus } & 5 & 11 \\ \text { inferior temporal gyrus } & 4 & 6 \\ \text { middle frontal gyrus } & 3 & 3 \\ \text { middle temporal gyrus } & 5 & 7 \\ \text { precentral gyrus } & 7 & 9 \\ \text { inferior frontal gyrus } & 5 & 5 \\ \text { supramarginal gyrus } & 7 & 12 \\ \text { superior parietal lobule } & 13 & 1 \\ \text { superior temporal gyrus } & 5 & 10 \\ \text { angular gyrus } & 2 & 2\end{array}$

Posterior cerebral artery territory

\begin{tabular}{lll} 
lingual gyrus & 2 & 1 \\
accipital lobe & 1 & 1 \\
cuneus & 2 & 0 \\
parahippocampal gyrus & 1 & 1 \\
fusiform gyrus & 1 & 0 \\
\hline
\end{tabular}

the four cardinal parkinsonian signs in logistic regression analysis with age, sex and leukoaraiosis as covariates. Of all 37 patients with one or more asymptomatic lacunar infarcts, 14 had rigidity (adjusted OR 2.2 $(0.72-6.7), p=0.16)$. Eightteen of these 37 patients could be examined on all 4 parkinsonian signs. Six of these patients had at least one of the four signs (adjusted OR 3.3 (0.49-21.8), $\mathrm{p}=0.22)$. The presence of rigidity or 
Table 2. Affected cortical gyri in 36 patients with a cortical infarct; distinction berween 3 pacients with at least one of four key parkinsonian symptoms and 9 without. In 24 of 36 parients, not all four symptoms could be evaluated. Number of patients with particullar gyrus damaged.

\begin{tabular}{|c|c|c|}
\hline Involved gyri & $\begin{array}{l}\text { Patients with at least one } \\
\text { of four symptoms } \\
(n=3)\end{array}$ & $\begin{array}{l}\text { Parients whithout ar least } \\
\text { one of four symptoms } \\
\qquad(\mathrm{n}=9)\end{array}$ \\
\hline \multicolumn{3}{|c|}{$\begin{array}{l}\text { Anrerior cerebral artery territory } \\
\text { cingulate gyrus }\end{array}$} \\
\hline \multicolumn{3}{|c|}{ Middle cerebral artery territory } \\
\hline post-central gyrus & 1 & 2 \\
\hline inferior temporal gyrus & 0 & 3 \\
\hline middle temporal gyrus & 0 & 2 \\
\hline precentral gyrus & 1 & 0 \\
\hline supramarginal gyrus & 0 & 5 \\
\hline superior temporal gyrus & 0 & 4 \\
\hline angular gyrus & 0 & 1 \\
\hline \multicolumn{3}{|c|}{ Posterior cerebral artery territory } \\
\hline lingual gyrus & 2 & 1 \\
\hline occipital lobe & 1 & 1. \\
\hline cuneus & 2 & 0 \\
\hline parahippocampal gyrus & 1 & $\mathbb{1}$ \\
\hline fusiform gyrus & 1 & 0 \\
\hline
\end{tabular}

at least one of four key parkinsonian symptoms in patients with asymptomatic lacunar brain infarcts in the three vascular territories is summarized in table 3. Multivariate logistic regression analysis showed that only the presence of at least one asymptomatic lacunar infarct in the territory of the anterior choroidal artery is related to rigidity (OR 7.6, $p=0.04,95$ $\%$ Confidence Interval $1.1-52.9$ ). 
Table 3. Rigidity and presence of at least one of four parkinsonian symproms related to location of different asymptomatic lacunar brain infarcts.

\begin{tabular}{|c|c|c|c|c|c|}
\hline \multicolumn{2}{|l|}{ Location } & \multicolumn{2}{|c|}{ rigidiny } & \multicolumn{2}{|c|}{$\begin{array}{l}\text { at least } 1 \text { of } \\
4 \text { symptoms }\end{array}$} \\
\hline & & - & + & - & + \\
\hline \multirow[t]{2}{*}{ Lenticuslostriace arteries } & - & 34 & 12 & 14 & 5 \\
\hline & + & 23 & 14 & 12 & 6 \\
\hline \multirow[t]{2}{*}{ Thalamostriate arteries } & - & 55 & 23 & 26 & 9 \\
\hline & + & 2 & 3 & 0 & 2 \\
\hline \multirow[t]{2}{*}{ Anterior choroidal artery } & - & 54 & 22 & 24 & 10 \\
\hline & + & 3 & $4 \frac{4}{3}$ & 2 & 1 \\
\hline
\end{tabular}

\#: OR 7.6, $\mathrm{p}=0.04,95 \%$ confidence interval $1.1-52.9$

\section{DISCUSSION}

In this study we report on location of ischaemic brain lesions and their possible relation with the presence of parkinsonian signs in a group of 83 consecutive patients admitted with an ischaemic first-ever stroke. In patients with a symptomatic territorial infarct, we found no relation. between the presence of parkinsonian signs and involvement of specific cortical gyri. In patients with a symptomatic lacunar infarct, lesion site also did not predict the presence of parkinsonian signs. Asymptomatic (silent) lacunar infarcts in general were not related to rigidity or the presence of at least one of four cardinal parkinsonian signs. When considering asymptomatic lacunar infarcts in different vascular territories however, infarcts in the supply area of the anterior choroidal artery related significantly and independently to the presence of rigidicy.

We found no relation between the involvement of any gyrus and parkinsonian signs. This accords with the current concept that VP results from a lacunar infarct in the basal ganglia or from diffuse white matter lesions with involvement of basal ganglia - frontal cortex projections $[8,28,40-43]$. Scanning patients with parkinsonism, several authors found an anatomical relation with ischaemic lesions in the basal ganglia $[2,21,27]$, as did Reider-Groswasser when examining a series of patients 
selected for basal ganglia lesions on CT [28]. Alarcón et al. following up patients with movement disorders one year after a stroke, found basal ganglia infarcts in 6 patients with parkinsonian syndrome [44]. White matter lesions are caused by cerebral small vessel disease and are closely related to asymptomatic lacunar infarcts $[45,46]$. We found rigidity to be related to one or more asymptomatic lacunar infarcts in the supply area of the anterior choroidal artery. This area comprises, among others, the posterior leg of the internal capsule (figure 1) [36,47]. The posterior leg of the internal capsule contains fibers of the corticospinal tract, passing to brainstem and spinal cord, sensory thalamic projection fibers to the parietal lobe and pathways to and from the cerebellum $[48,49]$.

The principal striatal circuit uses the anterior leg of the internal capsule for its output tracts to the cortex, mainly area 6 and the supplementary motor area, projecting from ipsilateral neocortex and bilateral from premotor, motor and somatosensory cortex. Lesions in the posterior part of the capsula interna probably cause dysfunction of the basal ganglia system as a result of a defective input from premotor, motor and somatosensory cortex. As regulation of muscle tone outside the context of coordination is not a function of cerebellar structures, it seems unlikely that the rigidity in our patients was caused by a lesion of cerebellar tracts alone [50].

Our study is somewhat limited by the relatively small number of patients, further reduced by separating different stroke types and vascular supply areas into different groups. Of the 21 patients without a symptomatic ischaemic lesion on CT or MRI, nine had rigidity and 5 had at least one of four parkinsonian signs. This may have obscured a relation of lesion type with parkinsonian signs. Further prospective studies on patients with lacunar infarcts and frequent follow-up are underway. 

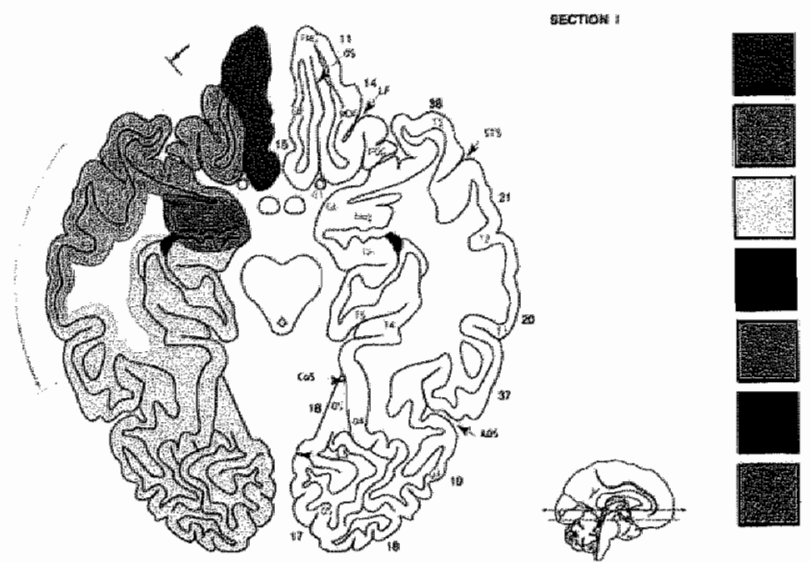

Leptomeningeal branches: of the $\mathrm{ACA}$

Leptumeningeal branches of the MCA

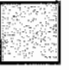

Leptomeningeal branches of the PCA

ICA perforating branches

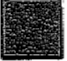

AChiA

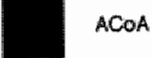

ACOA

ACA perforating branches
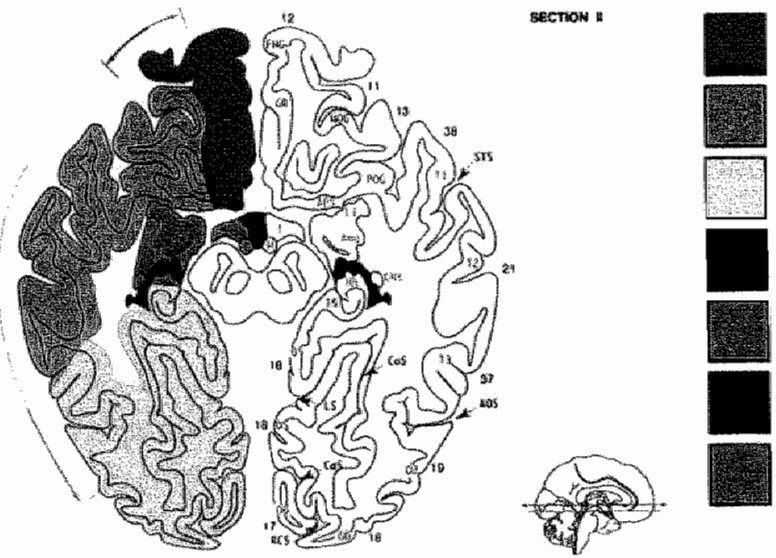

Leptomeningeal branches of the $\mathrm{ACA}$

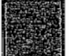

Lepptonteringeal branches of the MCA

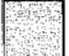

Laptomeningeial branchers of the PCA

ICA pertorating biranchas
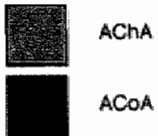

$A C O A$

ACA perforating branches

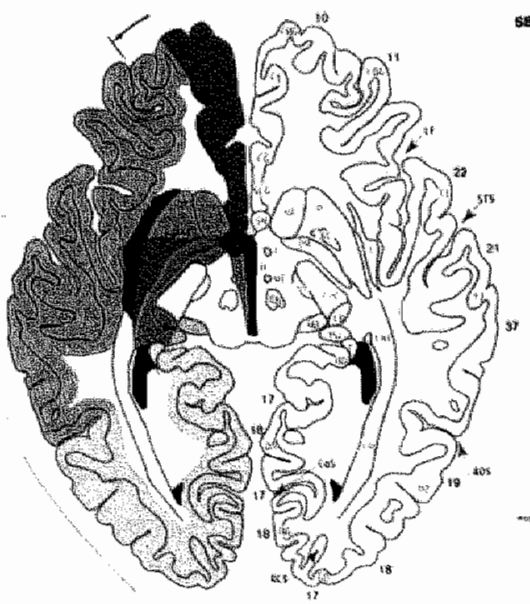

steTtow

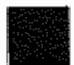

Leptomeningeal branches of the AC.A

Leplomeningeral branches of the $M A C A$

Leptomanirigeal branches of the PCA

ICA perforating branches

AChA

ACOA

ACA pertorating branches

Figure 1. Supply area of the anterior choroidal artery in three brain sections (red) [47]. 


\section{REFERENCES}

1. Critchley M. Arteriosclerotic parkinsonism. Brain 1929;52:23-83.

2. Chang CM, Yu YL, Ng HK, Leung SY, Fong KY. Vascular pseudoparkinsonism. Acra Neurol Scand 1992; 86(6):588-592.

3. Demirkiran M, Bozdemir $H$, Sarica $Y$. Vascular parkinsonism: a distimct, heterogeneous clinical enciry. Acra Neurol Sand 2001; 104(2):63-67.

4. FitzGerald PM, Jankovic J. Lower body parkinsonism: evidence for vascular etiology. Mow Disord 1989; 4(3):249-260.

5. Jankovic J. Lower body (wascular) parkinsonism. Arch Neurol 1990; 47(7):728.

6. Peters S, Eising EG, Przuntek H, Muller T. Vascular Parkinsonism: a case report and review of the literarure. \Clin Neurosci $2001 ; 8(3): 268-271$.

7. Sibon 1, Fenelon G, Quinn NP, Tison F. Vascular parkinsonism. I Neurol 2004; 251(5):513-524.

8. Thompson PD, Marsden CD. Gaic disorder of subcortical arteriosclerotic encephalopathy: Binswanger's disease. Mov Disord 1987; 2(1):1-8.

9. Tolosa ES, Samamaria J. Parkinsonism and basal ganglia infarcts. Neurology 1984; 34:1516-1518.

10. van Zagten M, Lodder J, Kessels F. Gait disorder and parkinsonian signs in parients with strotke relared to small deep infarces and white matter lesions. Mov Disord 1998; 13(1):8995.

11. Zijlmans JC, Poels PJ, Duysens I, van derStraten], Thien T, wan't HofMA, etal. Quantrarive gaut analysis in patients with vascular parkinsonism. Mow Disord 1996; 11(5):501508 .

12. Foltynie $T$, Barker $R$, Brayne $C$. Vascular patkinsonism: a review of the precision and frequency of the diagnosis. Neuroepidemiology 2002; $21(1): 1-7$.

13. Sibon I, Tison F. Vascular parkinsonism. Curr Opin Neurol 2004; 17(1);49-54.

14. Zijlmans JC, Daniel SE, Flughes A], Revesz T, Lees AJ. Clinicoparhological inwertigation of wascular parkinsonism, including clinical criteria for diagnosis. Mov Disord 2004; 19(6):630-640.

15. Zijlmans JC, Thiipsen HO, Vogels OJ. Kremer HI. Poels PJ, Schoonderwaldt HC, et al. MRI in patients with suspected vascular parkinsonism. Neurology 1995; 45(12):21832188.

16. De Reuck. J, Siau B. Decoo D, Santens P. Crevits L, Strijcknans K, et al. Parkinsonism in patients with vascular dementia: clinical, computed-and positron emission-tomographic findings. Cerebrovasc Dis 2001; 11 (1):51-58.

17. Yamanouchi $H$, Nagura $H$. Neurological signs and frontal whire matter lesions in vascular parkinsonism. A clinicopathologic study. Stroke 1997; 28(5):965-969.

18. De la Fuente Fernandez $\mathbb{R}$, Lopez JM, Rey del Corral $\mathbb{P}$. De la Iglesia Martinez I: Peduncular hallucinosis and right hemiparkinsonism caused by lefr mesencephalic infarction. J Neurol Neurosurg Psychiatry 1994; 57:870.

19. Hunter R, Smith J, Thomson T, Dayan AD. Hemiparkinsonism with infarcrion of the ipsilateral substancia nigra. Appl Neurobiol 1978; 4:297-301. 
20. Nakane $M$, Teraoka $A$, Asato R, Tamura $A$. Degeneration of the ipsilareral substantia nigrtallowing cerebral infarction in the striatum. Stroke $1991 ; 23: 328-332$.

21. Bhatia KP, Marsden CD. The behavioural and motor consequences of focal lesions of the basal ganglia in man. Brain 1994; 117:859-876.

22. Kim $\int S$. Involuntary movements after anterior cerebral artery territory infarction. Stroke 2001:32(1):258-261.

23. Sibon I, Rajabally $Y$, Tison F. Parkinsonism as a result of a giant aneurysm. Mov Disord 1999; 14(1): 159-161.

24. Sibon I, Guyot M, Allard M, Tison F. Parkinsonism following anterior chonoidal artery stroke. Eur ] Neurol 2004; 1/(4):283-284.

25. Tuzun E. Anterior choroidal artery territory infarcrion: a case report and rewiew. Arch Med Res 1998; 29:83-87.

26. Boon A, Lodder J, Heuts-van Raak L, Kessels F. Silent brain infarcts in 755 consecurive parients with a first-ever supratentorial ischemic stroke. Relarionship with index-stroke subtype, vascular risk factors, and mortalicy. Stroke 1994; 25(12):2384-2390.

27. Inzelberg R, Bornstein NM, Reider I, Korcyn AD. Basal ganglia lacunes and parkinsonism. Neuroepidemiology 1994; 13(3):108-112.

28. Reider-Groswasser I. Bornstein N, Korczyn A. Parkinsonism in patients with lacumar infarcts of the basal ganglia. Eut Neurol 1995; 35:46-49.

29. Korten AGGC, Lodder J, Vreeling FW, Boreas AMHP, Kessels AF, Weber WE]. Extrapyramidal system dysfuncrion in 101 patients with acute first-ever stroke. Submitred 2005.

30. Korten AGGC, Weber WEJ, Kessels AHF, Boreas AMHP, Vreeling FW, Lodder I. Vascular parkinsonism: evolution of symptoms in a cohort of 1.01 first-ever stroke patients. Submitted 2005.

31. Langston JW, Ballard $\mathbb{P}$. Tetrud JW, Irwin I. Chronic Parkinsonism in humans due to a product of meperidine-anallog synthesis. Science 1983; 219(4587):979-80.

32. Fatu S, Elicon R, comitce MorUd. Unificd Parkinson's disease rating scale. In: Fahn $S$, Marsden CD, Calne DB, Goldstein M, edirors. Recent development in Parkinson"s discase. Flortham Park: McMillan Health Care Information; 1987, p. $153,163$.

33. Geminiani $G$, Cesana BM, Tamma F, Contri P, Pacchetri $C_{3}$ Carella F, enal Interobserwer reliability between neurologists in training of Parkinson's disease rating scales. A multicenter study. Mov Disord 1991; 6(4):330-335.

34. Bories J, Derhy S, Chiras J. CT in hemispheric ischaemic atracks. Neurotadiol 1985: $27: 468-483$.

35. Damasio $\mathrm{H}$. A computed tomographic guide to the identificarion of cerebrat vascular territories. Arch Neurol 1983; 40:138-142.

36. Hupperts RM, Lodder J, Heuts-yan Raak EP, Kessels F. Infarees in the anterior choroidal artery territory. Anatomical distribution, clinical syndromes, presumed parhogenesis and early outcome. Brain 1994: 117 (Pt 4):825-834.

37. Gibb WR, Lees AJ. "The relewance of the Lewy body to the pathogenesis of idiopathic Parkinson's disease. J Neurol Neurosurg Psychiarry 1988:51(6):745-752.

38. Hachinski VC, Porter P. Merskey H. Leuko-araiosis. Arch Neurol 1987; 44:21-23.

39. Jankovic J. Parkinson-plus syndromes. Mov Disord 1989; 45:95-119. 
40. Benner $D$, Gilley D, Wilson $B$, Huckman $M$, Fox J. Clinical correlates of high signal lesions on magnetic resonance imaging in Azheimer"s disease. I Nearol 1992; 239:186190.

41. Briley D, Wasay M, Sergent S, Thomas S. Cerebral white matter changes (leukoanaiosis), stroke and gair disturbance. I Am Geriat Soc 1997; 45:1434-1438.

42. Masdeu], Woltson $L$, Lancos $G$, Grober E, Whipple R. Brain white matter changes in the elderly prone to falling. Arch Neurol 1989; 46:1292-1296.

43. Winkates J, Jankowic J. Clinical correlates of vascular parkinsonism. Arch Neurol 1999; $56(1): 98-102$.

44. Alarcon F, Zijlmans JC, Duenas $\mathrm{G}$, Cevallos $\mathrm{N}$. Post-stroke movement disorders: report of 56 parients. I Neurol Neurosurg Psychiarry 2004; 75(11):1568-1574.

45. Boiten ], Lodder J, Kessels F. Two clinically distinct lacunar infarct entities? A hypothesis. Stroke 1993; 24(5):652-656.

46. de Jong $G$, Kessets $F$, Lodder J. Two types of lacunar infarcts: Further arguments froma study on prognosis. Stroke 2002; 33(8):2072-2076.

47. Tatu L.. Moulin T, Bogousslavsky J, Duvernoy H. Arterial cerritories of the human brain: cerebral hemispheres. Neurology 1998; 50:1699-1708.

48. Luijck G, Boiten J, Lodder J. Heuts-yan Raak L, Wilmink J. Isolated hemiataxia following supratentoral brain infarction. J Neurol Neurosurg Psycharry 1994:57:742. 744 .

49. Snell $\mathbb{R}$. Clinical neuroanatomy for medical students. Boston: Lirde, Brown and Company; 1987.

50. Ghez C, Krakauer ]. The organization of movement. In: Kandel E, Schwartz J, Jessell T, editors. Principles of netral science. New York: MoGraw-Hill, 2000. p. 653-673. 


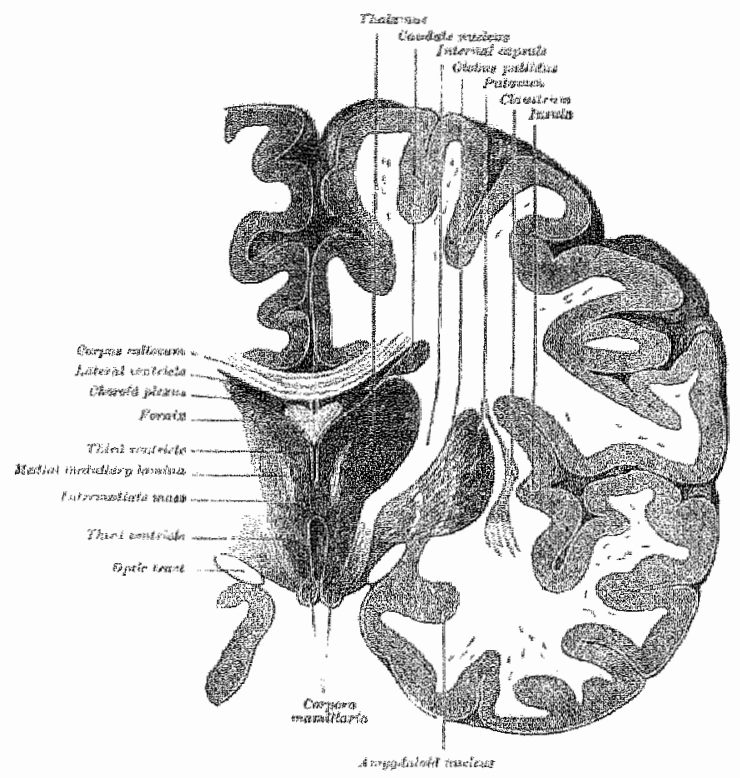

Ihr naht euch wieder, schwankende Gestalten, die früh sich einst dem trüben Blick gezeigt. Versuch' ich wobl, euch diesmal festzubalten? Fubl ich mein Herz noch jenem Wahn geneigt? Ihr drängt euch zu! nun gut, so mögt ihr walten, We ihr aus Dunft und Nebel um mich stergt; Mein Busen fiult sich jugendlich erschuittert Vom Zauberhauch, der euren Zug umwittert.

Goethe, Faust Figure taken from Gray's Anatomy, 1918 
CHAPTER 4

\section{Frontal lobe hyperperfusion in vascular parkinsonism patients}

A.G.G.C. Korten MD; J. Lodder MD, PhD; I.H.A. Al Younis MD; M.J.P.G. van Kroonenburgh MD, PhD; F.W. Vreeling MD, PhD; W.E.J. Weber MD, PhD.

BioMed Central Neurology, submitted. 


\section{ABSTRACT}

Background. Vascular parkinsonism (VP) is accepred as a parkinsonian syndrome dominated by postural instability with shuffling gait and absence of tremor, occurring in $3-5 \%$ of patients with parkinsonism. However, the precise spatiotemporal relation berween the vascular lesions and the ensuing parkinsonism remains undear. As CT and MRI imaging techniques do not allow the precise identification of the cerebral functions affected in VP, we decided to study cerebral perfusion in patients with parkinsonian symproms after stroke.

Methods. In seven parients fullfilling criteria for the diagnosis of VP, cerebral perfusion was evaluated with HMPAO SPECT and compared with seven patients with idiopathic Parkinson's disease.

Results. In all parients with vascular parkinsonism, there was statistically significant byperperfusion in the right frontal brain area as compared to patients with idiopathic Parkinson's disease.

Conclusions. The finding of frontal lobe hyperperfusion supporrs the idea that altered function and changes in cerebral perfusion in the frontal brain regions play a role in the pathophysiology of parkinsonian signs after stroke. 


\section{INTRODUCTION}

Cerebrovascular disease as a cause of parkinsonism was first reported by Critchley in 1929 [1]. Since this first report, several studies have adressed the subject. Main symptom in patients with vascular parkinsonism (VP) is a disturbance of gait. Often there is no tremor and no or only minimal improvement of symptoms on antiparkinsonian medication [2-13]. Affected patients have vascular risk factors, often hypertension, and/or suffered one or more strokes, usually of the lacunar type [2, 5-10, 12-15]. However, the precise spatiotemporal relation between the vascullar lesions and the ensuing parkinsonism remains unclear. Patients with VP from a single stroke in a specific cerebral location are a great minority and published as case reports: locations include mesencephalon [16], substantia nigra [17], striatum [18], basal ganglia [19], anterior cerebra] artery [20], cerebral peduncle [6,21] and anterior choroidal artery $[22,23]$. The great majority of patients with VP suffers an insidious onset, where the relation of timing, location, and size of the infarct with the clinical syndrome is poorly understood [7, 13-15, 24]. Scanning parients with parkinsonism, several authors found an anatomical relation with ischaemic lesions in the basal ganglia [2,19,25], as did Reider-Groswasser when examining a series of patients selected for basal ganglia lesions on CT [26]. In earlier studies we found frequent signs of parkinsonism in a consecutive series of acute first-ever stroke patients $[27,28]$. These were related to white matter lesions, and we found an association with the perfusion area of the anterior choroid artery [29]. However, the relation of clinical parkinsonian signs and ischaemic lesions on CT and MRI remains indirect, indicating that these imaging techniques do not allow the precise identification of the cerebral functions affected in VP. In the present study, we examined cerebral perfusion in $7 \mathrm{VP}$ patients diagnosed according to recent criteria [14], hypothesizing that cerebral perfusion in the frontal subcortical areas of these patients is altered, influencing projections between basal ganglia and frontal cortex. 


\section{METHODS}

\section{Patient selection}

We studied seven parients with vascular parkinsonism, diagnosed according to recently formulated criteria [14]. The clinical diagnosis had been made on predominantly parkinsonian symptoms of the lower extremities: short stepping, starting hesitation and turning problems and problems of a parkinsonian gait. All patients had one or more ischaemic lesions on CT and MRI scanning of the brain fitting the description of infarction, as well as white matter lesions (leukoaraiosis) $[30,31]$. No patient had a previous history of idioparhic Parkinson's disease, multiple system atrophy, progressive supranuclear palsy or any other obvious cause of parkinsonism. Motor function and gait were assessed using the Unified Parkinson's Disease Rating Scale (UPDRS) part III. A higher score corresponds with more severe parkinsonian symptoms [32]. Detailed information on the examined patients is listed in table 1. In all patients cerebral perfusion was evaluated with HMPAO SPECT imaging. SPECT findings in patients with vascular parkinsonism were compared with those in seven patients with a diagnosis of idiopathic Parkinson's disease.

\section{SPECT imaging protocol}

SPECT brain study was done in a quiet, half-dark room while the patient was left for 15 minutes and after the pulse rate had dropped below 100 beats per minute. $740 \mathrm{MBq}$ of $99 \mathrm{~m} \mathrm{Tc-HMPAO}$ (Ceretec, Amersham, England) was administered intravenously. On a large-field single-head gamma camera (Siemens Gammasonics, Hoffman Estate, IL, USA) a $128 \times 128$ matrix was used to image the head and the heart and 110 images of 1 second duration were obtained. Fifteen minutes later, brain SPECT was performed with triple-head gamma camera (Siemens Gammasonics, Hoffman Estate, IL, USA) using a matrix size of $128 \mathrm{x}$ 


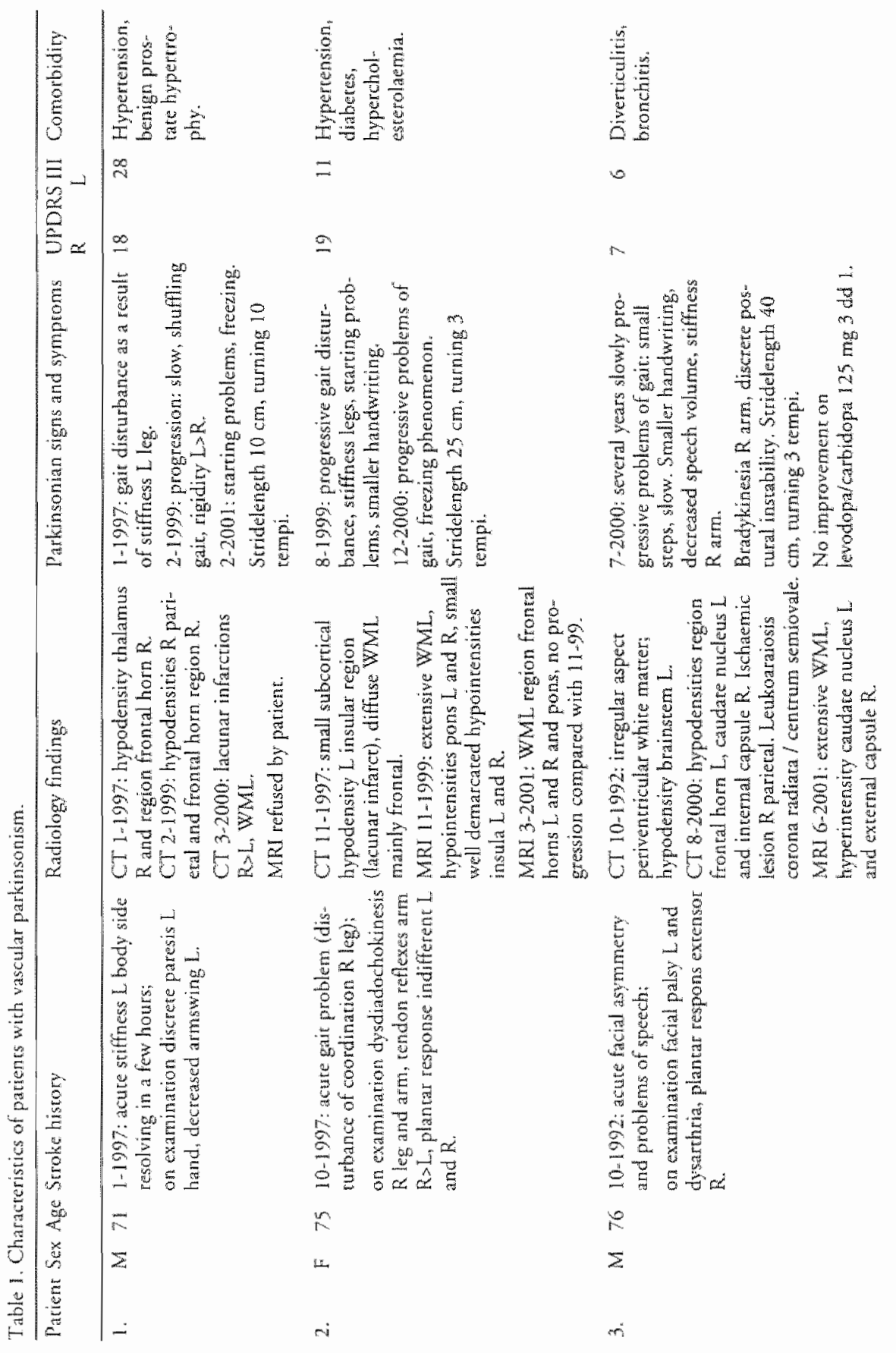




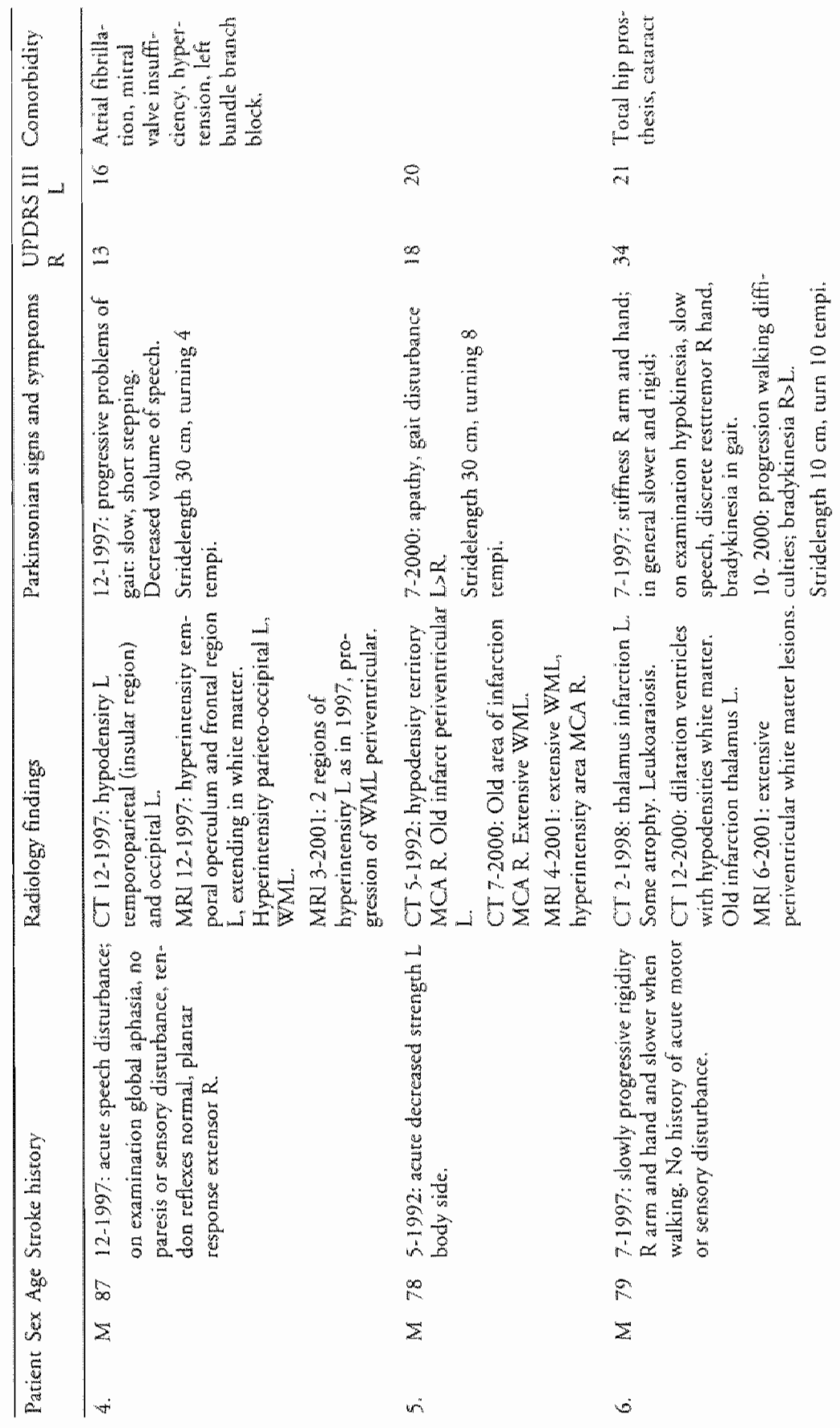


Frontal lobe hyperperfusion in vascular parkinsonism

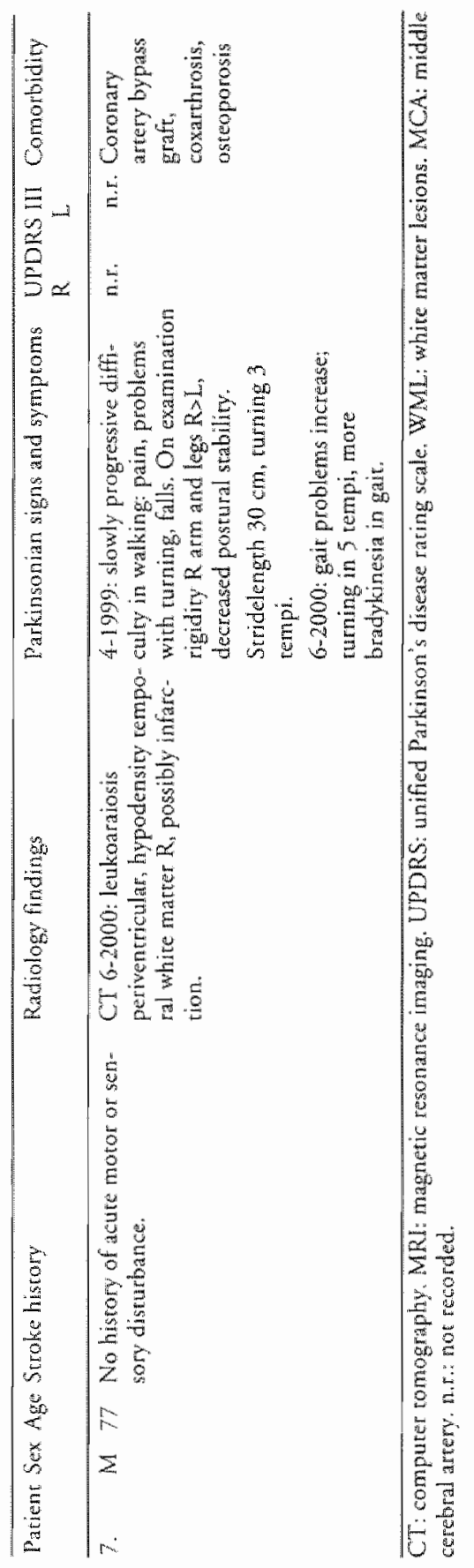



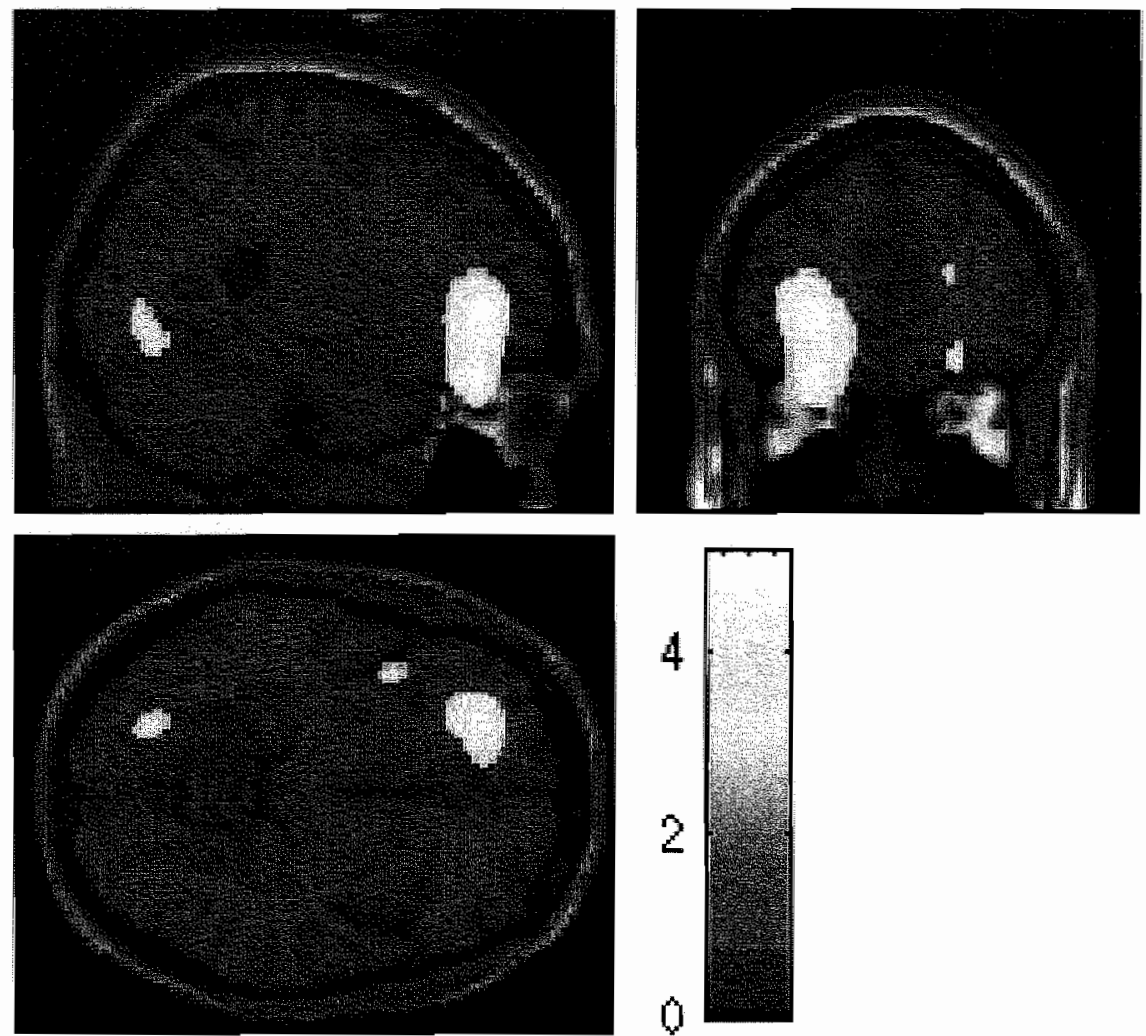

Figure 1. Images showing areas of increased uptake mainly in the right prefrontal area in parients with vascular parkinsonism as compared to the upmake in patients with IPD. The scale in the right lower corner represents the Z-score.

128 and high-resolution collimators. $3 \times 30$ views were obtained. Images were reconstructed using Butterworth filter of the order 5 or 6 and a cutoff value of $0.35-0.40$ of the Nyquist frequency. Chang's attenuation correction was applied using attenuation coefficient of $0.12 \mathrm{~cm}^{-1}$. Transverse images of the brain were reconstructed parallel to the orbitomeatal line. Applying the brain perfusion index allowed hemispheric blood flow and regional cerebral blood flow to be calculated. The Siemens brain quantification program was used to determine mean blood flow. A side- 
to-side difference between regions of more than $10 \%$ was taken as a significant sign of reduced luxury blood flow due to cerebrovascular insult.

\section{Statistical parametric mapping analysis}

SPM (version 1999, SPM'99) was used to determine the quantitative differences in the $99 \mathrm{~m} \mathrm{Tc-HMPAO}$ images between patients with vascular parkinsonism and idiopathic Parkinson's disease. Prior to statistical analysis, all of the images were spatially normalized using a standard template to remove the intersubject anatomical variability. Spatially normalized images were then smoothed to increase the signal-to-noise ratio and to account for the variations in subtle anatomical structures. The count of each voxel was normalized to the total count of the brain (proportional scaling in SPM '99) to remove the differences in global cerebral blood flow (CBF) between individuals. After spatial and count normalization, significant differences in $99 \mathrm{~m}$ Tc-HMPAO SPECT between the two patient groups were estimated at every voxel using $t$-statistics. The voxels with a $\mathrm{p}$ value of less than 0.01 were considered to be significantly different. The t-values were then transformed into the standard Gaussian distribution (Z-score).

\section{RESULTS}

There were clear areas of hyperperfusion compatible with the neuroimaging diagnostic pictures in all patients with VP while there were no regional cerebral blood flow ( $\mathrm{rCBF}$ ) changes in patients with IPD on the ${ }^{99}$ 'T $\mathrm{c}-H M P A O ~ S P E C T$ images by visual analysis. SPM '99 analysis showed areas of increased $\mathrm{rCBF}$ in patients with VP compared to those of IPD (figure 1). 99mTc-HMPAO SPECT images displayed relatively higher radiopharmacon uptake mainly in the right frontal area in patients with VP (figure 1). By contrast, 99m'Tc-HMPAO SPECT images did not show lower uptake in the basal ganglia region or elsewhere in the brain in 
Table 2. Areas with significantly higher uptake on $99 \mathrm{mTc}$-HMPAO SPECT in patients with vascular parkinsonism as compared to idioparhic Parkinson's disease.

\begin{tabular}{llrrl}
\hline Brain area & $\mathrm{X}$ & $\mathrm{Y}$ & \multicolumn{1}{c}{$\mathrm{Z}$} & Z-value \\
\hline Right frontalis medius region & 20 & 44 & -14 & 3.97 \\
Frontalis superior/ fasciculus occipitofrontal is region & 20 & 46 & 0 & 4.60 \\
Pregyrus angularis region & 38 & -58 & 32 & 5.07 \\
Left fasciculus longitudinalis superior region & 26 & 36 & 12 & 3.57 \\
\hline
\end{tabular}

$\mathrm{X}, \mathrm{Y}$ and $\mathrm{Z}$ : coordinates in Talairach space.

patients with VP compared to the uptake in IPD patients. Table 2 specifies brain areas of higher uptake.

\section{DISCUSSION}

Although case reports have identified specific vascular lesions leading to parkinsonian signs $[6,16-23,33]$, studies on series of patients with VP only found indirect relations with basal ganglia lesions and white matter lesions in general $[7,13-15,24,26,34]$, which may also be found in depression and dementia $[35,36]$. To our knowledge, ourstudy is the first report on cerebral perfusion measured with $99 \mathrm{~m}$ Tc-HMPAO SPECT in patients with vascular parkinsonism. We found a statistical significant byperperfusion in the right frontal brain regions as compared to control values, reflecting an altered function in these frontal regions. This location accords with findings of other researchers, who implicated the frontal lobe in the emergence of parkinsonian signs in some patients [37-42]. The finding of byperperfusion is unexpected. Based on the concept that metabolic demand and regional cerebral blood flow are coupled under physiological conditions, our findings suggest that in parients with vascular parkinsonism these are un-coupled. All our seven VP patients had leukoaraiosis. Leukoaraiosis results from atherosclerosis of the medullary penetrators, and is most often located in the frontal brain areas, especially 
around the frontal ventricular horns $[30,31,43]$. The presence of leukoaraiosis is clinically associated with dementia and cognitive disturbances, problems of gait and urinary incontinence[44]. However, it is also reported in healthy individuals [43-48]. Claus er al., using SPECT, found no consistent relationship between severity of cerebral white matter lesions and cerebral blood flow [49]. Shyu et al. found a reduction of cerebral blood flow in the frontal lobes in patients with mild to moderate vascular dementia and subcortical frontal leukoaraiosis [50]. Oppenheimer et al., with MR spectroscopy, also found a trend towards lower cerebral blood flow in white matter lesions [51].

Taken together, cerebral blood flow in white matter lesions of patients without parkinsonism seems to be decreased. This would imply that in our VP patients the frontal hyperperfusion must be linked with a dysfunction of the extrapyramidal system, as the sole presence of white matter lesions seems to lead to decreased blood flow.

To our knowledge, there are no previous prospective studies with technetium HMPAO SPECT or perfusion MRI in a series of patients with vascular parkinsonism. Ikeda et al. described one case of a patient with parkinsonism, basal ganglia lacunar infarcts, and periventricular high signal areas, in whom HMPAO SPECT showed diffuse cortical hypoperfusion [52]. In Parkinson's disease, studies on regional cerebral blood flow have given conflicting results: on the one hand, basal ganglia dysfunction is associated with increased regional blood flow $[53,54]$, on the other hand increased cerebral blood flow is associated with increased motor function [55]. Sestini et al. found that good clinical motor response with deep brain stimulation were associated with increased regional blood flow in the frontal areas [55]. Perhaps our results represent some kind of compensatory mechanism aimed at restoring the functional integrity of the extrapyramidal system. However intriguing, our first study on cerebral perfusion in a series of patients with vascular parkinsonism does need confirmation as the numbers of patients studied is small. 


\section{REFERENCES}

1. Crichley M. Arterioscletotic parkinsonism. Brain 1929; 52:23-83.

2. Chang CM, Yu YL, Ng HK, Leung SY, Fong KY. Vascular pseudoparkinsonism. Acta Neunol Scand 1992; 86(6):588-592.

3. Demirkiran M, Bozdemir H, Sarica Y. Vascular parkinsonism: a distinct, heterogeneous dinical entity. Acta Neurol Scand 2001; 104(2):63-67.

4. FitzGerald PM, Jankovic J. Lower body parkinsonism: evidence for vascular etiology. Mow Disord 1989; 4(3):249-260.

5. Jankovic I. Lower body (vascular) parkinsonism. Arch Neurol 1990; 47(7):728.

6. Peters $S$, Eusing EG, Pruntek H. Muller T. Vascular Parkinsonism: a case report and review of the literature. J Clin Neurosci $2001 ; 8(3): 268-271$.

7. Sibon 1, Fenelon G, Quimn NP, Tison F. Vascular parkinsonism. I Neurol 2004; $251(5): 513-524$

8. Thompson PD, Marsden CD. Gait disorder of subcortical arterioscleroric encephalopathy: Binswanger's disease. Mov Disord 1987; 2(1):1-8.

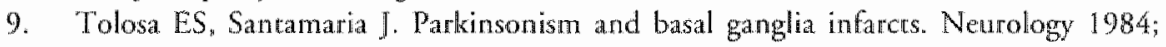
34:1516-1518.

10. van Zagten $M$, Lodder J, Kessels F. Gait disorder and parkinsonian signs in parients with stroke related to small deep infarcts and white matter lesions. Mow Disord 1998; 13(1):8995.

11. Zijlmans JC, Poels PJ, Duysens J, wan der Straten J, Thien T, van't Hof MA, et al Quantitative gait analysis in patients with wascular parkinsonism. Mov Disord 1996; 11(5):501508.

12. Foltynie T, Barker R, Brayne C. Vascular parkinsonism: a review of the precision and frequency of the diagnosis. Neuroepidemiology 2002; 21(1):1-7.

B. Sibon I, Tison F. Vascular parkinsonism. Curr Opin Neurol 2004; 17(1):49-54.

14. Zijilmans JC, Danid SE. Hughes AJ, Revesz T, Lees AJ. Clinicopathological investigation. of vascular parkinsonism, including clinical criteria for diagnosis. Mov Disond 2004; $19(6): 630-640$.

15. Zij tmans JC, Thijssen HO, Vogels OJ, Kremer HP, Poels PJ, Schoonderwald HC, et al. MRI in patients with suspected wascular parkinsonism. Neurology 1995; 45(12):21832188.

16. De la Fuente Fernandez R, Lopez JM, Rey del Corral P, De la Iglesia Martinez F. Pedunculat hallucinosis and right hemiparkinsonism caused by left mesencephalic infarcrion. J Neurol Neurosurg Psychiatry 1994; 57:870.

17. Hunter $R_{n}$ Smith $J$, Thonson ' $T$, Dayan $A D$. Hemiparkinsonism with infarction of the ipsilateral substantia nigra. Appl Neurobiol 1978; 4:297-301.

18. Nakane M, Teraoka A, Asaco R, Tamura A. Degeneration of the ipsilateral substantia nigra following cerebral infarction in the stritum. Stroke 1991; 23:328-332.

19. Bhatia KP. Marsden CD. The behavioural and motor consequences of focal lesions of the basal ganglia in man. Brain 1994; 117:859-876. 
20. Kim IS. Involuntary movements after anterior cerebral artery territory infarction. Stroke $2001 ; 32(1): 258-261$.

21. Sibon I, Rajabally Y, Tison F. Parkinsonism as a result of a giant aneurysm. Mov Disord 1999, 14(1):159-161.

22. Sibon I, Guyor $M$, Allard M, Tison F. Parkinsonism following anterior choroidal artery stroke. Eur J Neurol 2004; 11(4):283-284.

23. Tuzun E. Anterior choroidal artery territory infarction: a case report and rewiew. Arch Med Res 1998; 29:83-87.

24. Broon A, Lodder J, Heurs-van Raak L, Kessels F. Silent brain infares in 755 consecurive parients with a first-ever supratentorial ischemic stroke. Rellationship with index-stroke subrype, vascular risk factors, and mortality. Stroke 1994; 25(12):2384-2390.

25. Inzelberg R, Bornstein NM, Reider I, Korczyn AD. Basal ganglia lacunes and parkinsonism. Neuroepidemiology 1994; 13(3):108-112.

26. Reider-Groswasser 1, Bornstein N, Korcyn A. Parkinsonism in patients with lacunar infarcts of the basal ganglia. Eur Neurol 1995: 35:46-49.

27. Korten AGGC, Lodder J, Vreeling FW, Boreas AMHP, Kessels AF, Weber WEJ. Extrapyramidal system dysfunction in 10 I patients with acute first-ever stroke. Submitted 2005.

28. Korten AGGC, Weber WEJ, Kessels AHF, Boreas AMHP, Vreeling FW, Lodder J. Vascular parkinsonism: evolucion of symptoms in a cohort of 101 first-ever stroke patients. Submitced 2005.

29. Korten AGGC, Weber WE], Vreeling FW, Borreas AMHP, Kessels AF, Lodder J. Neuroradiologic correlates of parkinsonian signs in 83 furst-ewer stroke patienrs. Submitted for publication 2005.

30. Hachinski VC, Porter P, Merskey H. Leuko-araiosis. Arch Neurol 1987; 44:21-23.

31. van Zagten M, Boiten J, Kessels F, Lodder J. Signifficant progression of white matter lesions and small deep (lacunar) infarcts in patients with stroke. Arch Neurol 1996; $53(7): 650-655$.

32. Fahn S, Elron R, comintee MotUd. Unified Parkinson's disease rating scalte. In: Fahn S, Marsden CD, Calne DB, Goldstein M, editors. Recent dewelopment in Parkinson's disease. Florham Park McMillan Health Care Information; 1987. p. 153-163.

33. Lee MS, Lee SA, Heo JH, Choi IS. A patient with a resting tremor and a lacunar infarction at the border between the thalamus and the internal capsule. Mov Disord 1993; 8(2):244246.

34. Allarcon F, Z jijmans $] \mathrm{C}$, Duenas G, Cevallos N. Post-stroke movement clisorders: report of 56 patients. ] Neurol Neurosurg Psychiatry 2004; 75(11):1568-1574.

35. Barber R, Scheltens P, Gholkar A, Ballard C, McKeith I, Ince P, et all. White matter lesions on magnetic resonance imaging in dementia with Lewy bodies. Alzheimer's disease, vascular dementia, and normal aging. I Neurol Neurosurg Psychiatry 1999; 67(1):66-72.

36. OBrien J, Perry $R$, Barber R, Gholkar $A$, Thomas $A$. The association berween white matter lesions on magnetic resonance imaging and noncognitive symptoms. Ann $N$ Acad Sci 2000; 903:482-489. 
37. Abe K, Terakawa $H$, Takanashi $M$, Waranabe $Y$, Tanaka $H$, Fujica $N$, et al.. Proton magnetic resonance spectroscopy of patients with parkinsonism. Brain Res Bull 2000; 52(6):589-595.

38. De Reuck J, Siau B, Decoo D, Santens P, Crevis L, Srrijckmans K, er al. Parkinsonism in patients with wascular dementia: clinical, computed-and positron emission-romographic Gindings. Cerebrowase Dis 2001; 11(1):51-58.

39. Umahara $T$, Iwamoto $T$, Takasaki M, Katsunuma H. [A clinical sudy in elderly parients with Parkinson's disease using MRI and SPECT-Parkinson's disease and the lacumar state). Nippon Ronen Igakkai Zasshi 1991;28(6):755-760.

40. Umahara $\mathrm{T}$, Kano $\mathrm{H}$, liwamoto $\mathrm{T}$, Katsunuma $\mathrm{H}$, Tachikawa K, Tachikawa S. LAn MRI and SPECT sudy of frozen gait without other manifestations of parkinsonism in the elderly]. Nippon Ronen Igakkai Zasshi 1991; 28(3):377-384.

41. Yamanouchi H. [Vascular parkinsonism]. Nippon Rinsho 1997; 55(1):106-111.

42. Yamanouchi $H_{3}$ Nagura $H$. Neurological signs and frontal white matter lesions in vascular parkinsonism. A clinicoparhologic study. Stroke 1997; 28(5):965-969.

43. van Swieren JC, van den Hout JH, van Ketel BA, Hijdra A, Wokke JH, van Gijn J. Periventricular lesions in the white matrer on magneric resonance imaging in the elderly. A morphometric conrelation with arteriolosclerosis and dilated periwascular spaces. Brain 1991; $114(\mathrm{Pt} 2): 761-774$.

44. Tarvonen-Schroder S, Roytta M, Raiha I, Kurki T, Rajala T, Sourander L. Clinical features of leukomaraiosis. I Neurol Neurosurg Psychiarry 1996; 60(4):431-436.

45. Breteler MM, van Amerongen NM, van Swieten JC. Claus JJ, Grobbee DE, van Gijn J, et al. Cognitive correlates of ventricular enlargement and cerebral white natter lesions on magnetic resonance imaging. The Ratrerdam Study. Stroke 1994; 25(6):1 109-1115.

46. Kirkpatrick JB, Hayman LA. White-matter lesions in MR imaging of clinically healthy brains of elderly subjects: possible parhologic basis. Radiology 1987; 162(2):509-511.

47. Longstreth WT, Jr., Manolio TA, Arnold A, Burke GL, Bryan N, Jungreis CA, et al. Clin-

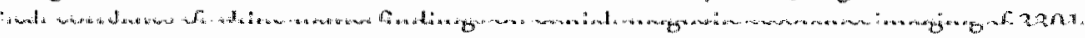
elderly people. The Cardiovascular Health Study. Stroke 1996; 27(8):1274-1282.

48. Steingart A, Hachinski VC, Lau C, Fox Al, Diaz F, Cape R, er al. Cognirive and neurologic findings in subjects with diffuse white matter lucencies on computed tomographic scan (leukowaraiosis). Arch Neurol 1987; 44(1):32-35.

49. Claus J]. Breteler MM, Hasan D, Krenning EP, Bors ML, Grobbee DE, er all. Vascular risk factors, atherosclerosis, cerebral white matrer lesions and cerebral perfusion in a populatrion-based study, Eur ] Nucl Med 1996; 23(6):675-821.

50. Shyu WC, Lin JC, Shen CC, Hsu YD, Lee CC, Shiah IS, et al. Vascular demenria of Binswanger's type: dinical, neuroradiological and $99 \mathrm{~m}$ Tc-HMPAO SPET study. Eur J Nud Med 1996; $23(10): 1338-1344$.

51. Oppenheimer SM, Bryan RN, Conturo TE, Soher BJ, Preziosi TJ, Barker PB. Proton magnetic resonance spectroscopy and gadolinium-DTPA penfusion imaging of asymptomatic MRI white matrer lesions. Magn Reson Med 1995; 33:61-68.

52. Ikeda K, Kotabe T, Kanbashi S, Kinoshita M. Parkinsonism in lacunar infarcts of the basal ganglia. Eur Neurol 1996; 36:248-249. 
Frontal lobe hyperperfusion in vascular parkinsonism

53. Sabatini U, Rascol O, Celsis P, Houin G. Rascol A, Marc-Vergnes JP, Montastruc JL. Subcutaneous apomorfine increases regional cerebral blood how in parkinsonism partents via peripheral mechanisms. Br J Clin Pharmacol 1991; 32:229-234.

54. Anronini A, Marota $G$, Benci $R$, Laudi $A$, De Notaris $R$, Mariani $C$, Gerundini P, Pexzoli $G$. Ganni SM. Brain flow changes before and after deep brain stimulation of the sulbrhalamic nucleus in Parkinson's disease. Neurol Sci 2003; 24:151-152.

55. Sescini S, Scotro di Luzio A, Ammannati F, De Cristofaro MT, Passeri A, Marrini S, Pupi A. Changes in regional cerebral blood flow caused by deep-brain stimulation of the subthalamic nucleus in Parkinson's disease. J Nucl Med 2002; 437725-732. 

Dopamine availability in vascular parkinsonism and idiopathic Parkinson's disease: a comparison with $\left[{ }^{123} \mathrm{I}\right]$ FP-CIT and $\left[{ }^{123} \mathrm{I}\right]$ IBZM SPECT

A.G.G.C. Korren MD; I.H.A. Al Younis MD; M.J.P.G. van Kroonenburgh MD, PhD; W.E.J. Weber MD, PhD; F.W. Vreeling MD, PhD; F. Kessels MD, MSc; I. Lodder MD, PhD.

Functional Neurology, submitted. 
ABSTRACT

Background. Parkinsonian symptoms and the parkinsonian syndrome may have warious causes with different therapeutic consequences. The diagnosis of a parkinsonian syndrome and idioparhic Parkinson's disease is made on clinical grounds. We investigated if single photon emission compurer romography (SPECT) using different radioligands can differentiate idiopathic Parkinson's disease from parkinsonism caused by cercbrovascular disease.

Methods. We examined FP-CIT and IBZM SPECT findings in 5 parients with a history of srroke, predominantly a parkinsonian gait and a clinical diagnosis of vascular parkinsonism. Findings in these patients were compared to those in 5 patients with a clinical diagnosis of idiopathic Parkinson's disease.

Results. Median uptake ratio of FP-CIT in putamen of parients with wascular parkinsonism was 7.8 and in patients with idiopathic Parkinson's disease (IPD) 4.2 ( $p<0.02)$. Median uptake ratio of IBZM was 3.6 in patients with valscular parkinsonism and 3.7 in patients with IPD.

Conclusions. FP-CIT SPECT can help to differentiate vascular parkinsonism from IPD. Furthermore, our findings concur with the hypothesis that vascular parkinsonism is not caused by dopamine deficiency or degeneration of dopamine receptors in striatum. Lesions in connecting white matter tracts might be responsible. 


\section{INTRODUCTION}

Vascular parkinsonism (VP) is a clinical syndrome with predominantly parkinsonian gait disorder and less frequently tremor [1-11]. In $3-5 \%$ of patients with parkinsonism, the syndrome can be attributed to vascullar lesions $[12,13]$. Patients with VP have vascular risk factors, often hypertension, and/or suffered one or more strokes, usually of the lacunar type $[2,5-1.0,12-15]$. However, in clinical practice diagnosis may be difficult, as the great majority of patients with VP suffers an insidious onset, where the relation of timing, location, and size of the infarct with the clinical syndrome is unclear [7, 13-16]. As treatment strategies for VP patients are different from those for patients with idiopathic Parkinson's disease (IPD) [7], a diagnostic test to distinguish the two would be helpful.

Recently, SPECT, to visualise dopamine availability in the striatum, has been used as such a test. Results have been conflicting: Gerschlager et al. and Tzen et al., found relatively normal values compared with IPD patients $[17,18]$, while others could not reliably discern VP from IPD $[19,20]$. Recently Plotkin reported both FP-CIT (123 I-FP-CIT (Iodine-

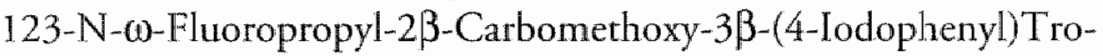
pane) and IBZM (123I-IBZM (Iodine-123-Iodobenzamide) SPECT" abnormalities in $4 \mathrm{VP}$ parients, suggesting that VP patients have abnormalities in both presynaptic and post-synaptic striatal dopamine receptors [21]. Conflicting resulls are partly caused by different methods to reach a clinical diagnosis of VP [2-11]. Recently, Zijlmans et al. formulated rigorous clinical criteria for the diagnosis of VP [14]. Using these to select VP patients we compared FP-CIT and IBZM SPECT findings in VP patients with patients with idiopathic Parkinson's disease. 


\section{METHODS}

\section{Patient selection}

Five patients with vascular parkinsonism clinically diagnosed according to recent criteria [14] entered the study. Patients predominantly had symptoms of the lower extremities and a parkinsonian gait: short stepping, starting and turning problems. All patients had one or more ischaemic lesions on CT" or MRI scanning of the brain fitting the description of infarction or white matter lesions (leukoaraiosis) [10,22]. No patients had a previous history of IPD, multiple system atrophy, progressive supranuclear palsy or other obvious cause of parkinsonism. Motor function was assessed bilaterally using the Unified Parkinson's Disease Rating Scale (UPDRS) part III [23]. A higher score corresponds with more severe parkinsonian symptoms.

SPECT findings of VP patients were compared with those of 5 patients with IPD, previously examined as part of a screening protocol for surgery for IPD.

\section{SPECT examination protocol}

Before SPECT examination, all patients were given thyroid protection agents and medication known to influence results of FP-CIT or IBZM SPECT was discontinued for a sufficiently long period. For SPECT studies of dopamine densities in the brain a dose of $185 \mathrm{MBq}$ of ${ }^{123}$ I-IBZM (Amersham Cygne, Eindhoven, the Netherlands; Radionuclide purity $>99.9 \%$ at time of calibration) was injected intravenously. Two hours later a SPECT study of the head was performed using a three headed gamma camera (MULTI-SPECT 3, Siemens Sonics, Hoffman Estate, Illinois, USA). Low energy high resolution collimator was used to construct the SPECT images. The three headed camera was rotated every 45 seconds for a total of 30 minutes using $128 \times 128$ matrix. The head of the patient was fixed using head and neck restful adjustment piece. We used 


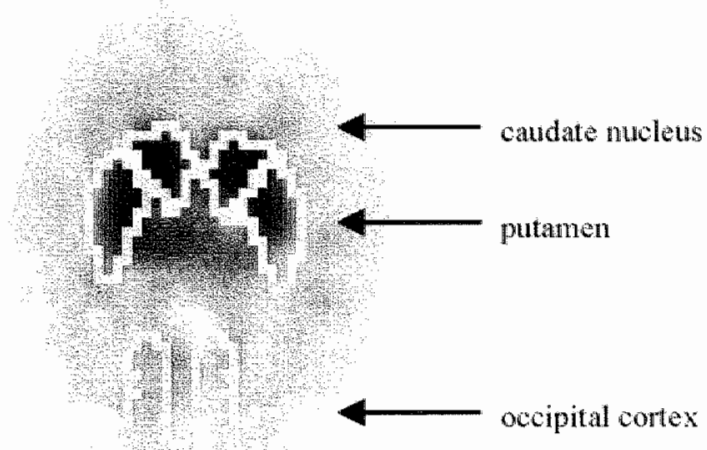

Figure 1 a. FP-CIT SPECT of a patient with vascular parkinsonism. Arrows indicate different regions of interest (ROIs).

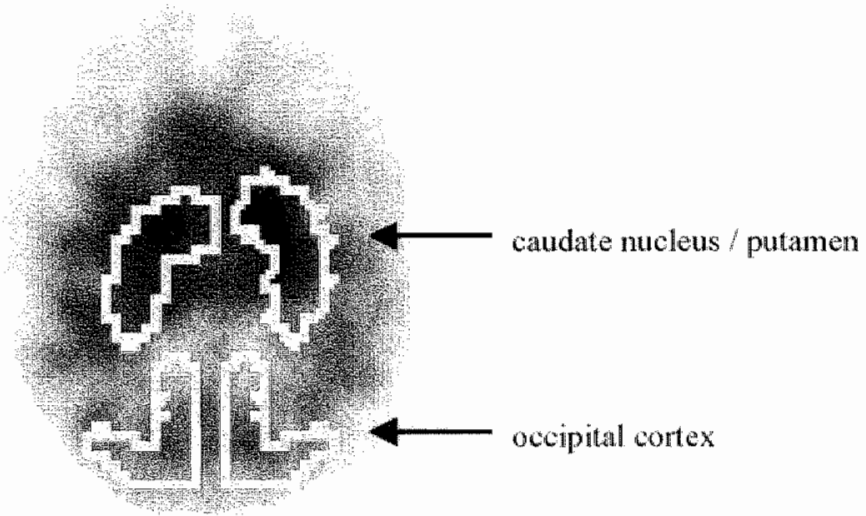

Figure 1 b. IBZM SPECT of a patient with vascular parkinsonism. Regions of interest encircled.

an Alderson Phantom to correct and normalize the SPECT data [9]. Image reconstruction was done using a Butterworth filter with a cutoff frequency of 0.4-0.5 and order of 5. Chang"s attenuation correction of 0.12 per $\mathrm{cm}^{-1}$ was applied. On the reconstructed images, regions of inter- 
est (ROIs) were drawn semi automatically over the basal ganglia (Figures $1 \mathrm{a}$ and $\mathrm{b}$ ). The occipital cortex was used for background correction (nonspecific binding). The results were shown in a form of ratio of activity over these two regions. At least two days later, $185 \mathrm{MBq}$ of ${ }^{123}$ I-FP-CIT (Amersham Cygne, Eindhoven, the Netherlands: specific activity $>185$ $\mathrm{MBq} / \mathrm{nmol}$, radiochemical purity of $>95 \%$ ) was injected intravenously and 3 hours later SPECT study was conducted. The same software and acquisition procedure as for ${ }^{23}$ I-IBZM SPECT was used. A separation in the activity between the caudate nucleus and the putamen was then obtained semi automatically to mark the highest total activity over these regions.

Criteria used in the evaluation of the SPECT results: The normal ratio for ${ }^{123}$ I-IBZM SPECT corrected for age was $3.58+i-0.36$ and for 123 I-FPCIT SPECT $7.76+/-3.54$ at the caudate nucleus/occipital cortex level and $8.25+1-3.70$ for the putamen/occipital cortex ratio. These normal Alderson corrected ratios were obtained from studying twenty healthy volunteers (aged above forty years) at the Academic Medical Center of Amsterdam, the Netherlands.

RESUL.TS

Five patients with vascular parkinsonism ( 4 males and 1 female, mean age 78 , range 71 to 88, SD 6.3 years) and five patients with IPD ( 4 males and 1 female, mean age 62 , range 53 to $67, \mathrm{SD} 5.3$ years) were studied with 123 I-IBZM SPECT and 123I-FP-CIT. Data on signs and symptoms, and additional investigations are listed in table 1. Striatum-occipital cortex activity ratio's of EP-CIT and IBZM SPECT of patients with vascular parkinsonism and idiopathic Parkinson's disease are listed in table 2. Table 3 provides mean ratio's for both patient groups. Distribution of ratio's of both groups was compared using the Mann-Whitney independent samples test. IBZM ratio striatum-occipital cortex on left and right side did not differ between patient groups ( $p>0.5$ ). FP-CIT ratio caudate 


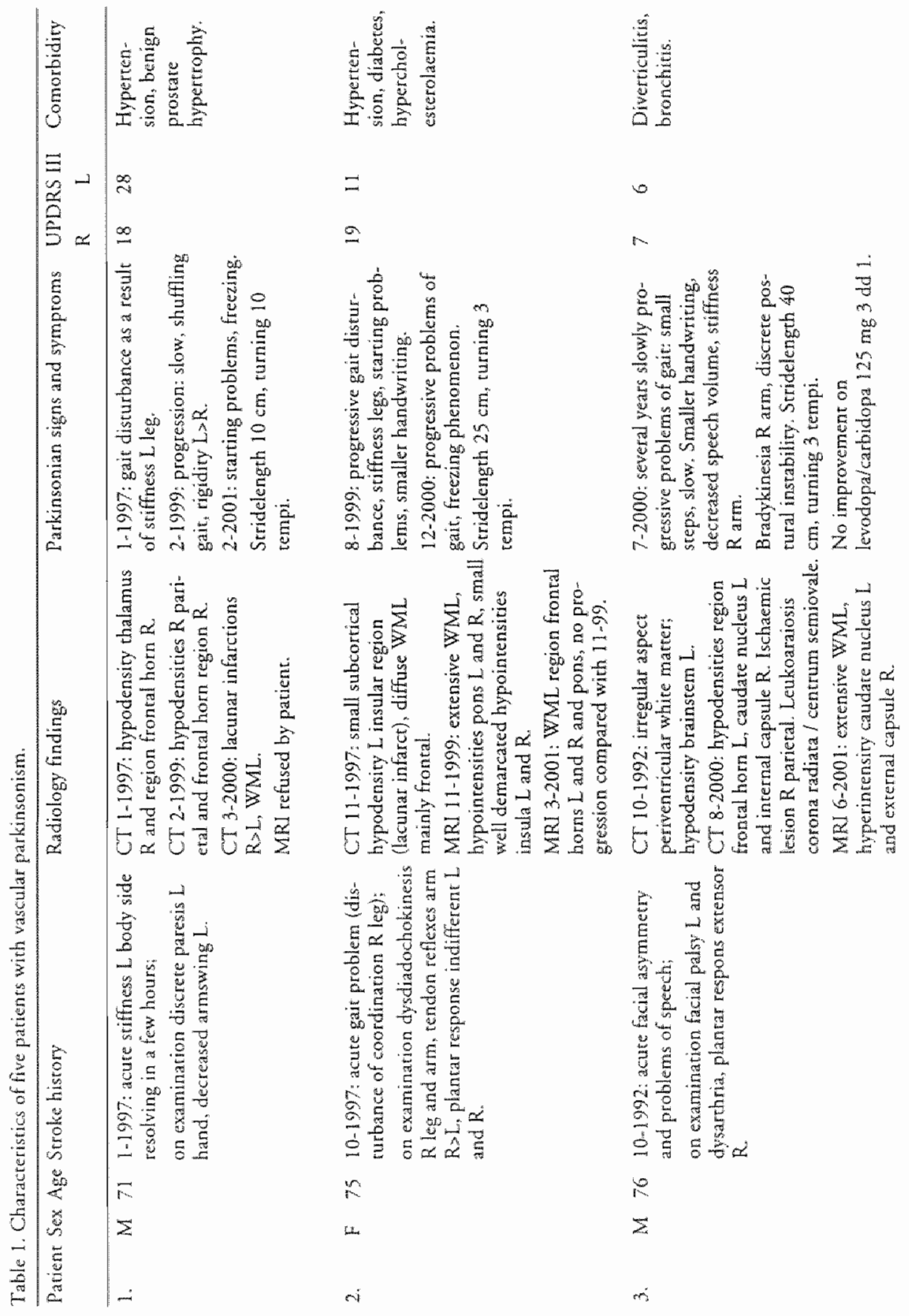




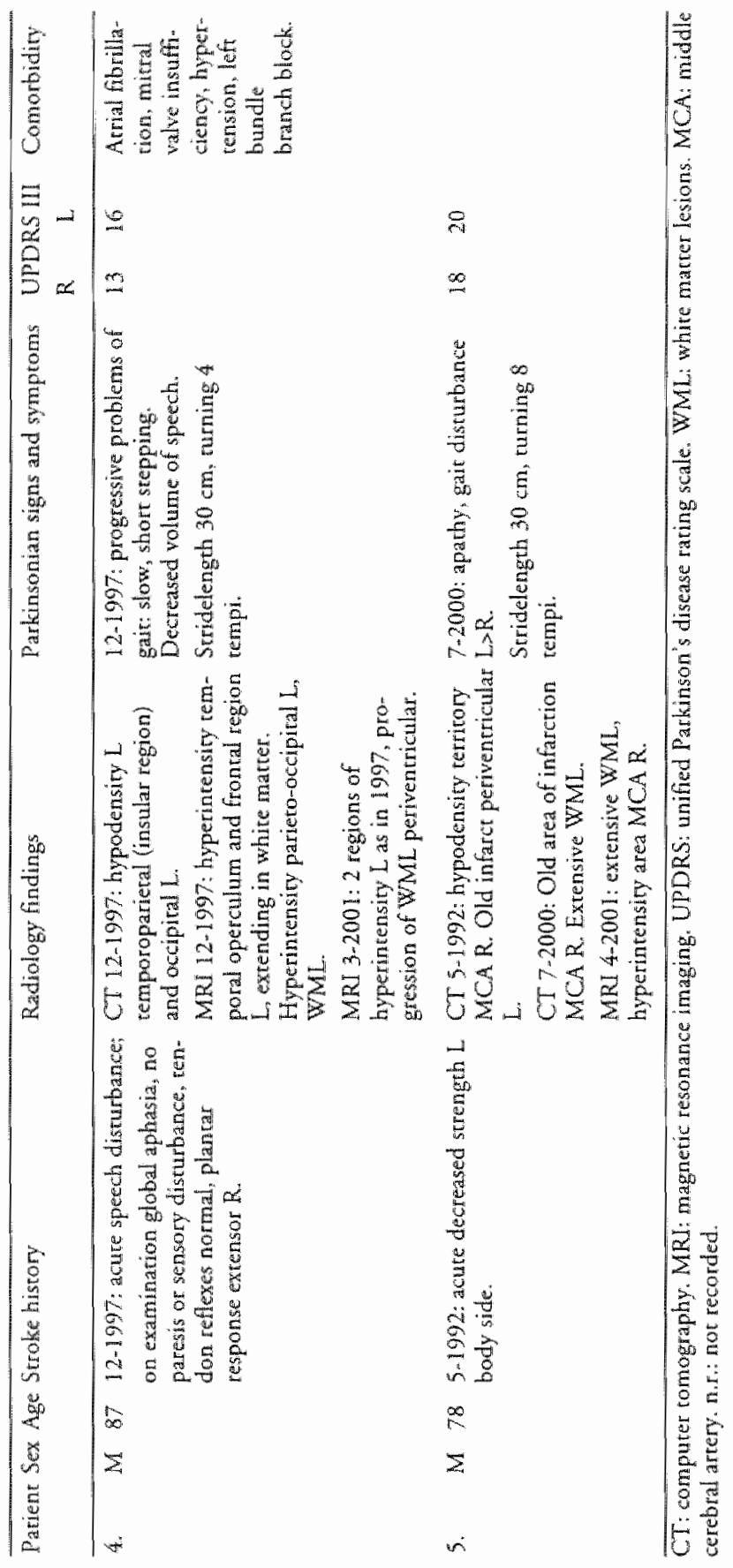


Table 2. Striatum-Occipiral cortex ratio's in IBZM and FP-CIT SPECT in individual parients.

\begin{tabular}{llllllrl}
\hline Patient & diagnosis IBZM R IBZM L & \multicolumn{2}{c}{$\begin{array}{c}\text { FP-CIT R FP-CIT L L } \\
\text { (caudate) }\end{array}$} & $\begin{array}{c}\text { FP-CIT R FP-CIT L } \\
\text { (cudate) }\end{array}$ & $\begin{array}{c}\text { (putamen) } \\
\text { (putamen) }\end{array}$ \\
\hline 1 & VP & 4.49 & 3.93 & 9.14 & 5.83 & 5.86 & 6.20 \\
2 & VP & 3.62 & 3.35 & 1.0 .57 & 11.21 & 7.57 & 7.19 \\
3 & VP & 3.26 & 2.71 & 10.45 & 11.12 & 9.76 & 7.68 \\
4 & VP & 5.11 & 4.38 & 10.90 & 15.26 & 10.75 & 9.95 \\
5 & VP & 2.15 & 2.73 & 6.21 & 6.52 & 5.07 & 7.77 \\
6 & IPD & 3.72 & 4.12 & 4.24 & 6.10 & 3.18 & 4.31 \\
7 & IPD & 3.93 & 3.82 & 5.52 & 5.88 & 4.12 & 5.66 \\
8 & IPD & 3.96 & 3.12 & 9.11 & 7.18 & 5.08 & 4.93 \\
9 & IPD & 3.55 & 3.25 & 8.26 & 5.06 & 4.69 & 3.57 \\
10 & IPD & 4.37 & 3.50 & 4.78 & 4.22 & 3.00 & 3.67 \\
\hline
\end{tabular}

VP: vascular parkinsonism. IPD: idiopathic Parkinson's disease.

Table 3. Median ratio's and range for both patients groups.

\begin{tabular}{llcl}
\hline & & Median ratio & Range \\
\hline IBZM R & VP & 3.62 & 2.96 \\
& IPD & 3.93 & 0.82 \\
IBZM L & VP & 3.35 & 1.66 \\
& IPD & 3.50 & 1.00 \\
FP-CIT R (caudate) & VP & $10.45^{*}$ & 4.69 \\
& IPD & 5.52 & 4.87 \\
FP-CIT L (caudate) & VP & 11.12 & 9.43 \\
& IPD & 5.88 & 2.96 \\
FP-CIT R (putamen) & VP & $7.57 \neq$ & 5.68 \\
& IPD & 4.12 & 2.08 \\
FP-CIT L (putamen) & VP & $7.68 \ddagger$ & 3.75 \\
& IPD & 4.31 & 2.09 \\
\hline
\end{tabular}

VP: vascular parkinsonism. IPD: idiopathic Parkinson's disease, *: $\mathrm{p}<0.03$. $\$$ : $\mathrm{p}<0.02$.

nucleus-occipital cortex on right side was significantly lower in patients with IPD $(p<0.03)$. On the left side, this difference was also present, but not reaching statistical significance $(p=0.076)$. FP-CIT ratio putamenoccipital cortex on left and right side was also significantly lower in patients with IPD $(p<0.02)$. Figures 1 and b show typical FP-CIT and IBZM SPECT findings in one patient with vascular parkinsonism. 


\section{DISCUSSION}

In an effort to test the diagnostic accuracy of FP-CIT and IBZM SPECT in delineating VP from IPD, we scanned 5 VP and 5 IPD patients. FPCIT SPECT showed a normal uptake ratio of the ligand in the striatum of VP patients, whereas in patients with IPD, the uptake ratio putamenoccipital cortex and caudate nucleus-occipital cortex was lowered compared to normal ratios (Academic Medical Center of Amsterdam) [2527]. IBZM SPECT showed normal ligand uptake in the striatum in patients with vascular parkinsonism, as was also the case in the patients with IPD.

Our study, for the first time employing recently formulated clinical criteria for VP, accords with two previous ones suggesting that FP-CIT SPECT can delineate VP from IPD in patients with a parkinsonian syndrome and cerebrovascular disease $[18,19]$. This observation concurs with the idea that levodopa or dopamine agonists have no clinical effect in VP, since endogenous dopamine availability is presumably normal [28]. Lorberboym et al. did not find any correlation between FP-CIT SPECT results and levodopa responsiveness among VP patients [20]. However, eleven patients had significantly diminished binding suggesting nigrostriatal degeneration, while five of these had a good response to $L$ dopa. The investigators themselves suggested an underlying development of idiopathic Parkinson's disease as a possible explanation [20]. Additionally, the dogma that VP patients do not respond to levodopa was recently challenged by Zijlmans et al. who showed in a retrospectivestudy that VP patients with lesions in the nigrostriatal pathways do respond to levodopa [29]. Taken together, these data suggest that FP-CIT SPECT may be used to discern patiens with VP from IPD, bue that it does not predict a clinical levodopa response in these patients.

IBZM SPECT data in our VP parients were within normal range, pointing out that in our patients dopamine D2 receptor availability in the striatum was normal and not reduced as a result of stroke involving areas of the putamen. This contrasts to common findings in other parkin- 
sonian syndromes, such as multiple system atrophy or Steele-Richardson-Olszewski syndrome $[30,31]$. IBZM SPECT may thus be of value to differentiate VP from other parkinsonism syndromes.

Combining the results of our FP-CIT and IBZM SPECT examinations in VP patients gives us new clues to the possible mechanisms causing parkinsonian symptoms after stroke. The striatal circuit projecring from caudate nucleus and putamen is the main circuic in the extrapyramidal motor system. Through the white matter of the corona radiata, these nuclei receive projections from the entire ipsilateral cerebral cortex and contralateral premotor, motor and somatosensory cortex. Caudate nucleus and putamen project to globus pallidus neurons and these, through ansa lenticularis, fasciculus lenticularis and fasciculus thalamicus, connect with the ventrolateral thalamic nucleus. From here, projections travel through the rostral part of the internal capsule back to the cerebral cortex, mainly area 6 and the supplementary motor area [32-34]. Normal findings in FP-CIT and IBZM SPECT suggest that dysfunction of this principal extrapyramidal motor circuit is not caused by loss of neurones in caudate nucleus, putamen or substantia nigra [35]. All our patients had white matter lesions on radiological examination of the brain. Possibly, lesions in white matter tracts serving projections between cerebral cortex and basal ganglia are the main cause of parkinsonian symptoms. A possible candidate area here is the frontal lobe, as we recently found that VP patients have local hyperperfusion in this location [36]. Future prospective cohort studies should be aimed at idencifying critical areas in the white matter responsible for damaging the extrapyramidal system leading to vascular parkinsonism.

\section{REFERENCES}

1. Critchley M. Arteriosclerotic parkinsonism. Brain 1929; 52:23-83.

2. Chang CM, Yu YL, Ng HK, Leung SY, Fong KY. Vascular pseudoparkinsonism. Acta Neurol Scand 1992; 86(6):588-592. 
3. Demirkiran M, Bozdemir H, Sarica Y. Vascular parkinsonism: a disrincr, hererogeneous clinical entiry. Acta Neurol Scand 2001; 104(2):63-67.

4. FirzGerald PM, Jankovic J. Lower body parkinsonism: evidence for vascular etiology. Mov Disord 1989; 4(3):249-260.

5. Jankovic J. Lower body (vascular) parkinsonism. Arch Neurol 1990; 47(7):728.

6. Peters S. Eising EG, Prauntek $H_{n}$ Muller T. Vascular Parkinsonism: a case report and rewiew of the literature. J Clin Neurosci $2001 ; 8(3): 268-271$.

7. Sibon I, Eenelon G, Quinn NP, Tison F. Vascular parkinsonism. J Neurol 2004; 251(5):513-524.

8. Thompson PD, Marsden CD. Gait disorder of subcortical arteriosclerotic encephalopathy: Binswanger's disease. Mov Disord 1987; 2(1):1-8.

9. Leong LK, O'Connor MK, Maraganore DM. Quantification of Lodine-123- $\beta$-CIT Dopamine Receptor Uptake in a Phantom Model. J of Nucl Med Tech 1999; 27:117-122.

10. Tolosa ES, Santamaria J. Parkinsonism and basal ganglia infarcrs. Neurology 1984; 34:1516-1518.

11. van Zagten M, Lodder J, Kessels F, Gair disorder and parkinsonian signs in patients with stroke relared to small deep infarcts and white matter lesions. Mov Disord 1998; 13(1):89 95.

12. Zijlmans JC, Poels PJ, Duysens J, van der Straaten J Thien T, van't Hof MA, er al. Quantirative gait analysis in patients with vascular parkinsonism. Mov Disord 1996; 11.(5):501508.

13. Foltynie $T$, Barker $R, B$ rayne $C$. Vascular parkinsonism: a review of the precision and Frequency of the diagnosis. Neuroepidemiology $2002 ; 21(1): 1-7$.

14. Sibon I, Tison F. Vascular parkinsonism. Curr Opin Neurol 2004; 17(1):49-54.

15. Zijlmans JC, Daniel SE, Hughes AJ, Revesz "T, Lees AJ. Clinicoparhological investigation of vascular parkinsonism, including clinical criteria for diagnosis. Mov Disord 2004; 19(6):630-640.

16. Zijllmans JC, Thijssen HO, Vogels OJ, Kremer HP, Poels PJ, Schoonderwaldt $H C$, et all. MRI in pacients with suspected vascular parkinsonism. Neurology 1995; 45(12):21.832188.

17. Boon A, Lodder J, Heuts-van Raak L, Kessels F. Silent brain infarcts in 755 consecutive parients with a first-ewer supratentorial ischemic stroke. Relarionship with index-stroke subtype, vascular risk factors, and morraliry. Stroke 1994; 25(12):2384-2390.

18. Gerschlager W, Bencsirs G, Pirker W, Bloem BR, Asenbaum S, Prayer D, er al. [123]]betaCIT SPECT distinguishes vascular parkinsonism from Parkinson's disease. Mov Disord $2002 ; 17(3): 518-523$

19. Tzen KY, Lu CS, Yen "TC, Wey SP, Ting G. Differential diagnosis of Parkinson's disease and vascular parkinsonism by $(99 \mathrm{~m})$ Tc-TRODAT-1. J Nucl Med 2001; 42(3):408-413.

20. Lorberboym M, Djaldetri R, Melamed $\mathbb{E}_{*}$ Sadeh $M$, Lampl Y. 123I-FP-CIT SPECT imaging of dopamine transporters in patients with cerebrovascular disease and clinical diagnosis of vascular parkinsonism. J Nucl Med 2004; 45(10):1688-1693.

21. Vamonde ], Ibanez R, Garcia AM, Poblete V. [Study of the pre and post-synaptic dopaminergic system by DATSCAN/IBZM SPECT in the differential diagnosis of parkinsonism in 75 patients]. Neurologia 2004; 19(6):292-300. 
22. Plotkin M, Amthater $H$, Quill S, Marzinzik F, Klostermann F, KlaPke S, er al I maging of dopamine rransporters and D2 receptors in vascular parkinsonism: a report of four cases. I Neural Transm 2005.

23. Hachinski VC, Porter P, Merskey H. Leuko-araiosis. Arch Neurol 1987; 44:21-23.

24. Fahn S, Elron R, comittee MorUd. Unified Parkinson's disease rating sale. In: Fahn S, Marsden CD, Calne DB, Goldstein M, edirors. Recent development in Parkinson's disease. Florham Park: McMillan Health Care Information; 1987. p. 153-163.

25. Booij J, Habraken JB, Bergmans P. Tissingh $G$, Winogrodzka A, Wolters EC, at al. Imaging of dopamine transporters with iodine-123-FP-CIT SPECT in healthy controls and patients with Parkinson's disease. I Nucl Med 1998; 39(11):1879-1884.

26. Booij J. Hemelaar TG, Speelman JD, de Bruin K, Janssen AG, van Royen EA. One-day protocol for imaging of the nigrostriatal dopaminergic pathway in Parkinson's disease by [123]]FPCIT SPECT. ] Nud Med 1999; 40(5):753-761.

27. Booij J, "Tissingh $G$, Winogrodzka A. Boer GI, Stoof $\mathbb{C}$, Wolters EC, ex al. Practical benefit of $[123 \mathrm{JFP}-\mathrm{CIT}$ SPET in the demonstration of the dopaminergic deficit in Parkinson's disease. Eur J Nucl Med 1997; 24(1):68-71.

28. Yamanouchi $H, N a g u r a H$. Neurological signsand frontal white matter lesions in vascular parkinsonism. A clinicopathologic study. Stroke 1997; 28(5):965-969.

29. Zijlmans JC, Karzenschlager R, Daniel SE, Lees AJ. The L-dopa response in vascular parkinsonism. J Neurol Neurosurg Psychiarry 2004; 75(4):545-547.

30. Tissingh $G$, Booii J, Winogrodzka $A$, van Royen EA, Wolters EC. IBZM-and CITSPECT of the dopaminergic system in parkinsonism. I Neural Transm Suppl 1997 ; 50:31-37.

31. Schwarz J, Tatsch K, Arnold G, Otr M. Trenkwalder C, Kirsch CM, et al. 123Iiodobenzamide-SPECT in 83 parients with de novo parkinsonism. Neurology 1993; 43(12 Suppl 6): $\$ 17-20$.

32. Alexander GE. Basal ganglia-thalamocortical circuits: their role in control of movements. I Clin Neurophysiol 1994; 11(4):420-431.

33. Alexander GE, Crutcher MD. Functional archiccture of basal ganglia circuits: neural substrates of parallel processing. Trends Neurosci 1990; 13(7):266-271.

34. Nieuwenhuys R, Voogd ], van Huijzen C. The human central nervous system. A synopsis and atlas. Berlin: Springer Verlag; 1988.

35. Booij J, Tissingh $G_{x}$ Winogrodzka $A$, wan Rayen EA. Inaging of the dopaminergic neurotransmission system using single-photon emission tomography and positron emission tomography in patients with parkinsonism. Eur] Nucl Med 1999;26(2):171-182.

36. Korten AGGC, Younis IHAA, Kroonenburgh MJPGv, Lodder J, Vreeling FW, Weber WEJ. Frontal lobe hyperperfusion in wascular parkinsonism patients. Submitted 2005. 

CHAPTER 6

Stroke and idiopathic Parkinson's disease: does a shortage of dopamine offer protection against stroke?

Arthur Korten MD; Jan Lodder MD, PhD; Fred Vreeling MD, PhD; Anita Boreas MD, PhD; Lisetre wan Raak MD, PhD; Fons Kessels MD, $\mathrm{MSc}$.

Movement Disorders 2001(16);119-123. 


\section{ABSTRACT}

Background. Data on the relation between idiopathic Parkinson's disease (IPD) and stroke are conflicting. In this study, we examined the frequency of IPD in stroke patients registered in the Maastricht Stroke Registry.

Methods and results. With three different search strategies, we found among a total of 1516 stroke patients eight individuals with IPD. Based on IPD prevalence figures from a Dutch population-based study, we suspected to find approximarely 30 IPD patients (relative risk $0.27 ; 95 \%$ confidence interval $0.11-0.53$ ).

Conclusions. We speculate that dopamine deficiency may protect against ischaemic brain damage, perhaps by reducing effects of excirotoxicity. 


\section{INTRODUCTION}

Data on the relation between idiopathic Parkinson's disease (IPD) and stroke are conflicting. Stroke related mortality in IPD patients is 1,5 and 3,6 times higher in studies of Gorell et al. and Ben-Shlomo [1,2]. Iwasaki et al. found no difference in stroke related mortality berween IPD patients and the general population [3].

Incidence of cerebrovascular disease as comobidity in IPD is increased to $27 \%$ in one study [4] compared to controls, whereas in another study it is decreased [5].

Experimental data indicate that under ischaemical conditions dopamine may act as a neurotoxic agent [6]. From these data one may hypothesize that shortage of dopamine may protect the brain from excitotoxic damage in case of vascular insufficiency or stroke. If so, this may imply a lower risk of stroke or less severe stroke in IPD patients. To verify or reject this idea would require a long term follow-up in a large number of IPD patients in comparison with controls, which would be a major and expensive endeavour. If IPD and stroke are inversely related, we would expect to find fewer IPD patients among a cohort of stroke patients than expected from population-based prevalence. In the present study, we made such comparison.

\section{METHODS}

Patients had been registered at the University Hospital of Maastricht in a prospective registry of all patients, regardless whether they were admitted to the hospital or visited the out-patient clinic, with a first-ever ischaemic supratentorial stroke with symptoms lasting longer than 24 hours: the Maastricht Stroke Registry (MSR). The University Hospital is the only hospital in the Maastricht region with an adherent population of approximately 190.000 people. Routine investigations included standard blood tests, electrocardiogram, chest X-ray, CT scan of the brain, and ultra- 
sound carotid studies. Echocardiography, 24-hour ECG monitoring, and cerebral angiography were done in selected cases $[7,8]$. In the periods 1987-1992 and 1996-1998 of our registry, extensive information was available on comorbidity, previous history and medication use.

The MSR is a registration of baseline data for facilitation of further studies. Two separate studies especially provided data on medication use. As medication is not regularly stored in the database, we used the available data of these two studies, performed in two different periods since we required medication use as a screening parameter to identify IPD patients.

The completeness of data in the MSR was studied previously [9]. Incidence rates for stroke, first ever stroke and cerebral infarction were compared to data from the "Tilburg Epidemiological Study of Stroke 19781981 " [10] and a population based study in France [11], concluding that up to $98 \%$ of all patients was registered.

We used various ways to identify idiopathic Parkinson's disease in our registered stroke patients. First, we screened all patients on a listed diagnosis of IPD in the stroke registry. Second, we screened the stroke data base on patients using antiparkinsonian medication. Finally, we compared the stroke data base with the data base of patients with Parkinson's disease, to identify stroke patients with Parkinson's disease who were not using antiparkinsonian medication and had not been recorded as such in the stroke registry.

For the purpose of this study, the following patient characteristics were listed: age at stroke, gender, year of diagnosis of IPD and of stroke, stroke symptoms, CT findings, comorbidity, vascular risk factors, Rankin score on admission and IPD symptoms.

Dutch IPD prevalence figures were available from the Rotterdam Study [12]. In this population-based cohort study, participants had been asked about a previous diagnosis of Parkinson's disease and the use of antiparkinsonian medication. In addition, every patient had been examined neurologically for cardinal signs of parkinsonism. As the Rotterdam and Maastricht population composition are quite similar with respect to age, 
we assumed prevalence rates of IPD to be similar (Central Statistical Bureau, The Netherlands, 1999).

\section{Definitions}

Lacunar strake was defined as an acute symptomatic stroke syndrome with a CT lesion compatible with occlusion of a single perforating artery, i.e., a small, subcortical, sharply marginated hypodense lesion with a diameter smaller than $15 \mathrm{~mm}$ (small deep infarct), or in case of a specific lacunar syndrome (unilateral motor and/or sensory symptoms and signs that completely involve at least 2 of 3 body parts (face, arm and leg) without disturbance of consciousness or language, visual field defect or other signs of cortical dysfunction) when the CT scan showed no specific lesion.

Territorial stroke was defined (1) as an acute stroke syndrome with CT findings compatible with infarction involving the cortex, or (2) when no specific lesion was visible on CT, as clinically identified cortical syndrome consisting of unilateral motor and/or sensory symptoms and signs in combination with signs of cortical dysfunction with or without visual field defect, or as incomplete involvement of two body parts, or as isolated monoparesis, or as isolated cortical dysfunction (usually dysphasia). White matter lesions (WML's) were defined as focal or diffuse hypodensities in the periventricular or deep white matter, not involving the cortex, and with ill-defined margins to distinguish them from infarction $[13,14,15]$.

Clinical diagnosis of Parkinson's disease was made according to the UK Parkinson's Disease Society Brain Bank (UKPDSBB) criteria. Key symptom in the diagnosis of parkinsonism is the presence of bradykinesia. Bradykinesia is defined as slowness of initiation of voluntary movements with progressive reduction in speed and amplitude of repetitive actions. Apart from bradykinesia, at least one of the following symptoms has to be present: muscular rigidity, 4-6Herz resting tremor, or postural instability not caused by primary visual, vestibular, cerebellar or proprioceptivedys- 
function. For the clinical diagnosis of Parkinson's disease UKPDSBB criteria give supportive positive criteria and exclusion criteria [16].

\section{RESULTS}

In the period 1987-1992, data on 816 first ever ischaemic strokes had been collected and on 700 patients in the period from 1996 to 1998 . Among these 1516 patients, we identified eight subjects with IPD; six were found in the combined search in our stroke database on IPD and use of antiparkinsonian medication. These 6 patients all used antiparkinsonian medication. Two patients were found after comparing our stroke data base with the IPD data base. Information on all patients is summarized in table 1 . There were five men and three women. Age ranged from 57 to 83 years (median 73 years). Time between diagnosis of IPD and first ever stroke ranged from 6 months to 19 years (median 5 years). Three of the eight IPD patients were smokers. At the moment of stroke occurrence, one IPD patient was in Hoehn and Yahr stage I, two in stage II, three in III, and two in IV. On brain CT following stroke, two patients had a lacunar infarct, three had white matter lesions, two had a territorial infarct, whereas one patient had no ischaemic lesion on CT. All patients used antiparkinsonian medication : levodopa (6), dopamine agonist (1), and amantadine in combination with selegeline (1). On admission, four patients of our series had a Rankin score between 0 and 3 , whereas the remaining four patients had a score of 4 or 5 . Among the 1516 patients in the stroke registry, 50 percent had a Rankin score on admission between 0 and 3 , and 50 percent had a score of 4 or 5 . Table 2 shows the frequency of IPD in different age groups of our stroke patients in comparison with the population-based Rotterdam cohort. On the basis of this study, we expected to find 30 patients in our population, whereas we found only 8 patients (relative risk $0.27 ; 95 \%$ confidence interval $0.11-0.53$ ). 


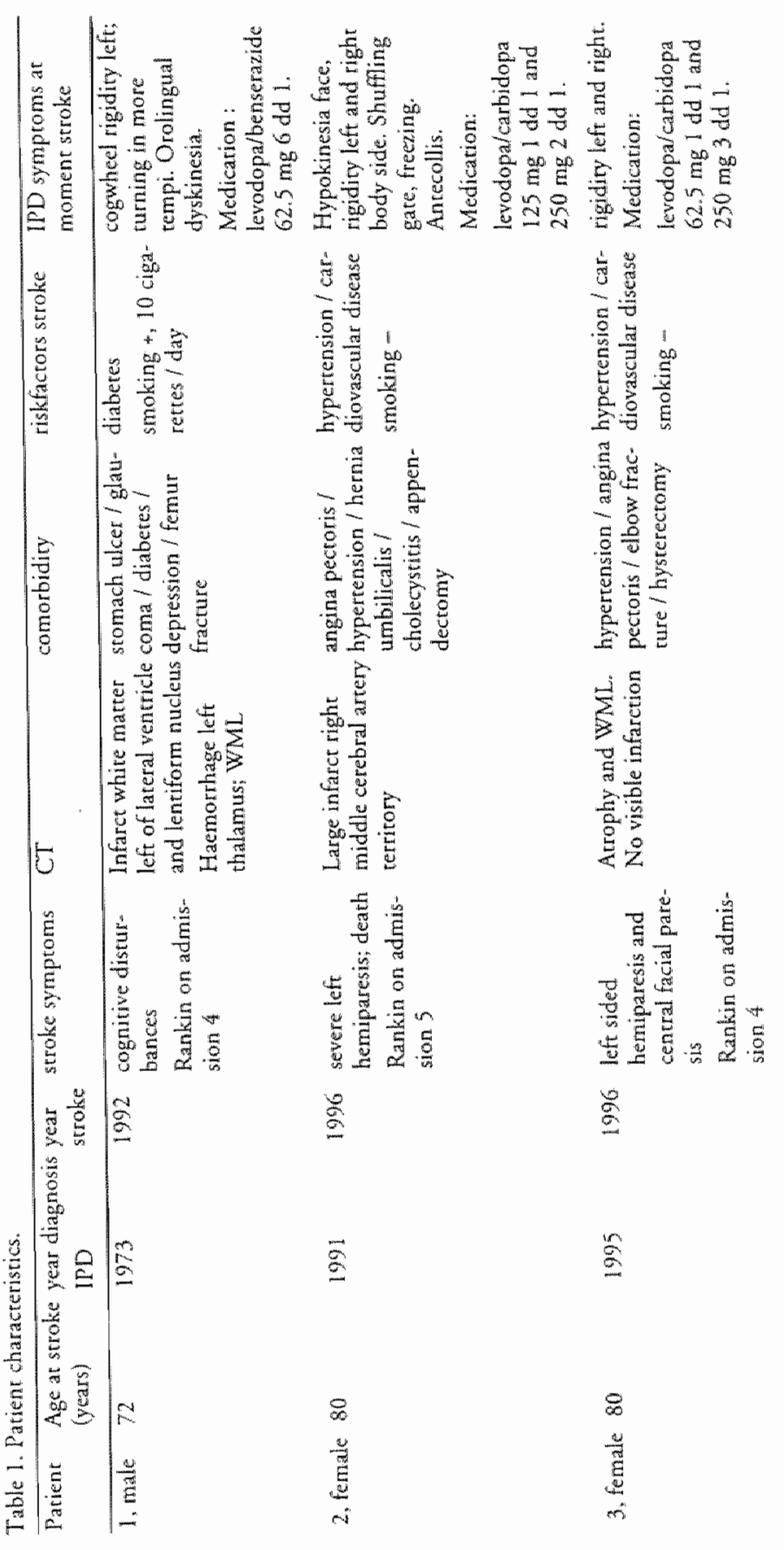


CHAPTER 6

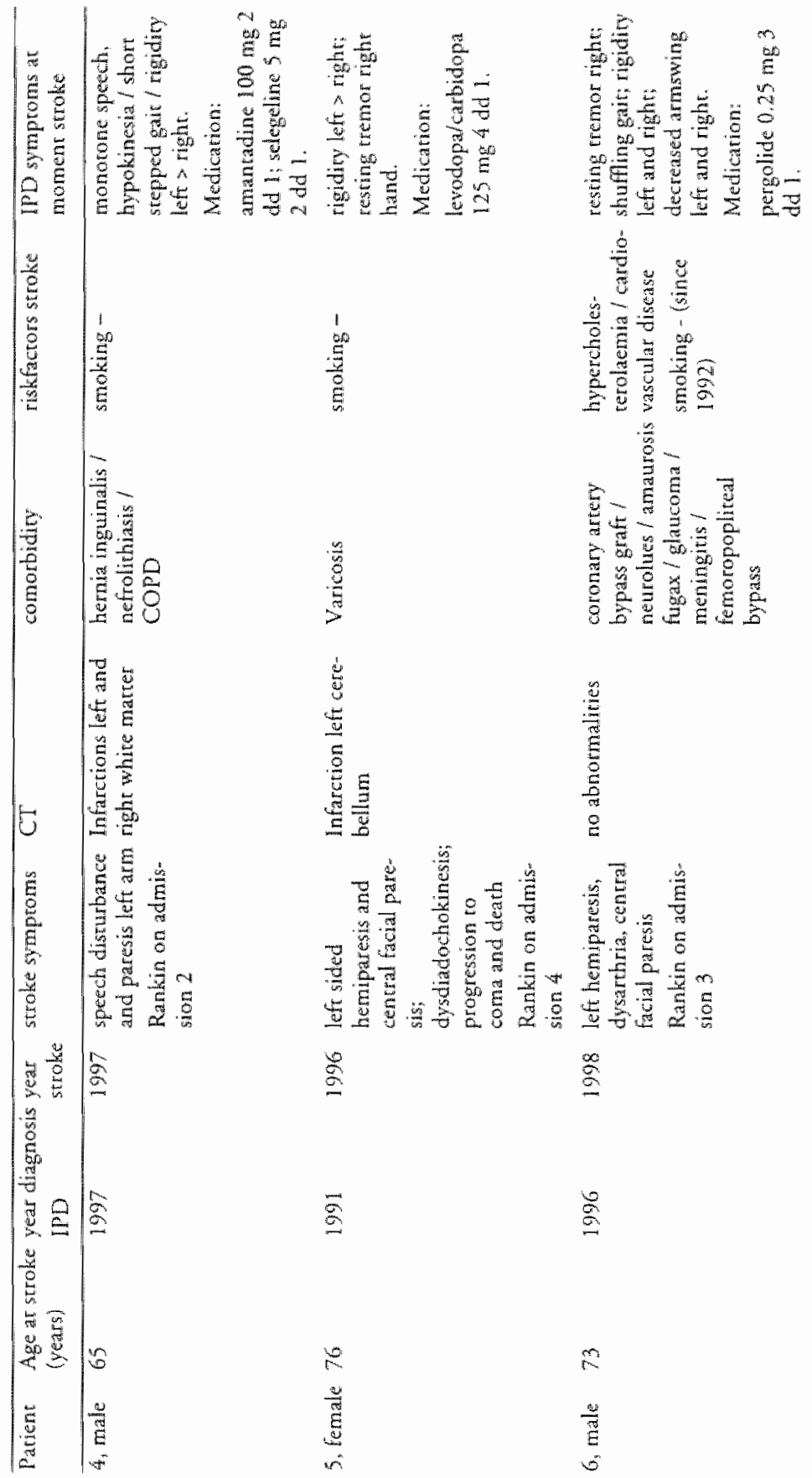


Stroke and idiopathic Parkinson's disease

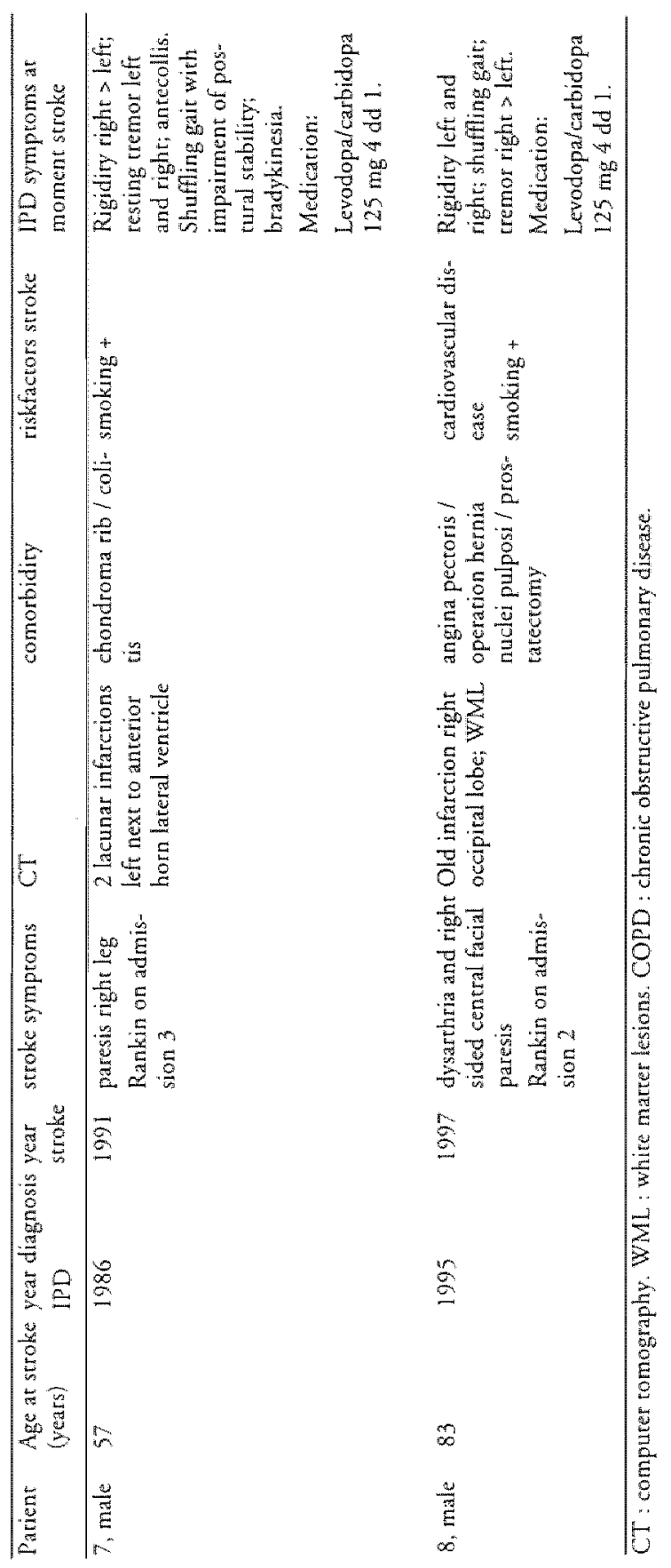


Table 2. Prevalence estimates of idiopathic Parkinson's disease (IPD) in stroke parients and general population.

\begin{tabular}{llllll}
\hline Age & Patients & IPD & IPD & $\begin{array}{l}\text { prevalence IPD } \\
\text { stroke patients }\end{array}$ & $\begin{array}{l}\text { prevalence IPD } \\
\text { general population } \\
(\%)\end{array}$ \\
\hline$<55$ & 164 & N observed & N expected & $(\%)$ & 0 \\
$55-64$ & 219 & 1 & 0 & 0 & 0.3 \\
$65-74$ & 489 & 3 & 1 & 0.5 & 1.0 \\
$75-84$ & 462 & 3 & 16 & 0.6 & 3.1 \\
$\geq 85$ & 182 & 1 & 8 & 0.7 & 4.3 \\
& & & & & \\
\hline
\end{tabular}

* relarive risk 0,$27 ; 95 \%$ confidence incerval $0,11-0,53$.

\section{DISCUSSION}

To our knowledge, our study is the first on the prevalence of IPD in a prospectively registered stroke series. We observed that the prevalence of Parkinson's disease was significantly lower in our patients than expected from general population prevalence estimates.

However, it has to be kept in mind that the number of IPD patients in our stroke series was small. Our study compares prevalence of IPD in a stroke population with that in a general population. Most other studies [1-5] were concerned with stroke related mortality and morbidity in IPD population. Therefore, it is not possible co compare these studies directly with our findings.

A low prevalence of IPD in a stroke population may be due to bias from an increased early death rate related to stroke. However, we looked for IPD diagnosis that had been made prior to a first-ever faral or non-fatal stroke, which excludes such bias. Our findings concur with the idea that dopamine deficiency may protect against stroke. In experimental models, dopamine increases excitotoxic ischaemic damage, whereas dopamine antagonists ameliorate such effect $[6,17]$. Whether an even small decreased stroke risk in IPD patients is duse to amelioration of ischaemia 
related excitotoxic effects, remains unclear; when we used the Rankin score as an indication of stroke severity, our eight IPD patients did not have less severe stroke than the non-IPD stroke patients. Based on our findings and experimental data, one may hypothesize that treatment with levodopa may increase the risk of stroke, stroke severity or both. Furthermore, levodopa may increase plasma homocysteine levels and may thereby contribute to an increased stroke risk $[18,19]$. On the other hand, levodopa may lower blood pressure and thus decrease stroke risk [20,21]. Our findings may also relate to a differential effect of smoking. Clinical epidemiological studies suggest a protective effect on IPD occurrence by smoking [22]. There is experimental evidence that relates growth factor (fibroblast growth factor-2, and brain derived neurotrophic factor) upregulation in the striatum to nicotine stimulation [23]. Therefore, smoking may increase the risk of stroke while decreasing the risk of IPD. Any stroke risk in IPD patients could also be lower than generally expected, as fewer IPD patients smoke than those who ultimately suffer a stroke [22]. A meta-analysis showed that cigarette smoking doubled the risk of stroke [24]. Wether such increased stroke risk alone explains our findings of a four times decreased risk, is unclear. A lower stroke risk in IPD patients cannot be inferred from our findings, as this would require a large, prospective long-term follow-up study. However, our data concur with the idea that dopamine deficiency may protect against the occurrence of ischaemic stroke, and against excitotoxic-ischaemic brain damage.

\section{REFERENCES}

1. Gorell JM, Johnson CC, Rybicki BA. Parkinson's disease and it's comorbid disorders: analysis of Michigan morraliry data, 1970 to 1990. Neurology 1994(44):1865-1868.

2. Ben-Shlomo Y, Marmot MG. Survival and cause of death in a cohort of parients with parkinsonism: possible dues co eriology? J Neurol Neurosurg Psychiarry 1995(58):293299. 
3. Iwasaki S, Narabayashi Y, Hamaguchi K, Iwasaki A, Takakusagi M. Cause of deach among parients wirh Parkinson"s disease: a rare mortaliry due to cerebral haemorrhage. I Neurol $1990(237): 77.79$.

4. Horner $\mathrm{S}$. Niederkom $\mathrm{K}$, Ni XS ex al. Evaluation of vascular risk factors in parients with Parkinson syndrome. Neryenarzt 1997 (68):967-97).

5. Struck LK, Rodnizky RL, Dobson JK. Stroke and its modificarion in Parkinson's disease. Sroke 1990(21):1395-1399.

6. Lotharius J, Dugan LL, OMalley KL. Distinct mechanisms underlie ncuro-toxin mediated cell death in cultured dopaminergic neurons. J Neurosci 1999(19):1284-1293.

7. Boon A, Lodder ], Heuts-van Raak L, Kessels F. Silent brain infarces in 755 consecutive parients: with a first-ever supratentorial ischemic stroke: Relarionship with index-stroke subrype, vascular risk factors, and mortality. Sroke 1994(25):2384-2390.

8. Van Zagren M, Boiten J, Kessels F, Lodder J. Significant progression of white marter lesions and small deep (lacumar) brain infarces in patients with stroke. Arch Neurol $1996(53): 650-655$.

9. Heurs-van Raak L. Denrographic dereminants of occurrence and prognosis of epileptic seizures following a first-ever supratentorial brain infarct. Data from an ongoing prospective register. In: Heuts-van Raak L. Seizures following a first cerebral infarct. Risk factors and prognosis. Maascricht thesis Rifksunversiteit Limburg, 1996:25-47.

10. Herman B, Leyten ACM, Luyk JH van, Frenken CWGM, Op de Coul AAW, Schulte BPM. Epidemiology of stroke in Tilburg. The Nerherlands. The population-based sroke incidence register: 2 Incidence, inirial dinical picture and medical care, and three-week case facaliry. Stroke 1982(13):629-634.

11. Ginoud M, Beuriac P, Vion P, D'Athis PH, Dusserre L, Dumas R. Stroke in a French prospective population study. Neuroepiderniology 1989(8):97-104.

12. Rijk MC de, Breteler MMB, Graveland GA, Otr A, Grobbee DE Meche FGA van der, Hofman A. Prevalence of Parkinson's disease in the elderly. The Rotterdam Study. Neurology 1995(45):2143-2146.

13. Boiren J, Lodder J. Isolated monoparesis is usually caused by superficial infaretion. Cerebrowasc Dis 1991(1):337-340.

14. Boiten ], Lodder J. Large striatocapsular in farcers: clinical presencation and pathogenesis in comparison wirh lacunar and cortical infarcs. Acta Neurol Scand 1992(86):298-303.

15. Steingart A, Hachinski VC, Lau Cetal. Cognirive and neurologic findings in subjecrs with diffuse white mater lucencies on computed tomography scan (leuco-araiosis). Arch Neurol 1987(44):32-35.

16. Hughes AJ. Danicl SE, Killerd L, Lees AJ. Accuracy of clinical diagnosis of idiopachic Parkinson"s disease: Aclinicomparhological scudy of 100 cases. INeurol Neurosurg Psychiatry 1992(55):181-184.

17. Jacobsson SO, Fowler CJ. Dopanine and glutamate neurotoxicity in cultured chick relencephali cells: effects of NMDA antagonists, antioxidants and MAO inhibitors. Neurochem Int 1999(34):49-62.

18. Miiller T, Werne B, Fowler B. Kuhn W. Nigral endorhelial dysfunction, homocysteine, and Parkinson's disease. Lancet 1999(354): 126-127. 
19. Kuhn W, Roebroek $\mathbb{R}$, Blom $H$. Elevated plasma levels of homocysteine in Putinson's disease. Eur Neurol 1998(40):225-227.

20. Clark BJ. The role of dopamine in the periphery. In: Flückiger $\mathbb{E}$, Müller $\mathbb{E}$, Thomer MO, eds. The dopaminergic system. Springer Verlag, Berlin 1985.

21. Iwasaki S, Hamaguchi K, Iwasaki A, Takakusagi M, Narabayashi Y. Hyporensive effect of long-term levo-dopa in patients with Parkinson's disease. Eur Neurol 1990(30): 194-199.

22. Marmor MG. Smoking and Parkinson's disease. In: Wald N, Baron J, eds. Smoking and hormone relared disorders. New York: Oxford Universicy Press: 1990:135-141.

23. Maggio R, Riva $M$, Vaglini F e al.. Nicotine prevents experimental parkinsonism in rodents and induces striatal increase of neurotrophic factors. J Neurochem $1998(71): 2439 \cdot 2446$.

24. Shinton $\mathrm{R}$, Beevers $\mathrm{G}$. Meta-analysis of relation between cigarette smoking and stroke. BMJ $1989(298): 789-794$. 


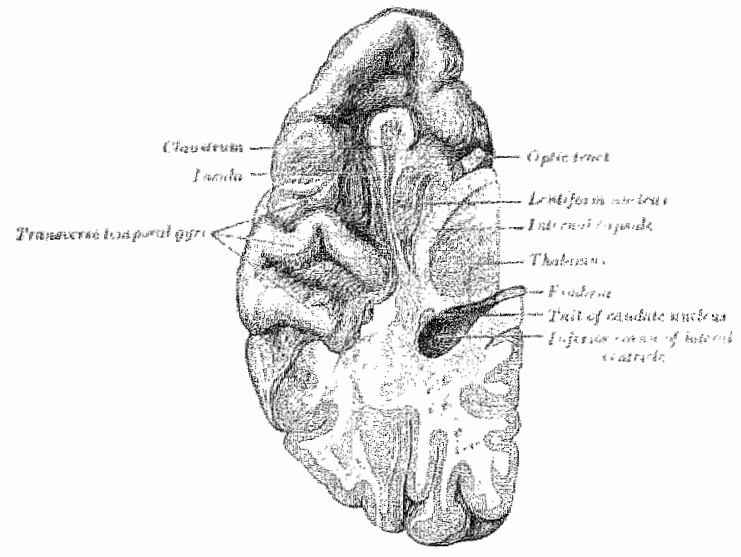

Zur Burg fubrt die Briucke, leicht, doch fest eurem Fuss; beschreitet kühn ibren schrecklosen Pfad!

Richard Wagner, Das Rheingold Figure taken from Gray's Anatowy, 1918 


\section{General discussion}

Parkinsonism is a distinct clinical syndrome defined by the United Kingdom Parkinson's Disease Brain Bank criteria [1-3]. The diagnosis of the presence of individual symptoms and of a complete parkinsonian syndrome is primarily made on clinical grounds. Bradykinesia has to be present in combination with tremor and/or rigidity and/or postural instability. Causes of the parkinsonian syndrome are numerous. The most frequent one is idiopathic Parkinson's disease. In an autopsy series of 700 patients with parkinsonism, $80.7 \%$ had pathological anatomical findings compatible with idioparhic Parkinson's disease [4].

There is sufficient evidence in the literature to regard cerebrovascular disease as an established cause of parkinsonism and parkinsonian symptoms: since Critchley's first description [5] of vascular parkinsonism (VP), this clinical concept has gained widespread acceptance. Most authors now agree on VP as a parkinsonian syndrome dominated by postural instability with shuffling gait and absence of tremor [6-15], occurring in 3-5\% of patients with parkinsonism $[16,17]$. Affected patients have vascular risk factors, often hypertension, and/or suffered one or more strokes, usually of the lacunar type [6, 9-14, 16-19].

Cerebrovascular abnormalities reported as a cause of parkinsonism and parkinsonian symptoms can be divided into three groups: Jacunar infarcts in basal ganglia and thalamus, lesions of suspected vascular origin in cerebral white matter (white matter lesions or leukoaraiosis [14,20]) and infarcts in the frontal brain region. Lacunar infarcts in strategic regions involving the extrapyramidal system can give rise to an acure parkinsonian syndrome clinically indistinguishable from idiopathic Par- 
kinson's disease: locations include mesencephalon [21], substantia nigra [22], the striatum [23], basal ganglia $[6,14,20,24,25]$.

In case of white marter lesions, patients suffer an insidious onset, where the relation of timing, location, and size of the lesions with the clinical syndrome is poorly understood $[11,17-19,26]$; clinically the gait disturbance predominates, resulting in "lower body parkinsonism". Frontal brain infarction causing parkinsonian signs is only seldomly reported, and is also primarily related to disturbances of leg motor function [2729]. Taken together, the exact spatial and temporal relation between the ischaemic lesions in vascular parkinsonism remains unclear. To tackle this issue we decided to assses parkinsonian symptoms in a cohort of firstever stroke patients.

In the previous chapters, we reported our findings in patients with parkinsonian symptoms after stroke. Already in the first two weeks after stroke, $4 \%$ of patients developed a complete parkinsonian syndrome. This incidence concurs with previously mentioned reports on incidence of vascular parkinsonism [16]. We also found a relation between these symptoms and white marter lesions (Chapter 1), as well as with asymptomatic infarcts in the supply area of the anterior choroidal artery (Chapter 3). Moreover, HMPAO SPECT showed abnormalities in perfusion of frontal brain regions in VP patients (Chapter 5).

The finding that parkinsonian symptoms relate to the presence of white matter lesions is of special interest. Already since the introduction of the terms subcortical arteriosclerotic encephalopathy or Binswanger's disease [30] and, later on, leukoaraiosis and white matter lesions [12,31], debate has been raging wether or not this radiological finding must be considered as a separate disease entity [32]. Although white matter lesions are seen in normal healthy persons, the strong association we and others found between these lesions and VP, suggests that these are not solely a radiological phenomenon, but must be considered as a separate disease entity.

The exact mechanism that causes parkinsonian symptoms after stroke is still unknown. Based on what we and others have found, we can offer the 
following speculations. Several of the deep nuclei of the brain are involved in the regulation of automatic movements: substantia nigra, thalamus, globus pallidus, nucleus caudarus and subthalamic nucleus. All these nuclei are connected through white matter tracts and influence each other excitatorily or inhibitorily by means of different neurotransmitters. In the past, this system of connected nuclei was called the extrapyramidal system to discern it from the pyramidal system involved in voluntary movement control (figure 1 a-e General Introduction). Currently, it is thought that the circuitry connecting nucle involved in automatic movement is more complex and primarily organized in parallel circuits [33]. Nevertheless, it is clear that both in the older concept of basal ganglia pathways and in the concept of parallel basal ganglia circuits, connecting white matter tracts are equally important as the nuclei themselves. So, lesions anywhere along connecting rracts and in the nuclei can distupt the system and henceforth cause disturbances in automatic movement with parkinsonian symptoms.

Cerebrovascular disease (ischaemia, haemorrhage and leukoaraiosis) can cause such lesions, involving the basal ganglia - frontal cortex projections $[12,25,34-37]$. This accords with the association we found with leukoaraiosis in VP patients, and more specifically with ischaemia in the supply area of the anterior choroidal artery [38]. Leukoaraiosis can interfere with output from the thalamus to the motor cortex, mainly supplementary motor area, thus reducing thalamocortical drive [39].

The anterior choroidal artery arises from the internal carotid artery. It supplies the choroid plexus in the inferior horn of the lateral ventricle, but also provides perforators penetrating the anterior perforating substance to reach the internal capsule and occasionally thalamus, lateral geniculate body, cerebral peduncle and optic tract [40]. Of the internal capsule, mainly the genu and posterior limb are supplied by the anterior choroidal artery. These parts contain corticobulbar and corticospinal tracts as well as corticostriate fibers (posterior limb) but also thalamocortical fibers (genu). Ischaemic lesions in the supply area of the anterior choroidal 
artery may thus influence cortical input to basal ganglia, but also output from thalamus to motor cortex.

As mentioned above, other studies relate parkinsonian symptoms to lacunar infarcts in external segment of globus pallidus, ventrolateral nucleus of the thalamus and substantia nigra resulting in reduced thalamocortical drive [18,39]. Frontal brain infarction is primarily related to disturbances of leg motor function as a result of involvement of leg motor area in the supply area of the anterior cerebral artery $[27,29]$.

Apart from direct disruption of connecting pathways or lesions in nuclei as described above, cerebrovascular disease may damage the extrapyramidal system through more remote mechanisms. Following stroke, secondary degenerative changes in the ipsilateral substantia nigra are seen as a result of excessive excitatory influences caused by loss of inhibitoy GABA input (transneuronal degeneration) [23]. Other studies report loss of mainly D1 receptors or less expression of subunits of acetylcholine receptors in the case of ischaemia-induced hypoxia or excitotoxicity $[41,42]$. Ischaemia can down-regulate parkin protein with increased sensitivity of dopaminergic neurons to endoplasmatic reticulum dysfunction and cell injury as a consequence [43]. Another link between parkinsonism and ischaemia is provided by research on adenosine $\mathrm{A} 2 \mathrm{~A}$ receptors: antagonists of these may relieve parkinsonian symptoms and protect against cerebral ischaemia [44], and are perhaps interesting therapeutic agents in VP.

Chapter 4 describes our IBZM and FP-CIT SPECT data on VP patients. Normal findings in both investigations suggest that neither dopamine deficiency nor loss of dopamine receptors play a key role in pathophysiology of parkinsonian symptoms after stroke. This finding does not concur with other studies demonstrating loss of dopamine receptors as a result of ischaemia. It theoretically contradicts the reported levodopa effects in VP patients [45], but it is also possible that FP-CIT SPECT is not a reliable predictor of clinical levodopa responsiveness [46]. Considering data from our study, but also from the literature, it is therefore justified in case of a clinical diagnosis of vascular parkinsonism 
to start a therapeutic trial with dopaminergic medication for a certain time period.

Finally, while speculating on the possible mechanisms underlying VP, one should not forget the burden to the patient: outcome after stroke is influenced by many factors: severity of neurological deficit, advanced age, cause of stroke, history of prior stroke and presence of concomitant disease as diabetes mellitus, cardiovascular disease, pulmonary disease and dementia [47]. In chapter 2 we found, in our cohort of 101 first-ever stroke parients, that the presence of parkinsonian symptoms in the acute phase after stroke negatively impacts prognosis, together with older age.

\section{CONCLUDING REMARKS}

Data presented in this thesis point out that parkinsonian symptoms are part of the extensive complex of symptoms that can result from acute stroke and negatively impact prognosis after 6 months. Lesions in connecting frontal white matter tracts are important in the pathophysiology of vascular parkinsonism, more than dopamine depletion or loss of dopamine receptors. The exact manner in which these lesions influence cerebral systems concerned with automatic movements is only in part known and has to be studied further. In particular, to further clarify the spatiotemporal relationship between the vascular lesion and the ensuing parkinsonism, a long-term cohort study on patients with cerebral small vessel disease must be undertaken.

\section{REFERENCES}

1. Hughes AJ. Daniel SE, Blankson S, Lees AJ. A clinicopathologic study of 100 cases of Parkinson's disease, Arch Neurol 1993; 50(2):140-148.

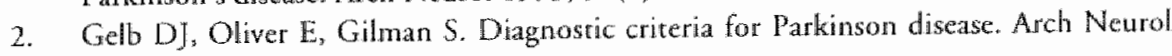
$1999 ; 56(1): 33-39$. 
3. Gibb WR, Lees AJ. The relevance of the Lewy body ro the pathogenesis of idiojathic Parkinson's disease. J Neurol Neurosurg Psychiatry 1988; 51(6):745-752.

4. Jellinger KA. Vascular parkinsonism-neuropahological findings. Acta Neurol Scand $2002 ; 105(5): 414-415$.

5. Critchley M. Arteriosclerotic parkinsonism. Brain 1929; 52:23-83.

6. Chang CM, Yu YL, Ng HK, Leung SY, Fong KY. Vascular pseudoparkinsonism. Acta Neurol Scand 1992; 86(6):588-592.

7. Demirkiran M, Bozdemir H, Sarica Y. Vascular parkinsonism: a distincr, heterogeneous clinical enticy. Acta Neurol Scand 2001; 104(2):63-67.

8. FitzGerald PM, Jankovic J. Lower body parkinsonism: evidence for vascular etiology. Mov Disord 1989; 4(3):249-260.

9. Jarkovic J. Lower body (vascular) parkinsonism. Arch Neurol 1990; 47(7):728.

10. Peters $S$, Eising $\mathbb{E G}$, Przuntek $H$, Muller T. Vascular Parkinsonism: a case report and review of the literature. J Clin Neurosci 200 l; 8(3):268-271.

11. Sibon I, Fenclon G, Quinn NP, Tison F. Vascular parkinsonism. I Neurol 2004; 251(5):513-524.

12. Thompson PD, Marsden CD. Gait disorder of subcortical arteriosclerotic encephalopathy: Binswanger's disease. Mov Disond 1987; 2(1):1-8.

13. Tolosa ES, Santamaria J. Parkinsonism and basal ganglia infarcts. Neurology 1984; 34:1516-1518.

14. van Zagten $\mathrm{M}$, Lodder J, Kessells $\mathrm{F}$. Gait disorder and parkinsonian signs in patients with stroke related to small deep infarcts and white matter lesions. Mov Disord 1998; 13(1):8995.

15. Zijlmans JC, Poels PJ, Duysens J, van der Straaten J, Thien T, wan' Hof MA, erall. Quantitative gait analysis in patients with vascular parkinsonism. Mov Disord 1996; 11(5):501508.

16. Foltynie T, Barker R, Brayne $C$. Vascular parkinsonism: a review of the precision and frequency of the diagnosis. Neuroepidemiology $2002 ; 21(1): 1-7$.

17. Sibon I, Tison F. Vascular parkinsonism. Curr Opin Neurol 2004; 17(1):49-54.

18. Zijlmans JC, Daniel SE, Hughes AJ, Reves\% T, Lees AJ. Clinicopathological investigation of vascular parkinsonisnn, including clinical criteria for diagnosis. Mov Disord 2004; 19(6):630-640.

19. Zijlmans JC, Thijssen HO, Vogels OJ, Kremer HP, Poels PA, Schoonderwalde HC, et al. MRI in parients with suspected vascular parkinsonism. Neurology 1995; 45(12):21832188.

20. Hachinski VC, Potter P. Merskey H. Leuko-araiosis. Arch Neurol 1987; 44:21-23.

21. De la Fuente Fernandex R, Lopez JM, Rey del Corral P, De la Iglesia Martinez F. Peduncular hallucinosis and right hemiparkinsonism caused by left mesencephalic infarction. J Neurol Neurosurg Psychiatry 1994:57:870.

22. Hunter R, Smith J, Thomson T, Dayan AD. Hemiparkinsonism with infarction of the ipsilateral substantia nigra. Appl Neurobiol 1978; 4:297-301.

23. Nakane $M$, Teraoka A, Asato $R$, Tamura A. Degeneration of the ipsilateral substantia nigra following cerebral infarcrion in the striatum. Sroke $1991 ; 23: 328-332$. 
24. Bhatia KP. Marsden CD. The behavioural and moror consequences of focal lesions of the basal ganglia in man. Brain 1994: 1.17:859-876.

25. Reider-Groswasser 1, Bornstein N, Korcsyn A. Parkinsonism in parients with lacunar infarets of the basal ganglia. Eur Neurol 1995; 35:46-49.

26. Boon A, Lodder ], Heuts-van Raak L, Kessels E. Silent brain infarcts in 755 consecurive patients with a first-ever supratentorial ischemic stroke. Relationship with index-stroke subcype, vascular rusk factors, and morality. Stroke 1994: 25(12):2384-2390.

27. Kin JS. Involuntary movements after anterior cerebral artery territory infarcion. Stroke $2001 ; 32(1): 258-261$.

28. Sibon I, Rajabally $\mathrm{X}$, Tison F. Parkinsonism as a result of a giant aneurysm. Mov Disord 1999; 14(1):159-161.

29. Tuzun E. Anterior choroidal artery territory infarcrion: a case report and review. Arch Med Res 1998; 29:83-87.

30. Mast H, Tatemichi TK, Mohr JP. Chronic brain ischemia: the contributions of Otto Binswanger and Alois Alzheimer to the mechanisms of vascular dementia. J Neurol Sci $1995 ; 132(1): 4-10$.

31. Shyu WC, Lin JC, Shen CC, Hsu YD, Lee CC, Shiah IS, et al. Vascular dementia of Binswanger's type: clinical, neuroradiological and $99 \mathrm{mTC-HMPAO} \mathrm{SPET}$ study. Eur ] Nucl Med 1996; 23(10):1338-1344.

32. Pantoni L. Garcia JH. The significance of cerebral white matter abnomalities 100 years after Binswanger's report. A review. Srroke 1995; 26(7):1293-1301.

33. Abe K, Terakawa $H$, "Takanashi $M$, Watanabe $X$, Tanaka $H$, Fujita $N$, et al. Proton magnetic resonance spectroscopy of parients with parkinsonism. Brain Res Bull 2000; 52(6): $589-595$

34. Bennet D, Gilley D, Wilson B, Huckman M, Fox J. Clinical correlates of high signal lesions on magneric resonance imaging in Alzheimer's disease. J Neurol 1,992; 239:186190.

35. Briley D, Wasay M, Sergent $S$, Thomas $S$. Cerebral white matter changes (leuthoaraiosis), stroke and gait disturbance. I Am Geriatr Soe 1997: 45:1434-1438.

36. Masdeu J, Wolfson L, Lancos G. Grober E, Whipple R. Brain white matter changes in the elderly prone to falling. Arch Neurol 1989; 46:1292-1296.

37. Winikares J, Jankovic J. Clinical correlates of wascular parkinsonism. Arch Neurol 1999; 56(1):98-102.

38. Korten AGGC, Weber WEJ, Vreeling FW, Boreas AMHP, Kessels AF, Ladder J. Neurotadiologic correlates of parkinsonian signs in 83 first-ever stroke parients. Submitted for publication 2005.

39. Wichmann T., DeLong MR. Functional and pathophysiological models of the basal ganglia. Curr Opin Neurobiol 1996; 6(6):751-758.

40. Day AL. Arterial distributions and variants. In: Wood JH, editor. Cerebral blood flow. Physiologic and dinical aspects. New York: McGraw-Hill Company; 1987. p. 19-36.

41. Tohgi H, Utsugisawa $K$, Yoshimura M, Nagane Y, Mihara M. Alrerations with aging and ischemia in nicotinic acerylcholine receptor subunits alpha4 and beta2 messenger RNA expression in postmortem human putamen. Implications for susceptibility to parkinsonism. Brain Res 1998; 791(1-2):186-190. 
42. Tohgi $\mathbb{H}$, Utsugisawa K, Yoshimura M, Yamagata M, Nagane $Y$, Sairoh K. Reducrion in the ratio of beta-preprotachykinin to prepromkephalin messenger RNA expression in postmortem human putamen during aging and in parients with status lacunaris. Implicat wons for the susceptibility to parkinsonism. Brain Res 1997; 768(1-2):86-90.

43. Mengesdorf $T$, Jensen $P H$, Mies $G$, Aufenberg $C$, Paschen W. Down-regulation of parkin protein in transient focal cerebral ischemia: A link between stroke and degenerative discase? Proc Natl Acad Sci U S A 2002; 99(23):15042-15047.

44. Ongini E, Adami M, Ferri C, Bertorelli R. Adenosine A2A receptors and neuroprotection. Ann NY Acad Sci 1997; 825:30-48.

45. Zijlmans JC, Karzensclalager R, Daniel SE, Lees AJ. The L-dopa response in vascular parkinsonism. J Neurol Neurosurg Psychiarry 2004; 75(4):545-547.

46. Lorberboym M, Djaldeti R, Melamed E, Sadeh M, Lampl Y. 123I-FP-CTT SPECT imaging of dopamine transporters in patients with cerebrovascular disease and clinical diagnosis of wascular parkinsonism. J Nucl Med 2004; 45(10):1688-1.693.

47. Adams HP, Hachinski VC. Norris JW. Introduction to ischemic cerebrovascular disease. In: Adams HP, Hachinski VC, Norris JW, edirors. Ischemic vascular disease. New York: Oxford University Press; 2001 . p. 1-28. 


\section{Samenvatting}

Parkinsonisme is een klinisch beeld met als belangrijkste symptomen bradykinesie, rigiditeit, tremor en houdingsinstabiliteit. Veel verschillende ziekten kunnen parkinsonisme veroorzaken. Meest bekend is ongetwijfeld de ziekte van Parkinson zelf: parkinsonisme ontstaat hierbij door degeneratie van dopamine producerende cellen in de substantia nigra.

"Cerebrovasculair accident" (CVA) of "beroerte" zijn verzameltermen voor neurologische ziektebeelden ten gevolge van afwijkingen van de cerebrale vaten: het herseninfarct en de hersenbloeding. Ofschoon de klinische en radiologische presentatie van deze twee vormen van CVA verschillen, is er een duidelijk pathofysiologisch verband. Beiden worden veroorzaakt door atherosclerose danwel arteriolosclerose van de bloedvatwand. Bekende symptomen van een CVA zijn onder andere afasie, hemihypaesthesie en hemiparese door schade in het "pyramidale systeem". Minder bekend is dat ten gevolge van een CVA ook functiestoornissen van het zogenaamde "extrapyramidale systeem" kunnen ontstaan met parkinsonsymptomen tor gevolg. Het CVA hoort dus ook thuis in de lijst van mogelijke oorzaken van parkinsonisme. In dit proefschrift worden de resultaten beschreven van onderzoek naar voorkomen en pathofysiologie van parkinsonisme na een CVA. In de inleiding worden allereerst de achtergronden beschreven van het cerebrovasculair accident enerzijds en parkinsonisme anderzijds. Vervolgens wordt een overzicht gegeven van resulltaten van ander onderzoek naar parkinsonsymptomen ten gevolge van een CVA. Parkinsonisme en parkinsonsymptomen worden gerapporteerd als gevolg van strategisch in de basale ganglia gelokaliseerde lacunaire infarcten. Deze vorm van 
parkinsonisme na een CVA ontstaat vaak acuut en is klinisch moeilijk te onderscheiden van parkinsonisme ten gevolge van de ziekte van Parkinson.

Veel vaker ontwikkelt parkinsonisme zich sluipend en is met name de onderste lichaamshelft aangedaan: "lower body parkinsonism". Dit beeld wordt in de literatuur vooral beschreven bij vasculaire laesies in de cerebrale witte stof: leukoaraiose.

In hoofdstuk 1 worden de resultaten beschreven van een prospectief onderzoek naar het ontstaan van parkinsonsymptomen twee weken na een eerste CVA. Met name rigiditeit komt bij $30 \%$ van de patiënten voor en is gerelateerd aan het voorkomen van leukoaraiose op CT of MRI onderzoek van de hersenen. Mogelijk belemmeren deze laesies in de witte stof het normaal functioneren van het extrapyramidale systeem door beschadiging van verbindende baansystemen.

In hoofdstuk 2 wordt gerapporteerd over de patiënten van hoofdstuk 1, nu echter zes maanden na de beroerte. Aanwezigheid van parkinsonsymptomen op dit tijdstip is eveneens gerelateerd aan leukoaraiose en voorspelt bovendien toename van parkinsonsymptomen bij patiënten bij wie deze al in de acute fase aanwezig zijn. De duidelijke relatie tussen parkinsonsymptomen en leukoaraiose ondersteunt het idee dat leukoaraiose ten gevolge van ziekte van de kleine cerebrale vaten als aparte categorie binnen de groep van cerbrovasculaire aandoeningen gezien moet worden.

Hoofdstuk 3 inventariseert bij 83 patiënten met een herseninfarct of en een relatie bestaat tussen het voorkomen van parkinsonsymptomen en de lokatie van dit infarct. Rigiditeit blijkt dan te correleren met de aanwezigheid van een asymptomatisch lacunair infarct in het verzorgings gebied van de arteria choroïdea anterior.

Aangezien bevindingen bij CT en MRI onderzoek van de hersenen niet zondermeer een afspiegeling zijn van gestoorde cerebrale functie, werd bij patiënten met parkinsonisme na een beroerte eveneens gekeken naar bevindingen bij andere technieken van aanvullend onderzoek. 
Technetium HMPAO SPECT, waarmee een indruk gekregen kan worden van de cerebrale perfusie, toont bij patiënten met vasculair parkinsonisme frontaal gelokaliseerde hyperperfusie (hoofdstuk 4). FPCIT en IBZM SPECT, technieken ter beoordeling van respectievelijk presynaptische dopamine beschikbaarheid en dopamine receptoren in het striatum, laten bij patiënten met vasculair parkinsonisme geen afwijkingen zien (hoofdstuk 5). Over de oorzaak van de frontale hyperperfusie kan slechts gespeculeerd worden: mogelijk is de perfusie in de frontale gebieden veranderd als gevolg van verminderde output vanuit het striatum naar de frontale cortex. De normale bevindingen bij FP-CIT en IBZM SPECT passen bij de gedachte dat parkinsonsymptomen na een beroerte gerelateerd zijn aan dysfunctie in de verbindende baansystemen en niet aan dopamine tekort danwel tekort aan dopamine receptoren.

Alle voorgaande onderzoeksresultaten hebben betrekking op het voorkomen van parkinsonsymptomen ten gevolge van een beroerte. In hoofdstuk 6 wordt geïnventariseerd in welke mate parkinsonisme ten gevolge van de ziekte van Parkinson voorkomt in een populatie van 1516 patiënten met een beroerte. Dit blijkt beduidend minder te zijn dan op grond van prevalentiecijfers van de ziekte van Parkinson in een algemene populatie werd verwacht. Mogelijk is dit verschil gerelateerd aan excitotoxische effecten van dopamine, levodopa gebruik of verschillen in risicofactoren zoals roken.

De bovenbeschreven bevindingen van dit onderzoek maken duidelijk dar parkinsonsymptomen deel uitmaken van het uitgebreide complex aan symptomen wellke kunnen optreden als gevolg van een beroerte. Het optreden van deze verschijnselen is met name gerelateerd aan vasculaire laesies in de cerebrale witte stof. Verder onderzoek is nodig om begrijpen op welke manier deze laesies de motoriek verstoren. 



\section{Summary}

Parkinsonism is a clinical entity with bradykinesia, rigidity, tremor and postural instability as key-symptoms. Causes of parkinsonism are numerous. Well known is idiopathic Parkinson's disease resulting from degeneration of dopamine producing neurons in the substantia nigra.

"Stroke" is a collective noun for neurological disorders as a result of cerebrovascular disease, mainly comprising cerebral ischaemia and haemorrhage. Although clinical and radiological presentation of these stroke types differ, there is a clear pathophysiological connection. Both are related to atherosclerosis or arteriolosclerosis. Afasia, sensory disturbance and paresis as a result of damage in pyramidal tracts are familiar symptoms of stroke. Less well known are disturbances of the so-called "extrapyramidal system" and parkinsonism resulting from stroke.

In this thesis, incidence and pathophysiology of this post-stroke parkinsonism are discussed.

The introduction describes backgrounds of stroke and parkinsonism. Furthermore, results of other studies and reports on post-stroke parkinsonism are reviewed. Parkinsonian symptoms are reported in literature as a result of strategically located basal ganglia infarcts. This type of post-stroke parkinsonism arises suddenly and can be clinically indistinguishable from parkinsonism as a result of idiopathic Parkinson's disease. More often, parkinsonism develops insidiously and is located primarly in the lower extremities, hence "lower body parkinsonism". This type of post-stroke parkinsonism is mainly related to vascular lesions in cerebral white matter.

Chapter 1 describes results of a prospective study concerning the emergence of parkinsonian symptoms 2 weeks after stroke. Rigidity is frequent 
and related to white matter lesions on CT or MRI examination of the brain. Possibly, these lesions interfere with normal function of automatic motor control by means of damage to connecting white matter tracts. Chapter 2 reports on parkinsonian symptoms 6 months after stroke. Presence of these symptoms in this stage is also related to whice matter lesions. White matter lesions also predict progression of parkinsonian symptoms. The clear relationship between parkinsonian symptoms and white matter lesions supports the idea that white matter lesions as a result of cerebral small vessel disease must be considered as a subgroup within cerebrovascular diseases.

Chapter 3 investigates parkinsonian symptoms and ischaemia location. The presence of rigidity is related to asymptomatic lacunar infarcts in the supply area of the arteria choroïdea anterior.

Findings on CT and MRI examination of the brain are predominantly a reflection of brain anatomy. Brain function is not visualised. Therefore, three SPECT techniques were used in patients with post-stroke parkinsonism in order to elucidate (parts of) pathophysiology. Technetium HMPAO SPECT, a means of studying cerebral perfusion, shows in patients with post-stroke parkinsonism frontal lobe hyperperfusion (chapter 4). FP-CIT and IBZM SPECT, tools to investigate presynaptic dopamine availability and striatal dopamine receptors, show no abnormalitis (chapter 5).

A definite explanation of the frontal hyperperfusion is not possible. It can be speculated that perfusion is changed as a result of decreased output from striatum to frontal cortex. Normal findings in FP-CIT and IBZM SPECT concur with the idea that parkinsonian symptoms after stroke are related to lesions in connecting white matter tracts and not to shortage of dopamine or dopamine receptors.

Previous chapters summarised study results on parkinsonian symptoms as a result of stroke. Chapter 6 reports on prevalence of parkinsonism as a result of idiopathic Parkinson's disease in a population of 1516 patients with stroke. This prevalence is significantly less than expected when comparing to prevalence numbers on idiopathic Parkinson's disease in a gen- 
eral population. Possibly, this difference can be explained by excitotoxic effects of dopamine, use of levodopa or differences in risk factors like smoking.

Several results of the studies described in this thesis clearly state that parkinsonian symptoms are part of stroke symptomatology. The presence of these symptoms is maily related to cerebral white matter lesions. Future studies should be concerned with clarifying the exact mechanism by which these symptoms arise. 



\section{Dankwoord}

Nu aan het einde van dit boek een periode van onderzoek en academisch werkzaam zijn dan toch echt afgesloten wordt, is een woord van dank aan allen die dit mogelijk gemaakt hebben op zijn plaats.

Dr. J. Lodder, "zenmeester" Jan: zoals bij zovelen die mij voorgingen, stond $\mathrm{jij}$ aan de basis van dit onderzoek. Ik herinner mij nog heel goed ons telefoongesprek waarin jij de eerste ideeën voor deze studie opperde en hierdoor mijn enthousiasme aanwakkerde. Ook in de jaren daarna leverde jij een belangrijke bijdrage aan de verdere uitwerking van het onderzoek. Ik hoop dat je ook in de toekomst veel vreugde kunt blijven putten uit het doen van wetenschappelijk onderzoek en het begeleiden van mensen die hun eerste schreden op dit gebied zetten. Jouw talenten zijn hierbij onmisbaar!

Dr. F. Vreeling, Fred: ook jij bent betrokkene van het eerste uur. Dankzij jou, konden onze ideeën getoetst worden aan een extrapyramidaal kader. Je vaak op ludieke wijze gebrachte taalkundige inbreng, zowel in Nederlands als Engels, was een gewaardeerde aanvulling en bracht mij ertoe naar jouw voorbeeld ook lid te worden van "Het Genootschap". Geniet van je nieuw verworven vrijheid!

Prof. dr. J. Troost, Jaap: jij ondersteunde vanaf het begin de aan dit onderzoek gerelateerde activiteiten. Daarbij vond het grootste deel van mijn neurologische opleiding onder jouw supervisie plaats. Naar het zich laat aanzien wordt ook mijn opleiding dan toch bekroond met de afronding van een promotie onderzoek, iets wat je bij bijna al je opleidingsassistenten voor elkaar kreeg. In alle opzichten was je steeds als positieve kracht aanwezig. Ongetwijfeld blijft deze kracht voor jezelf en 
voor anderen, ook in de nieuwe levensfase na je emeritaat, zijn posirieve invloed uitoefenen.

Ir. A. Kessels, Alfonso: jij dacht mee over de methodologie en statistiek van de verschillende stukken. Een waardevolle en deskundige inbreng welke eigenlijk bij geen enkel onderzoek gemist kan worden.

Dr. E. van Raak, Lisette: door analyse van jouw "Maastricht Stroke Registry" gegevens kwam hoofdstuk 6 tot stand. Daarbij was jij steun en toeverlaat bij vragen over SPSS.

Dr. A. Boreas, Anita: jouw ervaring met lokalisatie van ischemie en correlatie daarvan met symptomen werd gebruikt voor hoofdstuk 3 . Ook buiten de context van dit hoofdstuk kon bij jou altijd aangeklopt worden voor ondersteuning.

Dr. W. Weber, Wim: op het moment dat allesverhullende duisternis over her onderzoek dreigde te vallen, bracht jij Het Licht. Dit gebeurde op dezelfde manier als bij aanvang van het onderzoek: door middel van een simpel telefoongesprek. Daarna is door gezamelijke inspanningen uiteindelijk de definitieve versie van dit boek tot stand gekomen. Zonder jou was dit nier gelukt.

Prof. dr. M. Limburg, Martien: ondanks het feit dat je geen invloed op de tot stand koming van dit onderzoek hebt kunnen uitoefenen, was je toch bereid de afronding ervan als een waar promotor te ondersteunen. Wellicht kunnen we in de toekomst ook op andere manieren uiting geven aan neurologische samenwerking in de regio.

Dr. M. van Kroonenburgh en I. Al Younis, Marinus en Imad: de analyses van de bevindingen bij SPECT onderzoek werden door jullie op de afdeling Nucleaire Geneeskunde gedaan. Dank voor deze deskundige inbreng.

Last but not least: lieve Ingeborgh, lieve Floris en Victor: nieuwe werelden kunnen alleen maar verkend worden vanuit een warme thuishaven. Julliezijn dit tijdens alle jaren van dit onderzoek geweest. Dat deze haven voor ons allen ook in de toekomst nog vaak het startpunt mag zijn van nieuwe ontdekkingen...... 


\section{Curriculum Vitae}

The writer of this thesis was born on the 30th of June in 1970, in Roermond. After primary education, he visited the Gymnasium at "Bisschoppelijk College Broekhin" from 1982 until graduation in 1988. Subsequently, he started medical training at the Faculty of Medicine of the State University "Limburg" (currently Maastricht Universiry) in Maastricht, The Netherlands. The medical degree was obtained six years later, in 1994.

During medical education the author worked as assistant for the department of Anatomy and Embryology lead by prof. dr. J.J. Drukker. In this function he was mainly concerned with an activity which, by nature, has his interest up till now: teaching. At the same department of Anatomy and Embryology, the author also parricipated in research concerning closure of the neural tube in chicken embryo's for which the "Stichting Wetenschapsbeoefening" of Maastricht University awarded him the "students prize" in 1992.

In 1994, he started working as a resident at the neurology department of the University Hospital of Maastricht (head prof. dr. J. Troost). Neurological training was started in 1996 at the neurological department of the Maasland Hospital Sittard under supervision of dr. H. Anten. During this period he was awarded "Clinician of 1996" for his contribution to neurological education of medical students. Between 1997 and 2001 neurological and neurophysiological training was completed, again at the University Hospital Maastricht (prof. dr. J. Troost and prof. dr. F. Spaans). Since 2001 Arthur Korten works together with three colleagues as a neurologist in the Laurentius Hospital in Roermond, the place where this curriculum started. 